\title{
Falls in the elderly : a primary care-based study
}

Citation for published version (APA):

Stalenhoef, P. A. (1999). Falls in the elderly : a primary care-based study. [Doctoral Thesis, Maastricht University]. Datawyse / Universitaire Pers Maastricht. https://doi.org/10.26481/dis.19990205ps

Document status and date:

Published: 01/01/1999

DOI:

10.26481/dis.19990205ps

Document Version:

Publisher's PDF, also known as Version of record

\section{Please check the document version of this publication:}

- A submitted manuscript is the version of the article upon submission and before peer-review. There can be important differences between the submitted version and the official published version of record.

People interested in the research are advised to contact the author for the final version of the publication, or visit the DOI to the publisher's website.

- The final author version and the galley proof are versions of the publication after peer review.

- The final published version features the final layout of the paper including the volume, issue and page numbers.

Link to publication

\footnotetext{
General rights rights.

- You may freely distribute the URL identifying the publication in the public portal. please follow below link for the End User Agreement:

www.umlib.nl/taverne-license

Take down policy

If you believe that this document breaches copyright please contact us at:

repository@maastrichtuniversity.nl

providing details and we will investigate your claim.
}

Copyright and moral rights for the publications made accessible in the public portal are retained by the authors and/or other copyright owners and it is a condition of accessing publications that users recognise and abide by the legal requirements associated with these

- Users may download and print one copy of any publication from the public portal for the purpose of private study or research.

- You may not further distribute the material or use it for any profit-making activity or commercial gain

If the publication is distributed under the terms of Article $25 \mathrm{fa}$ of the Dutch Copyright Act, indicated by the "Taverne" license above, 
FALLS IN THE ELDERLY

A primary carebased study 
(C) 1999 P.A. Stalenhoef, Maastricht, The Netherlands

All rights are reserved, whether the whole part of the material is concerned. No part of the publication may be reproduced, stored in a retrieval system, or transmitted in any form or by any means, electronic mechanical, photocopying, recording, or otherwise without writen permission from the copywright owner.

ISBN 9052782466

Vormgewing en typografische verzorging: Anne van Slooten Ontwerp omslag en fotografie: Josje Reuten-Scholte Uitgever: Datawyse | Universitare Pers Maastricht

The publication of this thesis was financially supported by: Janssen-Cilag BV

Eli Lilly Nederland BV Yamanouchi BV Astra BV

Organon Nederland BV 


\section{Falls in the elderly}

A primary care-based study

ter verkrijging van de graad van doctor and Un Unersiteit Mastricht, op gezag van de Rector Magnificus,

Prof. dr. A.C. Niewwenhuijzen Kruseman volgens het besluit van het College van Decanen, in het openbaar te verdedigen op vrijdag 5 februari 1999 on 16.00 uur door 


\section{Promotores}

Prof. dr. H.F.M. Crebolder

Prof. dr. J.A. Knotmerus

Co-promotor

Dr.J.P.M. Diederiks

\section{Beoordelingscommissie}

Prof. dr. J. Troost (voorzitter)

Prof. dr. L.M. Botter (vrije Universiteit Amsterdam)

Dr. J.F.B.M. Fiolet

Prof. dr. A. Huson

Prof. dr. B. Meyboom-de Jong (Rijksuniversiteit Groningen)

The study presented in this thesis was conducted at the Research Institute for Extramural and Transmural Health Care (ExTra) and Institute HEALTH. The institutes participate in the Netherlands School of Primary Care Research (CaRe), acknowledged in 1995 by the Royal Dutch Academy of Science (KNAW).

The study presented in the chapters $4,7,8,9,10$ and 11 was supported by a grant from ZorgOnderzoek Nederland (ZON; formerly The Preventiefonds). 
"The worst of all is indifference"

Elie Wrasel

Dedicated to my parents and parents in law Opgedragen an mijn ouders en schoonouders

P. Stalenhoef and M.K.C. Stalenhoefoosterwigk A.J. Halling and N.L. Halling Haktesieget A.G. Scholke and J.Th Schole-Woerts 


\section{CONTENTS}

CHAPTER I

General introduction

CHAPTER 2

Introduction to the subject by cases from general practice Falls in the elderly: pitfalls?

CHAPTER 3 39

Preliminary study

Home visits by community wurses may tontribute to general practitioners" information about elderly patients.

CHAPTER 4 41

Literature review

Incidence, pisk factors and consequences of falls anong elderly subjects living in the community. A criteria-based analysis.

CHAPTER 5

Design and methods of the surveys

CHAPTER 6

Community survey 1

The impact of gait problems and falls on functioning in independenty liwing persons of 55 years and over: a community surwey.

CHAPTER 7 81

Community survey 2

A patient record-based risk model for falls in community-dwelling elderly.

CHAPTER 8 101

Prospective cohort study

Predictors of falls in community-dwelling elderly: a prospective cohort study. 
CHAPTER 9

Home-safety checklist

How predictive is a home-safety thecklist for indoor fall risk in whe elderly living in the connumity?

CHAPTER 10 141

Gait disorders

Chatacteristics of elderly with gait disorders and self reported causes.

CHAPTER 11 151

The general practitioner

Falls in the elderly: the involvement of the generd practitioner.

CHAPTER 12

General discussion

SUMMARY

179

SAMENVATTING 187

DANKWOORD (Acknowledgement) 197

CURRICULUM VITAE 209 
CHAPTER

General incroduction 


\section{Introduction}

General introduction
CHAPTER I
A tall by an elderly person is a sudden and unintentional event, which may cause personal suffering. The balance of the elderly is disturbed abrupty, which evokes feelings of shame, helplessness and dependence. Falls in the elderly are a major problem in heath care, because of their high incidence, important morbidity, mortaliry and high healthcare costs $(1-10)$. It has to be expected that this problem will grow in the coming decades, because life expectancy of the population is still growing and the old and especially the very old people are increasingly living with disabilities, of which many are risk factors for falls (11).

A fall can be considered as the result of a failure or defect in the mainterance of balance. It is often a marker for frailty or the first sign of a disease or disability and therefore needs an accurate evaluation of its cause $(12,13)$. Because of multi-morbidity in old age and the presence of many risk factors at the same time, it is often difficult to determine which risk factor is the main contributing factor.

General practitioners (GP) frequently face this phenomenon, although they are confronted with only approximately 20 percent of all falls, mostly injurious falls (14-17). About one-third of their elderly parients have at least one fall a year and about half of them two or more falls $(8,9,18-20)$. Only a minority of falls, about ten percent, have serious consequences $(7,8)$. Injuries, particularly fractures, are the most prominent direct consequences of falls in the elderly, with an incidence of hip fractures of one percent and other fractures of five percent of all falls $(21-23)$. However, mobility impairment, functional decline and psychosocial funcrioning. such as fear of falling and social isolation, both to be considered as causes and consequences of falls, deserve GPs' attention as well $(7,24-27)$. Moreover, the GPs experience the complexity of this problem due to the great differences of individual circumstances, determinants, causes and consequences. Another relevant aspect for the $G \mathrm{P}$ is the lack of transparency of the management of falls regarding immediate care, assessment and intervention of fall risk and risk factors, and fall preventive activities in primary care. There is increasing evidence of the effectiveness of interventions to prevent falls and subsequent injury, particularly interventions directed at improving mobility (28-33). However, it is yet not clear which risk factors should be targets for prevention in primary care and which categories of elderly people should be addressed (34).

These considerations have led to a community-based study on falls 
in the elderly. In this introduction the definitions and fall mechanisms are discussed. The four aims of the study are elucidated and the research questions are presented in relation to the ams, followed by the structure of the thesis.

\section{Definitions and fall mechanisms}

Generally, a fall is defined as an unintentional event wheh results in the parson coming down on the ground on to a lower level (2.35). Some authors exclude overwhelming hazards like loss of conscionsness, traffic accidents, wiolence, stroke and insults $(8,9)$. Falls associated with syncope are relatively uncommon: sycope causes probably only about one percent of all falls (36), although a rate of 13 percent has been reported (37).

Observational balance and gait studies in elderly persons have revealed, that falls can be described in three phases (5). The first phase deals with the displacement of the centre of body mass beyond its base of support. This phase can be initiated by envirommental factors as well by intrinsic factors and by activities in progress at the time of the fall. The second phase of a fall concerns the failure of the systems for maintaining upright posture, generally due to intrinsic factors, such as loss of sensory functions and weakness of muscles. The third phase is caused by insufficient counteracted gravitational forces and results in the impact of the body on a surface, usually the ground or floor, with a tramsmission of forces to body tissue and/or organs, which may cause the damage. Whether, and to what extent, damage accurs, depends on the magnitude and the direction of forces, the susceptibility of tissues and organs and the properties of the environmental surfaces.

Disturbance of balance frequently accurs in old age. Causes are related to a lot of conditions. due to physiological and pathophysiological changes (38). If mantenance of balance in inadequate or disturbed a fall may result, with or without injury.

\section{Aims and related study questions}

\section{Aim 1 . Occurrence and incidence}

Question 1. What is the incidence of falls?

Ainu II. Deteminans and risk factors

Question 2. What are the determinants of and risk factors for falls?

Question 3. What is the relationship between intrinsic (personrelated), extrinsic (environment related) and activity-related risk factors for falls? 
General

intuduction

Question 4. What are the characteristics of the elderly with onetime, recurrent and no falls?

Ain lill. Heallh consequences

Question 5. What are the health consequences and the impact on daily fanctioning?

Aim IV. Relation to gereral practice

Question 6 . What is the involvement of the general practionor with falls and fallers?

Question 7 . What are the elements of a fall risk assessment in general practice?

Question 8. Which recommendations can be made to the general practioner regarding fall risk assessment and prevention?

\section{Occurrence and incidence of falls}

The armual incidence of falls in the community-dwelling elderly varies from about $25 \%$ to $40 \%$, dependent on characteristics of the selected population and study design $(8,9,18-20,39-42)$. One third to a half of the fallers experience more than one fall each year $(8,9,18-20,39,42)$. These figures mean that an average general practice, consisting of 2300 persons, with 15 percent of persons aged 65 years or over, has to expect each year at least 120 elderly subjects with one or more falls. About 60 percent of them will have one and 40 percent two or more falls. With a mean fall rate for recurtent fallers of 2.5 , these 120 elderly people will have circa 200 falls cach year. Approximately, 20 percent are reported to the GP, what means that a GP yearly will be informed of about 40 falls in the $65+$ population.

Indoor falls occur more frequently than outoor falls: sppproximately 75 percent of falls in the elderly occur indoors (8). Falls in the younger age group has a cendency to occur more frequently in the active time of day and falls at night more in the older group (43). Distribution by month and day shows a patrern of more falls in the period November till January and in the weekend $(43,44)$.

\section{Deteminants and risk fartoms}

Falls in the elderly are mostly multi-factorial events, in which many determinants and risk factors play a role (5-9). Evidence-based knowledge of determinants and risk factors is the basis of fall prevention $(45,46)$. Risk factors can be divided into intrinsic (person-related) and extrinsic (environment-related) risk factors $(8,9,47,48)$. Some authors add to these the activity-related risk factors, which seem to be increasing due to a growing mobility and 
activity level in old age (8).

Generally, fall risk is determined by a number of factors of diferent origin. Risk for falling is determined more by the personal conditions as health status and mobility than by the enwiromental situation: extrinsic risk factors play an additional role to the intrinsic risk factors $(8,9,19,20)$, The literature shows a great variety in regard to the relative contribution of risk factors $(8,9,16,19,20,39-42)$. This can be wplaned by differences in population, methodology and staristicall techinues (49). The strength of evidence of the contribution to fall risk of a number of risk factors is not consistent (5). Falls are age-related in most studies, but the sex difference, regarding a higher incidence of falls in women, is not apparent in all studies $(8,9,18,19,20,39,40)$. Nevertheless, there is consensus about the relevance of an important number of risk factors $(5,6,49)$. Determinants and risk factors which have strong evidence for an independent contriburion to falls in many studies are advanced age, a high level of dependence, cognitive impaiment, depression, balance and gait disorders, use of sedatives and hypnotics and a number of other medications, a history of stroke, arthritis of the knee, a history of falls, reduced grip and muscle strength $(5,6,8,9,18-20,49)$. An inconsistent association with falls was shown in many studies for female gender, postural hypotension, foot problems, impaired lower extremity sensory function, cardiovascular problems and impared vision $(5,49)$. Many risk factors for falls have been identified ats having shared contributions with other geriatric syndromes $(50,51)$.

\section{Health consequences}

Fall-melated mortality is the leading caluse of deatlin from injury in old age (52). The rate of fall-related death is mainly associated with survival after hip fracture or other major trama with an ang and sex-related pattern, although improved crauma management has reduced mortality due to falls (53-55). "Long lies" due to inability to get-up after a fall is a marker for a bad prognosis and high mortality $(56,57)$.

Major physical injuries are reported to occur in six to ten percent of all talls, with a fracture incidence of five to six percent and hip fracture incidence of one to three percent of falls $(8,9,49,58-60)$. Most fractures in elderly people are caused by a fall $(8,9,58)$. Risk of fracture is determined by the combined effects of falls, mpact of falling and bone qualities (59). In the Netherlands each yoar clderly people have about 1.5 million falls. It means about 15,000 bip fractures a year, a number which is rising each year $(60)$. Other 
Ceneral introduction fall-related fractures amount to about 60,000 . For an average general practice with an annual incidence of 200 falls in the 65 \# population, these figures imply about 20 major injuries due to falls, including about two hip fractures and about 9 other fractures. Minor injuries like sprains, contusions and skin lesions account for 20 to 30 percent of all falls $(8,9,49)$.

Important potential consequences other than injury are fear of falling, loss of self-confidence, functional decline and a decrease of social activities (7). All of these consequences may hamper daily functioning, and may be in turn risk factors for recurrent falling, resulting in vicious circles (4).

\section{Relation to general practice}

In several population-based studies the task and rolle of the GP regarding falls in the elderly is underexposed (49). Falls are underreported to the health care system and most reported falls concern injurious falls $(15-18,61)$. The management of falls in the elderly regarding cure, care and prevention by the GP often presents an unclear and insufficient picture. The attention paid by the GP to an elderly person with a fall is usually confined to the management of the injury and is mostly not also directed to the assessment of risk factors in view of rational prevention (61). One of the main conditions of a fall prevention strategy entails the GP developing an attitude of alertness and concern regarding falls and fall risk. GPs have a key position in the devellopment of anticipatory care and preventive activities in primary health care (62,63).

Other basic conditions for rational prevention are an understanding of the etiology of falling and the avaliability and feasibility of validated assessment procedures $(34,64,65)$. A risk model composed of data from medical history and fall-related tests has proved to be predictive in identifying the elderly at risk at an early stage and to predict falls (66). Fall prevention can be considered in a social epidemiological model, divided into primary, secondary and tertiary prevention, in three subsequent stages of falls: pre-fall stage, fall stage and post-fall stage, respectively (46). At all levels the GP will have a task, especially in the second and third stage.

\section{Structure of this thesis}

By way of introduction to the subject chapter 2 presents three case recurrent fall and the elderly at risk in view of fall prevention. 
Chapter 3 gives a description of the results from a preliminary study on health status and functioning in a random sample of 50 persons aged 70 years or over, registered in a primary health care centre. This study amed especially to identify the contribution of the home visit by community nurses to the GPs' information of the health status. Chapter 4 detals a literature review on the incidence of, risk factors for and consequences of falls among communitydwelling elderly. According to inclusion criterta concerning originality, subject, population at risk and relevance to general practice of the pre-selected studies, 14 studies were selected and subnitted to analysis based on ten criteria for quality.

Chapter 5 presents a general description of the design and methods of the surveys as an introduction to the following chapters. Chapter 6 deals with the results of a mail survey on the impact of gant problems and falls on daily functioning in a population of persons of 55 years or ower on the list of a primary health care centre. The results of another more extensive mail survey on incidence of, risk factors for and consequences of falls in the community-living elderly of 70 years or over are presented in chapter 7 . The result is a risk model composed of data directly and easily derivable from patient records.

Chapter 8 describes the results of a prospective cohort study among a random sample from the respondents of the mail survey described in chapter 7 , dealing with predictors for "ever falls" and recurrent falls. Two logistic models, mainly based on balance and gait performance tests, for the prediction of ever falls and recurrent falls, were developed and may be considered as complementary to the risk model based on the patient records, described in chapter 7. Chapter 9 gives a description of the development and evaluation of a home-safety checklist on indoor falls. Chapter 10 deals with the analysis of gait problems and self-reported causes, important risk factors for falls.

Chapter 11 concerns the involvement of GPs with falls, particularly the reporting of falls to the GP, their management in case of a fall or falls and estimation of fall. risk and risk factors for falls.

In chapter 12 the main results, methodological considerations "the implications for and recommendations to general practice and primary care, are discussed. In addition, some suggestions for further reseach and training ate given. Finally, summaries in English and Dutch, are given. 


\section{General} introduction

\section{References}

1. Sheldon $J H$. On the natural history of falls in old age. Br Med J $1960 ; 2: 1685-1690$.

2. Kellogg Intemational Work Grosup on the prevention of falls int the elderly. The prevention of falls in later life. Dan Med Bull $1987 ; 34$ (suppli) $4: 1-24$.

3. Tideiksar R. Falls in the elderly. Bulletin New York Acad Med $1988: 64: 145-63$.

4. Brummet-Smith $K$. Falls in the aged. Prim Care 1989;16:377-93.

5. Nevitt MC. Falls in older persons. Risk factors and prevention.

In: Berg RL, Cassells JS, eds. The second fifty years. Promoting health and preventing disabilities. Washington: National Academy Press, 1990,pp 263-90.

6. Lilley JM, Arie $T$, Chiluers CED. Accidents involving older people: a review of the literature. Age Ageing 1995;24:346-65.

7. King MB, Tineti ME. Falls in community-dwelling older persons. JAGS 1995;43:1146-54.

8. Tineti ME, Spechley $M$, Ginter SF. Risk factors for falls among clderly persons living in the community. N Engl J Med $1988 ; 319: 1701-7$.

9. Nevit $M C$, Cummings $S R$, Kidd $S$, Black $D$. Risk factors for recurrent nonsyncopal falls: a prospective study. JAMA 1989;

$261: 2663-8$.

10. Campbell AJ, Reinken J, Allan BC, Marinez GS. Falls in old age: a study of frequency and related clinical factors. Age Ageing $1981 ; 10: 264-70$.

11. Campion EW. The oldest old. New Engl I Med 1994;330:181920.

12. Rubinstein LZ, Robbins AS, Josephson $K R$, Schulman $B L$, Osterwe il $D$. The value of assessing falls in the elderly population. A randomized clinical trial. Ann Intern Med 1990;113:308-16.

13. Speedhley $M$, Tinetri ME. Falls and injuries in frail and vigorous community elderly persons. J Am Geriatr Soc 1991;39:46-52.

14. Soomers-Turlings JMSJG, Crebolder HFMM, Bensmans GHMI, Bal R.M. Het vallen van ouderen. Een exploratieve studie in de huisartspraktijk (Falls in the elderly. An exploratory study in general practice). Huisarts Wet 1992;35(2):57-60.

15. Hale WA, Delaney MJ, Cable $T$. Accuracy of patient recall and chart documentation of falls. I Am Board Fam Pract 1993;6:239-42.

16. Graham HJ, Firth J. Home accidents in older people: rolle of primary health care team. Br Med J 1992;305:30-2. 
people at home? Br Med J 1981:282:266-8.

18. Camplell AJ, Borre, Spears GF. Risk factors for talls in community-based prospective study of people 70 years and older. I Gerontol $1989 ; 44, M 112-117$.

19. Campbell AJ, Borre MJ, Spears GF, et al. Circumstances and consequences of falls experienced by a community population 70 years and over during a prospective study. Age Ageing $1990 ; 19: 136-41$.

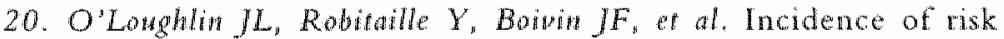
factors for falls and injurious falls among the community-dwelling elderly. Am J Epidemiol 1993;137;342-54.

21. Ooms ME, Vlasman P, Lips P, Nawta J, Bowter LM, Valkenburg $H A$. The incidence of hip fractures in independent and institutionalized elderly people. Osteoporosis Int 1994:4:6-10.

22. Boeveoon FTJ, Raymakers JA, de Groot RRM, Dursma SA. Epidemiology of hip fractures in the Netherlands: women. compared to men. Osteoporosis Int 1992:2:279-284.

23. Cooper $C$, Camion $G$, Melion LJ. Hip fractures in the elderly: a world wide projection. Osteoporosis Int 1992;2:285-289.

24. Vellas BJ, Wayne SJ, Romero LJ, Banngartner RN, Gary PJ. Fear of falling and restriction of mobility in elderly fallers. Age Ageng $1997 ; 26: 189-93$.

25. Vella: $B$, Cayla $F$, Bocquet $H$, Pemille de F, Albarede IL. Prospective study of restriction of activity in old people after falls. Age Ageing 1987;16:189-93.

26. Tineti $M E$, Richman $D$, Powell $L$. Falls efficacy as a measure of fear of falling. J Gerontol Psy Sci 1990:45(6):

P239-43.

27. Tinetis ME, Mendes de Leon CF, Doucte JT, Batuer DI. Fear of falling and fall-related efficacy in relationship to functioning among community-living elders. J Gerontol Med Sci 1994:49:M140.7.

28. Oakley A, Dawson MF, Holland f, al Preventing falls and subsequent injury in older people. Quality in Health Care $1996: 5: 243-9$

29. Tineti ME, Baker DI, McAvay Gier al. A mulcifactoriall intervention to reduce the risk of falling among elderly people living in the community. N Eng J Med 1994:331:821-7.

30. Prowince MA, Hadley EC, Hombrook MC, et al. The effects of exercise on falls in elderly patients. A preplanned meta-analysis of the FICSIT trials. JAMA 1995;273:1341-1347T

31. Howbrook MC, Stevens VJ, Wingfich DJ, Hollis JF, Gipenliche MR, Ory MG. Preventing falls among community-dwelling older persons: results from a randomized trial. Gerontologist 1994:34:16- 
23.

32. Fiatarame $M A, O N e i l l E F$, Doyle $R N$, at al Exercise training and nutritional supplementation for physical fraily in very elderly people. New EngJ Med 1994;330:1769-75.

Ceneral

introduction

33. Lord SR, Ward JA, Willaws $P$, Strudwick $M$. The effect of a 12month exercise trial on balance, stength, and falls in older women: a randomized controlled trial. JAGS 1995;43:1198-1206.

34. Tineti ME. Prevention of falls and fall injuries in elderly persons; a research agenda. Prev Med 1994;23:756-62.

35. Cibson M. Falls in later life. Improving the health of older people. Geneva: World Heath Organization, 1990,296-315.

36. Rubenstein LZ, Robbins AS, Schulman BL, Rosado J, Osterweil D, Josephson $K R$. Falls and instability in the elderly. I Am Geriatr Soc 1988:36:266-78.

37. Camm FL, Evams KE, Ward DE, et al. The thythm of the heart in active elderly subjects. Am Heart J 1980;99:598-603.

38. Overstall PW. Prevention of falls in the elderly. JAGS 1980:XXVIII: $481-4$

39. Prudham D, Grimley Evans J. Factors associated with falls in the elderly: a community study. Age Ageing 1981;10:141-6.

40. Blake AJ, Morgan K, Bendall MI, ef al. Falls by elderly people at home: prevalence and associated factors. Age Ageing 1981;10:26470 .

41. Downton JH, Andrews K. Prevalence, characteristics and factors associated with falls among the elderly living at home. Aging $1991 ; 3: 219-28$.

42. Hale WA, Delaney MJ, McGaghie WC. Characteristics and predictors of falls in elderly patients. I Fam Pract 1992;34:557-81.

43. Rynnänen O-P, Kivatla S-L, Honkaner R. Times, places, and mechanisms of falls among the elderly. Zeitschr Gerontol $1991: 24: 154-61$.

44. Hugono: R, Pasquier $J$. Contribution de la télétalarme à l'etude epidemiologique des chutes nocturnes (The contribution of remote alarms to the epidemiological study of nightime falls). Revue Geriatrie 1996;21:687-8.

45. Tinetri ME, Speechley M. Prevention of falls among the elderly. N Engl I Med 1989;320:1055-9.

46. Cuikel $J$, Fried $A V$. The social epidemiology of falls among community-dwelling elderly: guidelines for prevention. Disabil Rehabil 1992;14(3):113-121.

47. Lach $H W$, Reed AT, Arfken CL, Miller JP, Paige GD, Birge SJ, perk WA. Falls in the elderly: reliability of a classification system. JAGS 1991;39:197-202. 
48. Mofit JM. Falls in old people at home: Intrinsic versus environmental factors in causation. Publ Health 1983;97:115.

49. Staterhoef PA, Crebolder HJFM, Kotherus JA, waller Horst FGEM. Incidence, risk factors and consequences of falls anong elderly subjects living in the community. A criteria-based analysis. Eur J Publ Health 1997,7:328-334.

50. Tineth ME, Inowye $5 K$, Gill TM, Doucente IT. Shared risk factors for falls, incontinence, and functional dependence. JAMA 1995:273:1348-53.

51. Fiolet JFBM. Flankerend geriatrisch beleid. Het functioncen van geriatrische patienten tijdens ziekenhuisopname (Complementary Geriatric Management. The functioning of geriatric patients during hospitalization). Thesis University Mastricht; CIP-Gegevens Koninklijke Bibliotheek, Den Hag. Maastricht, 1993.

52. Baker SP, Haryey AH. Fall injuries in the elderly. Clin Geriatr Med 1985;1:501-12.

53. Satin $R W$. Falls among older persons: a public health perspective. Annu Rev Publ Health 1992;13:489-508.

54. ONeill TW, Varlow J, Silman AJ, Reve J, Reid DM, Todd C, Woolf $A D$. Age and sex influences on fall characteristics. Ann Rheum Dis 1994;53:773-5.

55. Rigs: JA. Mortality from accidental falls among the elderly in the United States, 1962-1988: demonstrating the impact of improved trauma management. J Trauma 1993;35:212 19.

56. Tineti ME, Lin W-L, Claus EB. Predictors and prognosis of inability to get up after falls among elderly persons. JAMA $1993 ; 269: 65-70$.

57. Ryynanen O-P, Kivella S.L. Honkamen $R$, Laippala P. falls and lying helpless in the elderly, Zeitschr Gerontol 1992;25:278-82.

58. Grisso JA, Kelsey JL, Strom BL, al Risk factors for talls as a cause of hip fracture in women. N Engl I Med 1991;324:1326-31.

59. Gradmans $W C$. Risk factors for fractures in the elderly (Introduction: pp. 1-17). Thesis, Free University Amsterdam, 1997. 60. Boevebow FTJ, de Groot RRM, Raymakers JA, Dursma SA. The incidence of hip fractures in The Netherlands. Neth J Med $1991 ; 38: 51-57$.

61. Stalenhoef PA, wan der Busse S. Knotinerus JA, Crebolder HFJM. Vallen van ouderen: het horen, zien, doen en laten van de husars (Falls in the elderly: the involvement of the general practitioner). Huisarts Wet 1998;41(5):241-5.

62. Crebolder HFJM, wan der Horst FG. Anticipatory care and the role of Dutch general practice in health promotion - a critical 
General introduction reflection. Patient Educ Couns 1996;28:51-5

63. Weel wan C, Vermeulen $H$, Bosh wan den W. Falls, a community care perspective. The Lancet $1995 ; 345: 1549-51$.

64. Tineth ME, Willaws TF, Mayewski $R$. Fall risk index fors elderly patients based on number of chromic disabilicies. Am J Medl $1986 ; 80: 429-34$.

65. Patterson $C$, Chambers $L W$. Preventive health care. The Lancer $1995: 345: 1611-15$.

66. Craafmans WC, Ooms ME, Hofstee HMA, Bezemer PD, Bowter $L M$, Lips $P$. Falls in the elderly: a prospective study of risk factors; and risk profiles. Am I Epidemiol 1996:143:1129-36. 
CHAPTER 2

Introduction to the subject

by cases from general practice

Falls in the elderly: pitfalls?

Published as:

P.A. Stalenhoef, J.F.B.M. Fiolet and H.F.J.M. Crebolder. "Vallen van ouderen: een valkuil?"

Huisarts en Wetenschap 1997;40(4);158-61. 


\section{Introduction}

Case histories
Falling in the elderly is a problem with a thigh occurrence (1-3): in The Netherlands every year one millon older persons ( 40 percent) have at least one fall $(4,5)$. Thre-quarters of these cases concern indoor falls (6). The risk of falling is greater for women than for men and increases with age (2). Only 20 percent of all falls are reported to the general practitioner (GP) (6).

Approximately ten percent of all falls cause major injury; in the half of hip fractures in one to three percent and other fractures in six percent of falls $(2,7,8)$. A notable example is hip fracture, the incidence in the elderly is thigh: 15,000 per year in the Netherlands. About 90 percent of hip fractures are caused by falls $(9.10)$.

The plysical consequences of a fall are determined by a number of factors, of which the most important are: the direction of the fall, the fall-breaking capacity, the extent to which energy can be absorbed by the contact surfaces and the qualities of bone and/or its surrounding tissues (11). Also important are the psychological consequences of falls: many elderly persons, who have experienced a fall, subsequently lack confidence or are fearfull, which in tum may lead to a new fall (2). A fall in an elderly indicates a disturbance of the balance and therefore has to be considered as a symptom of alam: in a great number of cases a fall is a signal of an underlying disorder $(12,13)$.

On the basis of three examples from general practice we aim to elucidate the diagnostics, treatment and prevention of falls in the elderly.

\section{Accidentally fallen}

Patient $A$ is a woman, aged 77 years, living at home, lively and independent, who did not rely often on medical aid. She has fallen and lies groaning on the stone kitchen floor. Her 52-year-old son, who is caring for her, calls for an emergency wisit. In the history taking she can report exactly what has happened: when standing up after breakfast, she had felt light-headed; and she had fallen "accidentally", "just if my legs could not bear me any more". She had fellt a sharp pain in her hip.

In the examination she is compos wethe. The bistory taking reveals nothing of any acute, serious disorder, such as a myocardial infarct, and the vital functions are intact. The pulse is regular and steady with frequency of 84 beats a minute. The blood pressure is $145 / 85 \mathrm{~mm} \mathrm{Hg}$. She cannot get up. There is local tenderness to 
pressure in the region of the left trochanter major, but there is no axis pain or exorotation of the left leg.

Because of the possibility of an inclavation fracture. for which the classical symptoms of a tracture are lacking (14). the patient is admitted by ambulance to the emergency department of the hospital. There she is diagnosed as not having a hip fracture. After consulting her GP by telephone the patient is discharged that afternoon and at the end of the day the GP visics her again. It appears that she has got fever, caused by pneumonia. In addition. further examination reveals a disturbed glucose tolerance and a macrocytal anaemia.

The patient is treated with antibiotics, prescribed Iyydrocolamine and folium acid, and advised to follow a diet. Mortover, home care is applied for. She picks up quickly.

\section{Fallen once again}

Patient $B$ is 83 years of age and living in a flat for the elderly. The nurse calls for a home visit. During the last couple of months Mr.B has been fallen several times a week. Today it occurred again. The patient is known as an excitable and dominating man, "heavy in mood and weight". He has been a widower for two years now and "that leaves its mark on me". In the last few months walking has been more difficult and especially getting np gives a lot of trouble. After the death of his wife he has been taking sleep medication (benzodiazepines), and he keeps on asking for stronger medication. Recently, a nurse discovered that he knows how to get sleeping pills clandestinely. The patient is found in his customary posture: sagging in his chair. He is sullen and deptessive, complaining of pain in his lower back. In the physical examitiation there are no symptoms of a fracture. The balance and gait in the "get-up and go" test (15) are evidently disturbed. Patient management is aimed at reducing the sleeping medication, offering a structured contact with the nurses and a guidance by a physiotherapist to improve the mobility and the self-confidence. The prescription of antidepressants is considered, but for the moment the decision is not to do so. A couple of weeks later the patient dies suddenly, probably due to a myocardial infarct.

\section{Fall risk}

Patient $C$, a widow of 89 years old, lives alone in an old farmhouse with a yard and a large garden. She is very ADL-dependent, but 
Case histories finds it hard to accept help. Threc of her five children are living in the neighbourhood. After her husband had died ten years ago, she became increasingly socially isolated, party due to her depressive mood. Also her physical state is defective: polyarthrosis, loss of wision due to degeneration of the macula, heart falure with a poor patient compliance, COPD with recurrent airway infections and weera cruris. She potters around a bit in her house and garden and cooks her own food. The dwelling is cluttered with obstacles, is uneven, with loose carpets and things everywhere. Two yapping little dogs keep her company. Every day she shufles through the barns, full of discarded agricultural equipment, vegetable boxes and tools. The smells remind her of an idealized past. Every time her GP visits, he wonders whether her living independently is still justined. Now, her children are asking for measures, because she has fallen in the shed. It appears that she falls, but keeps this a secret in the fear not being allowed to stay at home any more. With her children's agreement, as many obstacles and loose objects. as possible will be removed. Also efforts are made to encourage her not to walk alone any more in the sheds and yard, which is only partly succesful.

Half a year lacer the patient is bedridden due to general tiredness accompanied by vomiting and haemorrhagic stools. After deliberations between her, her children and the physician clinical diagnostics and treatment are foregone. Afrer one week intensive home care she dies in her own bed.

\section{Diagnostics}

In diagnostic if is important to find in all cases a justified balance between the burden, caused by the examination on the one hand. and the therapeutical possibilities on the other hand - a rule, above all relevant in the elderly.

The first case concerns an acute fall and primarily whether there is injury. To answer this question an $X-r a y$ is indicated because of the suspicion of an inclavation fracture (14). The question why she has been fallen is finally answered in second instance. The number of possibilities is great in that case: a cardial cause facute myocardial infarct or another cardial ischaemia, aorta stenosis, arrhythmia, sinus carotis syndrome), a non-cardial cause (stroke, absence), a post-miction or post-defaecation syncope, orthostatic low blood pressure, a decrease of blood pressure due to a disturbance of electrolytes, a vasovagal stimulus by medication, or another respiratory insufficiency, a.g. caused by an acute lung infiltration. 
The last one funally appeared to be the probable cause (16). However, in a single tall the relation whth risk factors is weak (17). The diagnostics in the second case are quite different. Here the accent lies on patient"s disturbed mobility. Balance and gait are evidently abnormal, which is an important fall risk (2). Many cases may be responsible. Clearly the abuse of benzodiazepines comes to the fore, a relevant risk factor for falls in the elderly $(2,18,19)$. Even the depressive mood is a possibly etiologic factor, though the relation with falls has not proven beyond doubt (2). Before therapeutic and preventive management can be determined, it seems significant also in this case to look into an underlying disorder, possibly neurological in origin (20). To assess the fall risk the "get-up and go" test can be used (15). This test is easy and quick to perform. The patient is asked to get-up from a chair, stay still for a second, next to walk three metres, turn around, walk back and sit again. In all stages of the test balance and gat are observed. Scoring is done on a 5 -point rating scale. An increased fall risk exists if there is danger of falling at any moment in the test. In the third case the diagnostics relate almost exclusively to the determination of the fall risk. This risk can be determined by tracing the risk factors (21). These may be distinguished into intrinsic risk factors, related to health status of the person concened, the extrinsic risk factors, related to the enviromment, and risk factors related to (hazardous) behaviour (2). In this case all three are present in abundance.

Intrinsic risk factors concern, besides the general health conditions, muscle strength and neuro-muscular diseases, disorders of the locomotion system, disturbances of balance and gatt, cognitive disorders, disturbances of senses and the use of medication. Artention has to be paid to these factors systematically. Concerning extrinsic risk factors, it is important to find out if the removal of obstacles and elimination of dangerous situations are significant and possible. Probably this will meet resistance, particularly if the patient has lived in these surroundings for many years. In addition, from the literature it does not appear that elimination of extrinsic risk factors allone will decrease the fall risk significantly (22). The same is likely to apply to changing behaviour.

\section{Therapy}

The therapy in fall problems allways depends on the underlying causes and the specific circumstances. An underlying disorder may need to be treated, but that disorder will not always be so plain as 
in the frrt case. In the second case the treatment is directed to a change of behaviour regarding the use of benzodiacpines, treatment of the depression and an active, intentional stimulating by a physiotherapist to improve the muscle strength, the mobility and the stability. Recently, regularly positive news has appeared on this subject $(23-26)$. In the third case a substantial part of the treatment consists of contact with the family members, who have reason to be worried. But is it wise in this case? How great is the patient's suffering? Is it not more a problem for the farnily and the care providers? Too strong an approach concerning adjustment of the dwelling may have an inverted effect.

Treatment in this case also means renewed attention to the medical status, e.g. a small check-up, simplification of the medication, and an effort to elewate patient's cooperation. Also removing the main and most dangerous obstacles and ensuring that the patient will walk outside only when accompanied, can yield results. In this regard the aid of the nurse and/or home care provider is indispensible.

\section{Provention}

Preventive measures are expensive and time consuming. A definitve judgement about the results canot be given at the moment, but in some trials clear positive effects have been found (23-25). In all cases prevention is of interest, taking account of the high incidence of falls in the elderly, and the morbidity and mortality originating from falls. A distinction can be made between primary, secondary and tertiary prevention (27).

Primary fall prewention concerns the identification of elderly persons at high fall risk, the promotion of physical and social activities, directed education and instruction, signalling of physical and psychological problems, attention to extrinsic fall risk and wf necessary, change of habits. With a few questions and the "get-up and go" test an assessment of the fall risk can be made. Assessment questions are: "How often have you fallen in the previous year? If you have fallen, did you suffer injury? If you have not fallen, have you had a near-falle? If there is an increased fall risk, a further history taking and examination are needed.

Concerning treatment of osteoporosis to prevent fall-related fractures, the jury is still out. It is a fact that every treatment, that results in a decrease of the reduction of the total bone mass, will reduce the brittleness of the skeleton. On the other hand, it is valuable to remember that the energy, generated in an accidental 
fall from upright position, romally has such a magninde that even a non-osteoporotic sketeton will fracture.

Secondary fall prevention consists of a directed assesment of background causes in fallers and the reduction of injury due to falls: absorbing floor-covering, hip protectors, teaching techniques how to break a fall, teaching how to getmp from the ground adjusting footwear and using a walking aid. Reduction of the fall risk by adjustment of the dwelling comes under both primary and the secondary prevention. However the results are generally disappointing $(28)$.

Tertiary prevention includes measures on the long term. such as aid in fear of falling, offering contact, surveillance of lonesome elderly persons, a central alarm system and summoning volunteers to prevent social isolation. Moreover, rehabilitation after fallrelated injury comes under this category.

\section{Acknowledgement}

This article is the result of three family practice conferences, held in three academic primary health care centres in Mastricht, in cooperation with the department of general practice of Mastricht University.

We thank all those who have participated and the firm Glaxo.

\section{References}

1. Campbell, AJ, Reinken J, Allan, BC, Manthez GS. Falls in old age: study of trequency and related clinical factors. Age Ageng $1981 ; 10: 264-70$.

2. Timeti $M E$, Speechley $M$, Ginter SF. Risk factors for falls anong elderly persons living in the community. N Eng J Med, 1988 ; 26:11701-7.

3. O'Loughlin JL, Robitaille $Y$, Boisin $J-F$, Suissa S. Incidence of and risk factors for falls and injurious falls among the communitydwelling elderly. Am J Epict, 1993; 1137-54.

4. Prudham D, Grimley Evans J. Factors associated with falls in the elderly: a community study. Age Ageing 1981: 10:141-6.

5. Blake AJ, Morgan K, Bendall MJ, Dalasso H, Ebrahim SBJ, Arie THD, Fentem PH, Bassey EJ. Falls by elderly people at home: prevalence and associated factors. Age Ageing 1988; 17:365-72.

6. Soomers-Turlings JMSJG, Crebolder HFJM, Beusmans GHMI, Bal 


\section{Case histories}

RM. Het wallen wan ouderen (Fals in the elderly. An exploratory study in general practicel. Een exploratieve studie in de huisarepraktik. Huisarts wet 1992;35: $57-60$.

7. Downton $J H$, Andrews $K$. Prevalence, characteristics and factors associated with falls among the elderly living at home. Aging 1990 ; 3: $219-28$.

8. Camplell AJ, Borrie MY, Spears GF, Jackson SL, Brown JS, Fitzgerald $J \mathrm{~L}$. Circumstances and consequences of falls experienced by a community population 70 years and over during a prospective study. Age Ageing 1990; 19:136-41.

9. Boereboom FTI, de Groot RRM, Raymakers JA, Dumswa SA. The incidence of hip fractures in The Netherlands. Neth J Med 1991; $38: 51-7$.

10. Boonen 5 , Dequeker $J$, Pelenaws $W$. Risk factors for falls as a cause of hip fracture in the elderly. Acta Clin Belg 1993; 3:190-4.

11. Cummings $S R$, Nevit MC. A hypothesis: the causes of hip fractures.J of Gerontol: medical sciences 1989; 44:M107-11.

12. Osterweil $D$. The value of assessing falls in an elderly population. A randomized clinical trial. Ann Intern Med. 1990; 113:308-16.

13. Specthley $M$, Tineth $M E$. Falls and injuries in frail and vigorous community elderly persons. I Am Geriatr Soc. 1991; 39:46-52.

14. Broos PLO, Stappaers KH. Heupfracturen bij bejaarden. Behandelingsmethoden en functionele resultaten. Tijdschr Gen. $1992 ; 48: 1051-60$.

15. Mathias $S$, Nayale USL, Isaacs B. Balance in elderly patients: The "gret-up and go" test. Arch Phys Med Rehabil 1986;67:387-9.

16. Lipsitz LA, Wei IY, Rowe JW. Syncope in an elderly, institutionalised population: prevalence, incidence, and associated risk. Quaterly J Med 1985;216:45-54.

17. Newint MC, Cummings $S R$, Kidd $S$, Black D. Risk factors for recurrent monsymcopal falls. A prospective study. JAMA $1989: 261: 2663-68$.

18. Sorock GS, Shimkin EE. Benzodiazepine sedatives and the risk of falling in a community-dwelling elderly cohort. Arch Int Med. $1988 ; 148: 2441-44$.

19. Cumming $R G$, Miller JP, kelsey JL, Davis P. Arfken CL, Birge SJ, Peck WA. Medications and multiple falls in elderly people: The St Louis OASIS study. Age Ageing 1991;20:455-61.

20. Sorom $C S$, Labiner $D M$. Peripheral neuromuscular dysfunction and falls in an ellerly cohort. Am J Epid 1992;136:584-91. Austr Fam Physician 1994;23:873-82. 
22. Stalenhoef PA, Crebolder HFM, Kuntwent JA, Horst wan dot FGEM. Incidence, risk factors and consequences of falls among elderly subjects living in the community. A criteriabased analysis. Geaccepteerd door Eur J Publ Health (maart 1996).

23. Fiatarone MA, O'Neill EF, Doyle Ryan $N$, Clements $K M$, Solons GR, Nelson ME, Roberts SB, Kehayias J. Lipsitz LA, Enam WJ. Exercise training and mutritional supplementation for physical frailty in very elderly people. New Eng J Med 1994: 330: 1769-75. 24. Tineti ME, Bater DI, MAAlay G, Clats EB, Gaviot P, Gotschalk M, Koch ML, Trainor K. Hortuiz RI. A multifactorial intervention to reduce the risk of falling among elderly people living in the community. 1994; 331:821-7.

25. Province ME, Hadle EC, Hombrook MC. Lipsitz LA, Miller JP, Mulrow CD, Ory MG, Satin RW, Thineti ME, Wolf SL. The effects of exercise on falls in elderly patients. JAMA, 1995; 273:1341-7.

26. Hornbrook MC, Stevens $\mathrm{J}$, Wingfield DJ, Hollis JF, Grendick MR, Ory MG. Preventing falls among community-dwelling older persons: results from a randomized trial. The Gerontol 1994;34:1623.

27. Cwikel $f$, Fried $A V$. The sacial epidemiology of falls among community-dwelling elderly: guidelines for prevention. Disabil Rehabil 1992;14:113-21.

28. Ben-Sira Z. Falls among the elderly: risks, risk and the contribution of media campaign. Israel Institute of Applied Social Research, Jerusalem, Israel, 1989. 

CHAPTER 3

Preliminary study

Home vists by communty murses may contribute to gemeral pratritioners information abow elderly patients.

Published as:

Stalemhoef PA, Huynen LG], Schonck RSM, Knotmerus JA, Horst FGEM van der, Crebolder HFJM.

Huisbezoek door de wijkverplecgkundige kan bijdragen aan de kennis van de huisarts over oudere patienten. Ned Tijdschr Geneesk 1996;140(49):2464-7. 


\section{Abstract}

Objective To determine to what extent the general practitione (GP) is aware of the health status and functioning of his elderly parients and in which areas this knowledge can be complemented whth the aid of community nurses.

Design Crosswectional, descriptive.

Setring A primary health care centre, connected to the Deparment of General Practice, Mastricht University, Mastricht, the Netherlands.

Methods A random sample of 50 patients aged 70 years and over, belonging to the popularion of a primary health care centre, were visited by community aurses. One patient was lost. The nurses made an inventory of the patient's health complants and their daty functioning by means of a structured questionnaire. Data from these liome visits were compared with data from the same questionmaire, regarding the same patients, which the three GPs of the health centre had filled in on the basis of their medical records. Results of the complaints recorded by the community nurses. $34 \%$ were not known to the GPs. This concerned mainly symptoms of depression, urinary incontinence, disabilities and impaiments of the locomotion system, sleep disturbances, daily functioning and coping ability. The main determinants of coping ability were gait problems and to a lesser degree symptoms of depression.

Conclusion A structured interview of elderly patients by a community anse yiclds substantial information about health problems. 


\section{Introduction}

The general practioner (GP) is often incompletely informed about the health status and functioning of his elderly parients $(1-4)$. To prowide effective health care it is desirable to be informed not only about diseases and problems, but also to have insight into the functional status of these patients $(5,6)$. Functional status. particularly coping ability, determines whether pationts may stay ar home or not (7). Multidisciplinary cooperation, especially with community nurses, is a favourable condition to obtain axtrat information $(2,8)$. These considerations bave led us to conduct a study, in cooperation with community nurses, on the incidence of problems, complaints and imparments in the elderly and to what extent the $\mathrm{GP}$ is informed about these. We havechosen a population of elderly persons, aged 70 years and over, because from that age relatively many problems and limitations of functioning exist (9). The study questions were the following:

- To what extent are the health problems and the functioning of the elderly patients known to the GP

- To what extent and in which areas does the GPS" knowledge adjust when they are confronted with recent data collected by a community nurse during a home visit in a systematic way?

\section{Patients and method}

From the register of 6500 patients of a primary health care centre, at random sample of 50 independently living persons of 70 years and over was taken. The patients carne under the care of three GPs and two community nurses of the health centre, which participates in the Registration Network Family Practices (RNH) of Mastricht University (10). One person was lost duc to an administrative mistake.

Original problen list The GPs hach already at their disposal a problem list of every patient from the sample, named by us "the original problem list". "These problem lists were constructed according to the "International Classification of Primary Care" (ICPC) (11).

For each patient the GPs filled in, using their medical register, a questionnaire designed to assess the activities of dally life and the particular daily activities. (ADL/PDL functions) (12), the catent of coping ability and the physical and psychosocial complaints. (PDL functions concern activities such at houschold activities, cooking, administrating, and the use of public transport.) The physical 
complaints covered dizziness, balance disturbances, gait problems, shortess of breath, slecping problems, falling, overweight, hearing, vision, speech problems, and perceived health and other relevant problens. The psychosocial complaints concerned short and long term memory deficits, orientation problems of time, place and person, problems with word finding, complants of depressive origin and loneliness. Scorng was done using 2-and 3-point rating scales. Complaints of depressive origin were recorded during the home visit by use of the "Symptom Check List" (SCL-90) (13).

Independenty from the $G P$, around the same time the community nurse made a home wisit, after writcen consent of the patient. Using the same questionnaire, as was filled in by the $G P_{\text {, the community }}$ nurse interviewed the elderly. The validity and the reproducibility of the investigation by the community nurses was ensured by the instructions before and the standardized questionnaires.

Final problem list Subsequently, the data werc compared with each other by the GPs and the community nurses, discussed and, if consensus was reached, then recorded. If consensus was lacking, preference was given to the patient's answer in the inquiry.

In this way for each patient one complete series of answers was developed. The new problems, elicited from this procedure, were inserted into the original problem list, resulting in a new list, the "final problem list".

Discrepancies berween the problem lists Comparing of the answers of the GP questionnaires to the series of answers resulting from the discussion between the GPS and the community nurses, enabled the extent to which the GP was informed about complaints and impairments of functioning in his patients to be determined. "Underestimation of problems" was defined as when the GP unjustly the patient classified as "free of complaints" or "without impairment of functioning". Conversely, the number of times that the GP made an "overestimation of problems" was determined.

Shatistics In the statistical analysis the correlation rest according to Spearman, the Chi-square test and the Fisher Exact test were used. Differences were defined as significant at $p<0.05$. A stepwise forwand logistic regression analysis was used to analyse determinants. of coping ability.

\section{Results}

Problem lists Table 1 shows that following the discussion between the GPs and the community nurses 109 problems were added to the original problem. list. This is $34 \%$ of the total number of codes of 
Table 1 Problems of 45 persons aged 70 years or oxer, of which the $G \mathrm{P}_{\mathrm{s}}$ were aware (original problem list) compared to the problems found in the interwiew by the community nurses (final problem list)

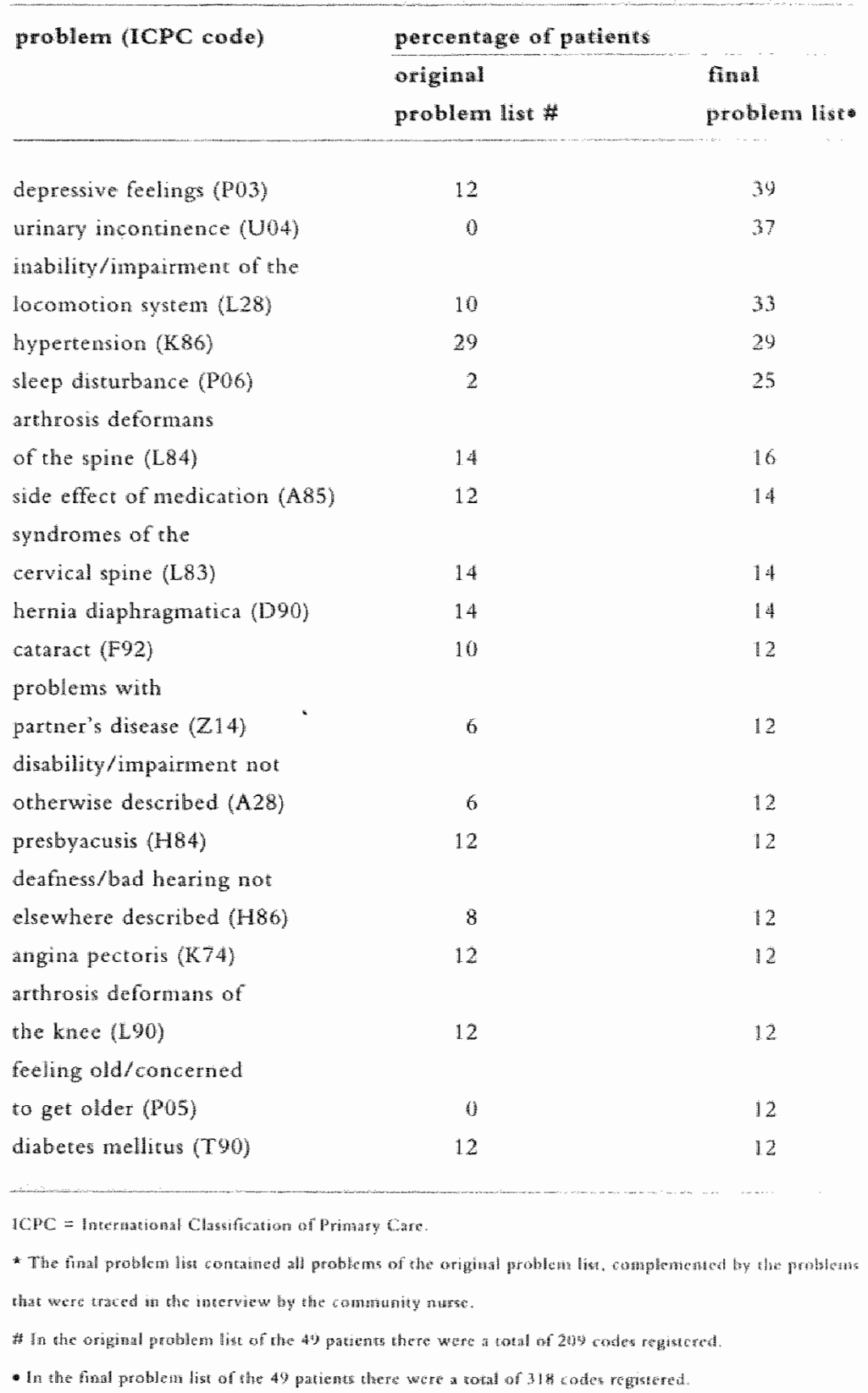




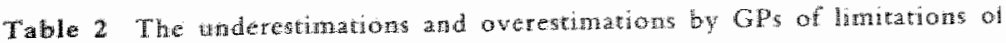
funcioning in 49 permons aged 70 years or ower, at a resule of the commoniry nurge incervicus.

activity

number of ellerly with limitations

rotal $(\mathrm{n}=49) \frac{\text { imparment by } \mathrm{GP}}{\text { underestimated owerestimated }}$

ADL acrioules

$\begin{array}{lccr}\text { washing } & 8 & 4 & 1 \\ \text { watking } & 7 & 5 & 1 \\ \text { clothing } & 5 & 3 & 1 \\ \text { rising from chat } & 2 & 0 & 2 \\ \text { lie down } & 1 & 0 & 2 \\ \text { roilet } & 1 & 0 & 2 \\ \text { in and ow bed } & 0 & -* & 4 \\ \text { eating } & 0 & -* & 0\end{array}$

mean number of

limintations per alderly

$0.50 .25 *$

0.1

POL acuivities

31

heary housthold activities

administration

18

shopping

17

lighte household activicies

16

cooking

15

public transport 14

2.3

(2. 5

0.3

$23-05$ 6 5 3 1 1 1

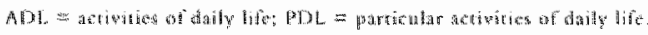

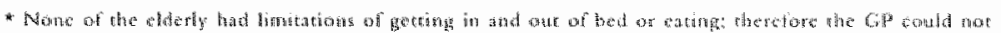

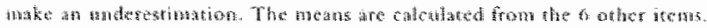

the final problem list. The additions were not so much determined by diagnoses, but particularly by complaints: depressive feelings, urinary incontinence, disability/mpaiment of the locomotion system, sleep disturbances, problems with the partner's disease and feeling older of being concerned about getting older. The mean number of ICPC codes per patienc consequenty rose by a factor of 1.5: from 4.3 to 6.5 . 
General and particular activities of daly life (ADL/PDL) None of the elderly was completely ADL/PDL dependent. A high percentage of them $(76 \%)$ were even fully $A D L-i n d e p e r d e n t$. The mean number of ADL limitations per elderly person amounted to 0.5 and in case of PDL to 2.3 (table 2). Half of the ADL limitations and $23 \%$ of the PDL limitations were underestimated by the GPs. Overestimation of the ADL and PDL limitations amounted to $20 \%$ and $13 \%$. respectively.

Physical and psychosocial complaints "The complaints reported to the community nurses were divided into physical and psychosocial complaints (table 3). Of the physical complaints disturbances of senses were found the most prevalent: $50 \%$ of the elderly had disturbances of hearing and/or vision. Gait disorders, shortness of breath during effort, dizziness, sleep disturbances, and urinary incontinence were reported by approximately $40 \%$ of the participants. In one of five elderly persons there was accidental or recurrent falling. On the basis of the SCL-90, complaints of depressive origin were often found: $41 \%$ scored above the standard. The complaint of loneliness rose by $35 \%$. We found a positive relation between loneliness and the presence of complaints of depressive origin (rank correlation coefficient: 0.68 ).

In two men and eight women (20\% of the elderly) no single complaint was raised. The percentage of underestimations by the GP ranged from $10 \%$ in case of complaints of depressive origin to $75 \%$ regarding faecal incontinence. The mean percentage of underestmated complaints was $43 \%$; mean overestimation was $18 \%$. Coping ability Because coping ability (classified as "good", "moderate" or "bad") had a strong correlation with ADL/PDL. functioning (rank correlation coefficient: 0.72), we might assume that the coping ability was a valid measure of functioning. The coping ability was perceived by $34(70 \%)$ of the elderly as good, while $14 \%$ perceived it as moderate and $16 \%$ as bad. Of the 15 patients who reported a moderate or bad coping ability, the GP had unjustly estimated the coping abillty in $13 \%$ as good. Of the 34 elderly who reported good coping ability, the GP had unjustly estimated $38 \%$ of them as having moderate or bad coping abillity.

From the stepwise regression analysis with the independent variables gender, age and physical and psychosocial complaints, it appeared that the main determinanes of decreased coping ability consisted of gait disorders, and to lesser extent of the presence of complaints of depressive origin. The other variables did not give an independent contribution. 
Table The underestimations and overesmations by GPs of phesical an peyohosocil complaints of 49 persong aged 70 years or over, as a walt of th community nume inderview.

\begin{tabular}{|c|c|c|c|}
\hline \multirow[t]{3}{*}{ complaints } & \multicolumn{3}{|c|}{ waber of elderly } \\
\hline & \multirow{2}{*}{$\begin{array}{l}\text { total } \\
(\mathrm{n}=49)\end{array}$} & \multicolumn{2}{|l|}{ complainus by GP } \\
\hline & & underestimated & overestumated \\
\hline
\end{tabular}

physital complaints

\begin{tabular}{|c|c|c|c|}
\hline hearing & 26 & 12 & \\
\hline vision & 23 & 15 & 6 \\
\hline gait problems & 21 & 8 & 3 \\
\hline \multicolumn{4}{|l|}{ shortness of breath } \\
\hline during effort & 21 & 3 & 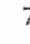 \\
\hline dizziness & 19 & 13 & 3 \\
\hline seep distumances & $\pi 9$ & 6 & \\
\hline hunary incontinence & 18 & 10 & \\
\hline disturbances balance & 16 & 10 & \\
\hline overweight & 11 & 4 & \\
\hline falling & 10 & 5 & \\
\hline shortmess of breath at rest & 8 & 5 & \\
\hline faecal incomtinence & 4 & 3 & \\
\hline
\end{tabular}

poychosocial complatins

depressive complaint

$(50 \mathrm{C})$

20

loneliness

17

4

2.0

0.9

mesu number of

complaines per elderly

\section{Discussion}

The GPS of the health centre in this investigation appeared not to know about $34 \%$ of the problems of their older patients or, in case of depressive feelings, urinary incontinence, sleep disturbances and an inability or imparment of the locomotion system, not to incorporate these problems into the problem list as a matter of course.

The good functional status of the elderly was noticeable. Threequarters of them was fully ADL-independent and one-third fully 
PDL-independent. What was also remarkable was that as many as 20 elderly persons (41\%) had complaints of a depressive origin in which, as could be expected, a clear relation with loneliness was found.

Generally, the GPs had a clearer picture of the impaiments of functioning of their older patients than of their physical and psychosocial complaints. In all complaints, there was an underestimation by the GP, which accords with the findings of other authors $(1,14)$. The number of underestimations regarding complaints of depressive origin was low, but more than one-third of the gait disorders were not known to the GP.

We conclude, that there are important gaps in the information of the GP regarding the complaints of his patients. The question arises, however, whether it is necessary for the $Q P$ to be informed about this in all cases. The relewant criteria are whether the complaint (or a combination of complaints) has important comsequences for daily functioning and whether there are therapentical, possibilities. In that regard, the outcomes of table 3 are of interest. Approximately five complaints were recorded per elderly person. Two of these complaints were unknown to the GP and the GP incorrecty supposed the presence of one other complaint per elderly person. Of all signalled complaints - even if they are present in combination - one may suppose that they have a negative influence on daily functioning, and for anmber (disturbances of senses, gait disorders, sleep disturbances, urinary incontinence, depressive complaints) therapeutical possibilities may be attempted. Structural cooperation between GP and community nurse offers possibilities for building up an inventory. Subsequently, interventions per patient and per discipline can be chosen. By means of an intervention study on a large scale the final effect of such cooperation can be determined.

\section{Acknowledgement}

We thank Truus Breukers and Herbert Habets, community nurses, and Pie Castermans, GP of the heath care centre in question for their advice and activities during the operationalization of this study. 


\section{References}

1. Molzan AE, Norhowt HC. The social basis of discrepancies in healthillness perceptions. J Adw Nurs 1989;14:132-40.

2. Wetter NJ, Jones DA, Victor CR. A health visitor affects the problems other do not reach. Lancet 1986;i130-2.

3. Patritk DL, Peach $H$, Gregg I. Disablement and care: a comparison of patient vicws and general practitioner knowledge. J R Coll Gen Prace 1982;32:429-34.

4. Wison CO, Netting FE. Comparison of self and health protessionals" ratings of the health of community-based eldarly. Int J Aging Hum Dev 1987:25:11-25.

5. Nelson E, Conger $B$, Donglass $R$, et al. Functional health status levels of primary care patients. JAMA 1983;249:3331-8.

6. Weel C van, Meiboom-de Jong $B$, Weert $H$ wan. Het functioneren van de patient: climimetrie in de huisartspraktijk. Ned Tijaschr Geneeskd 1990;134:1039-43.

7. Weel $\mathrm{C}$ van, Rosser WW. Measuring functional status in family practice. Fam Pract 1991;8:394-5.

8. Rossmm HJL van, Frederiks CMA. Heeft preventice ouderenbezoek door wijkwerpleegkundigen zin? Tijdschr Gerontol Geriar 1988:19:3-6.

9. Meijboom-de Jong B. Bejaarde patienten (proefschrift). Groningen: Rijksuniversiteit Groningen, 1989.

10. Melsemakers JFM, Hoppener $P$, Knotrnems JA, Kocken RJJ, Limonard CBG. Computerized health information in the Netherlands: a registration network of family practices. Br J Gen Pract 1992;42:102-6.

11. Lamberts $H$, Wood M. ICPC. International Classification of Primary Care. Oxford: Oxford University Press, 1983.

12. Kempen GIJM. Summetier TPBM. The development of a nierarchical polychotomous ADL-IADL scale for noninstitutionalized elders. Gerontologist 1990;30:497-502.

13. Fenmenter CA, Boswa AMM. De gezondheid van ouderen: epidemiologic en beleid (proefschrift). Amsterdam: Universiteit van Amstardan.

14. Uzermans CJyM, Schowemburg HC. Huisartsen en hun problecmpatienten: kwaliteit van de arts-patient communicatie. Huisarts Wor $1976 ; 19: 185-9$ 
CHAPTER 4

LITERATURE REVIEW

Intidence, risks futors and consequences of falls anomy elderly subjects living in the cownumity.

A criteria-based analysis.

Published as:

Stalenhoef PA, HFJM Crebolder, Knottnerus JA, Horst FGEM van der. Incidence, risk factors and consequences of falls anong elderly subjects loving in the community: a criteria-based analysis. Eur I Publ Health 1997;7:328-34. 


\section{Literature review}

\section{Abstrace}

In order to obtain an overwiew of the incidences, risk tactors an healch consequences of falls among elderly persons living in th community from the available literature, a Medline compute search of publications over the period 1981-1994 was carried out Fourteen studies met the following inclusion criteria: (I) the study is an original investigation of falls among the elderly. (II) the study deals with the incidence, risk factors and/or conseguences of fall: among the elderly and (III) the study refers to population at risk consisting of persons aged 60 years or over belonging to a population relevant to general practice. The selected studies were subjected to a methodological assessment on the basis of ten methodological criteria. All the studies were independently assessed by one author and one assistant to obtain methodological consensus. The relevane outcomes of these studies are reported. Pooling of data was not performed because of relevant differences between the studies. Two studies met all methodological criteriat and two other studies were second best. These four studies ware given preference. Approximately $30 \%$ of subjects older than 65 years fall at least once a year and approximately $15 \%$ fall recurrently. The main risk factors for falls among the elderly belong to the intrinsic (patient-related) risk factors: cognitive imparment, balance and gait disorders, use of sedatives and hypnotics, a history of stroke, advanced age, arthritis of the knee and a high level of dependence. Extrinsic (environment-related) risk factors did not play a significant role in any of the studies. Not all studies dealt with the health consequences of falls among the elderly. Major injuries were reported in $0.5-9 \%$ and fractures in $3-14 \%$.

Keywords; accidental falls, aged, elder]y, incidence, risk factors, morbidity 


\section{Introduction}

Falls among the alderly are a common problem in gemeral practice. Approximately $30 \%$ of people aged 65 years and over who are living in the communicy fall at least once a year $(1-7)$. This percentage rises with age. The fall rates for people aged 80 years and over are approxinately $50 \%$ a year. Most falls among the elderly are not reported to a general practitioner. In a primary carebased study of the population aged 65 years and over in four general practices, 79.2 falls per 1000 persons per year $(8 \%$ were reported to the general practitioner (8). Approximately $5 \%$ of the falls result in fractures and $5 \%$ in other injuries (1).

Considering the importance of the problem of falls among the elderly in the context of the increased number of communitydwelling elderly people, it is a matter of interest for genetal practice to obtain a more detailed picture of the outcomes of studies. The results of studies published on this subject vary widely. In order to develop a solid preventive strategy for the elderly, it is necessary to haye a valid and concise survey of the literature. particularly concerning the incidence of, risk factors for and consequences of falls among the elderly. Over the last few years the reports of the first intervention trials on fall risk have been published. Generally, intervention programmes appear to be effective (9-12). Particulary, exercise reduces falls and fall-related injuries in the elderly (9) or decreases muscle weakness (10). The risk of falling is also reduced by a multiple risk factor intervention strategy (11). However, if the intervencion is not sufficient the effect on serious falls appeared not to be preventive (12).

In this paper edescribe the characteristics and results of studies of falls among elderly persons living in the community. In order to evaluate the validity of the different sudies we investigated whether the selected studies met important methodological criteria. We had three questions:

- What is the methodological guality of the selected studies on falls among the community-dwelling elderly?

- What are the results of these studies wh regard to incidence of risk factors for and health consequences of falls among clderly people liwing in the community?

- What is the relationship between the methodological quality of the studies and their results? 


\section{Methods}

Literature revilew

A literature search was performed using three inclusion criteria.

- The study had to be an original investigation of falls among th elderly, living in the community.

- The study had to deal with the incidence, risk factors ank consequences of falls among the elderly.

- The study had ro comprise a population at risk of persons aged 66 years or over and relevant to general practice.

A Medline computer search was carried out in January 1994. The keywords (Medical Subject Headings: Mesï) were accidental falls, aged, elderly, incidence, risk factors and morbidity. The search included the period January 1981 to February 1994. The keywords yielded 274 references. Application of the above criteria led to the identification of 14 publications which could be subjected to methodological evaluation by means of a criteria-based analysis.

In order to obtain a measure for the quality of the studies selected, all studies were checked independently by one of the authors (P.S.) and an assistant, who is mentioned in the acknowledgements (R.L.), against a criteria list. The criteria are listed in the footnote of table 1. We used ten criteria for quality, partly based on those used by sacket et al. (13) and partly arising from our own objectives. The criteria were dichotomous: each study was given a "* or a "- according to whether a particular criterion was net or not. Disagreements were discussed to reach consensus.

The first criterion (A) checked was whether a clear definition of falling was given. An example of a clear definition used by Tinetti et al. is 'A fall is defined as a subject's unintentionally coming to rest on the ground or at some lower level, not as a result of a major intrinsic event (e.g. stroke or syncope) or overwhelming hazard" (1).

The second criterion (B) was whether an adequate sample size had been chosen and whether sampling procedures had been carried out and described in a proper maner. For an adequate sample size we chose a minimum number of 100 persons.

The third criterion (C) was whether the outcomes were applicable to the elderly population in general practice.

The fourth criterion (D) was whether the design was prospective or retrospective. Prospective approaches are generally preferred over retrospective designs, with their disadvantages of recall and selection bias, particularly in studies of the elderly.

The fifth criterion (E) was whether both intrinsic (patient-related) and extrinsic (environment-related) risk factors for falling had been 
taken into account.

The sixth criterion ( $F$ ) was whether an adequate clinical asseswant had been made with the usual techniques, such as questionnaires, interviews and/or clinical examinations during home visits wich standardized procedures and measurements.

The seventh criterion $(G)$ was whether, in prospective studies, the duration of the follow-up was at leat 6 months.

The eighth criterion (H) was whether, in prospective studies, the loss during follow-up had been less than $20 \%$.

The ninth criterion (I) was whether the data analysis, data interpretation and data prescration were appropriate. This meant, that all relevant outcones were reported, the outcome parametcrs were presented in an appropriate way, and the data were analysed using methods for multivariate analysis.

The tenth and final criterion. (J) was whether the study could be reproduced by other investigators on the basis of the description of methods and outcomes.

For each of the above criteria the definitive score was noted. Combining all "+" and " " then resulted in a total impression which provides a certain quality label.

\section{Results}

\section{Methodological evaluation}

Table 1 presents the results of the mechodological evaluation of the 14 studies selected.

Samples had not always been taken in the same way, differed considerably in size and in some cases evidently suffered from selection processes. The studies by Wild et al.(14) and Hale at. (15) were office-based. The poptlations in the sudies by Wild et al.(14) and Nevitt ex al.(16) were confined to elderly people with at least one fall accident in the previous year. People living in residential homes were excluded from the study by Downton and Andrews (17). In the study by Nevitt et all.(15) participants, fallers only, were recruited from senior centres, senior residences, churches and out-patient clinics. Lord et al. "s(20) study was confined to women. In Clak at 's(18) study all the participants were living in a tesidential home. In the studies by Prudham and Grimley Evans(5). Campbell et al.(6), Blake et al.(7), Clark et al.(18) and Cwikel(19) the health conseguences of falls were not the subject of investigation at all. Data analysis and data presentation were incompletely reported in 2 studics: Campbell et al.(6) and Cwikel et al.(19) In Wild et al. "s(14,26) study data 


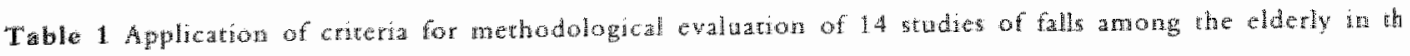
pertod al $1981-194$

\section{Siluditiog and}

reference numbe

\begin{tabular}{|c|c|c|c|c|c|c|c|c|}
\hline$A$ & $B$ & $c$ & $\mathbb{D}$ & E & $F$ & $G$ & $\mathrm{H}$ & $I$ \\
\hline+ & $a, c, b$ & - & + & - & - & $-f$ & - & $-k$ \\
\hline
\end{tabular}

Wild ex al. 4,20

Prudtand and

Grimley Evang

Campobll et al

Tinetul ex an.'

Wlatater al

Nevite ex al ${ }^{16}$

Camplaell at al, 1

Downton and

Andrewg

Cwatk and

Cwikel al. 27

Male a r is

Chat at al

O'loughtin at al. ${ }^{2}$

Lord at al 20

Yasunourate al at

\begin{tabular}{|c|c|c|c|c|c|c|c|c|c|}
\hline- & $+c, d$ & 4 & - & - & - & 0 & 0 & - & $?$ \\
\hline+ & $+d, i$ & + & $\ldots$ & - & 4 & 10 & 0 & + & - \\
\hline+ & + & + & 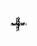 & + & $\neq$ & +1 & + & + & + \\
\hline+ & $d e$ & + & - & - & 4 & 0 & 0 & + & + \\
\hline+ & $e^{a}, g$ & - & + & + & + & + & + & + & 4 \\
\hline 4 & $f$ & + & + & tw & + & +1 & + & $+k$ & at \\
\hline+ & $+b i$ & $\#$ & $=$ & - & + & 0 & 0 & + & + \\
\hline- & $+\mathrm{d}, \mathrm{i}$ & $H$ & - & - & - & 0 & 0 & $+k$ & - \\
\hline+ & h & - & + & + & + & +1 & +1 & - & - \\
\hline+ & $-d, f$ & - & + & - & + & $\frac{1}{2+1}$ & + & ot & - \\
\hline 4 & + & + & $*$ & - & + & +1 & + & + & $\frac{t}{8}$ \\
\hline+ & $4 \mathrm{i}$ & + & - & - & - & 0 & 0 & th & $*$ \\
\hline+ & 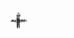 & $\sharp$ & - & - & - & 0 & 0 & + & + \\
\hline
\end{tabular}

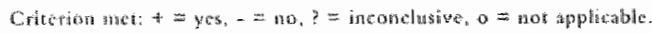

Crituriat

A cland defirition of a fill

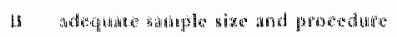

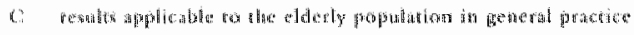

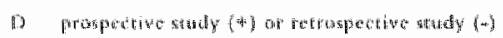

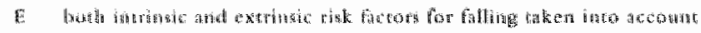

7) :

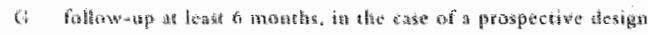

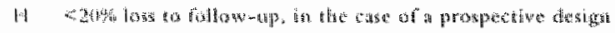

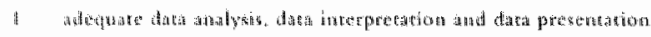

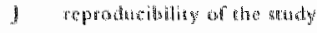

Reguarks

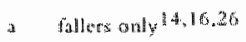

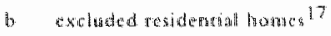

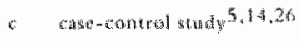

4

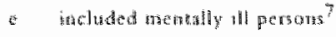

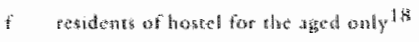

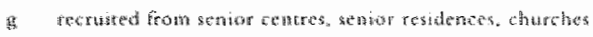

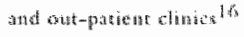

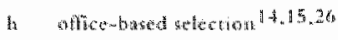

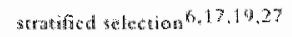

j worlye an aly 20

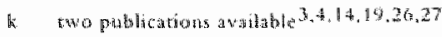

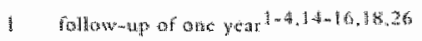


analysis was insufficen. From three studies two publications were avalable and were taken into account: Campbell ot a $1 .(3,4)$, Wild et al (14,26) and Cwikel(19), Cwikel et al. (27).

This table makes it clear that only the studies by Tinett et al.(1) and Campbell et al. $(3,4)$ met all our methodological criteria.

\section{Characteristics and outcomes}

Table 2 presents the main characteristics, incidences and health consequences of falls in the 14 studies selected.

- Characteristics

We included the year of publication, country, number of participants, age, mean age and sex ratio at time of recruitment. Twelve studies were from English-speaking countries, one study was from $1 \mathrm{srael}(19)$ and one from Japan(21). The period of publication was in most cases between 1988 and 1994 , but three publications dated from $1981(5,6,14)$.

There was an important divergence in the number of participants, varying from $76(18)$ to $761(3,4)$ in the prospective studies and from $203(17)$ to $3494(19)$ in the retrospective studies.

Most studies included persons of 65 years and older $(2,5-$ $7,14,15,19,20$ ) or from 65 to 84 years( 21$)$, although the study by Nevitt et al.(16) included persons aged 60 years and over. Others included persons of 70 years and over $(3,4,18)$ or even 75 years and over $(1,17)$. The differences in age of the persons included should be taken into account when considering the incidences of, risk factors for and consequences of falls reported. The mean age of the participants ranged from 72 years(19) to 83 years $(17,18)$, but was reported in only seven studies Tinetti et al.(1). O'Loughlin et a.(2), Hate et al.(15), Downton and Andrews(17), Clark et al.(18), Cwikel(19) and Lord et al.(20), with standard deviations in the studies: Tinetti et al.(1), Downton and Andrews(1.7) and Curket al.(18). The sex ratio was missing in four studies: Wild et al.(14), Campbell et al.(6), Blake et al.(7) and Cwikel(19). Lord et al's(20) study concerned only women.

\section{- Incidences}

All studies investigated how many persons had a fall at least once a year. This percentage varied from $13 \%$ for men in Yasumura et al's(21) study, which excluded very aged persons, to $57 \%$ in Nevitt et al. "s(16) study, with a population rectuited from senior centres. and such like. The percentage of persons who had more than one fall a year had an approximately equal diversity: $12 \%(2)-42 \%(18)$. Only eight studies gave percentages of two or more falls a year(1$5,15,16,18,20$ ). In those studies which provided mean ages there is 


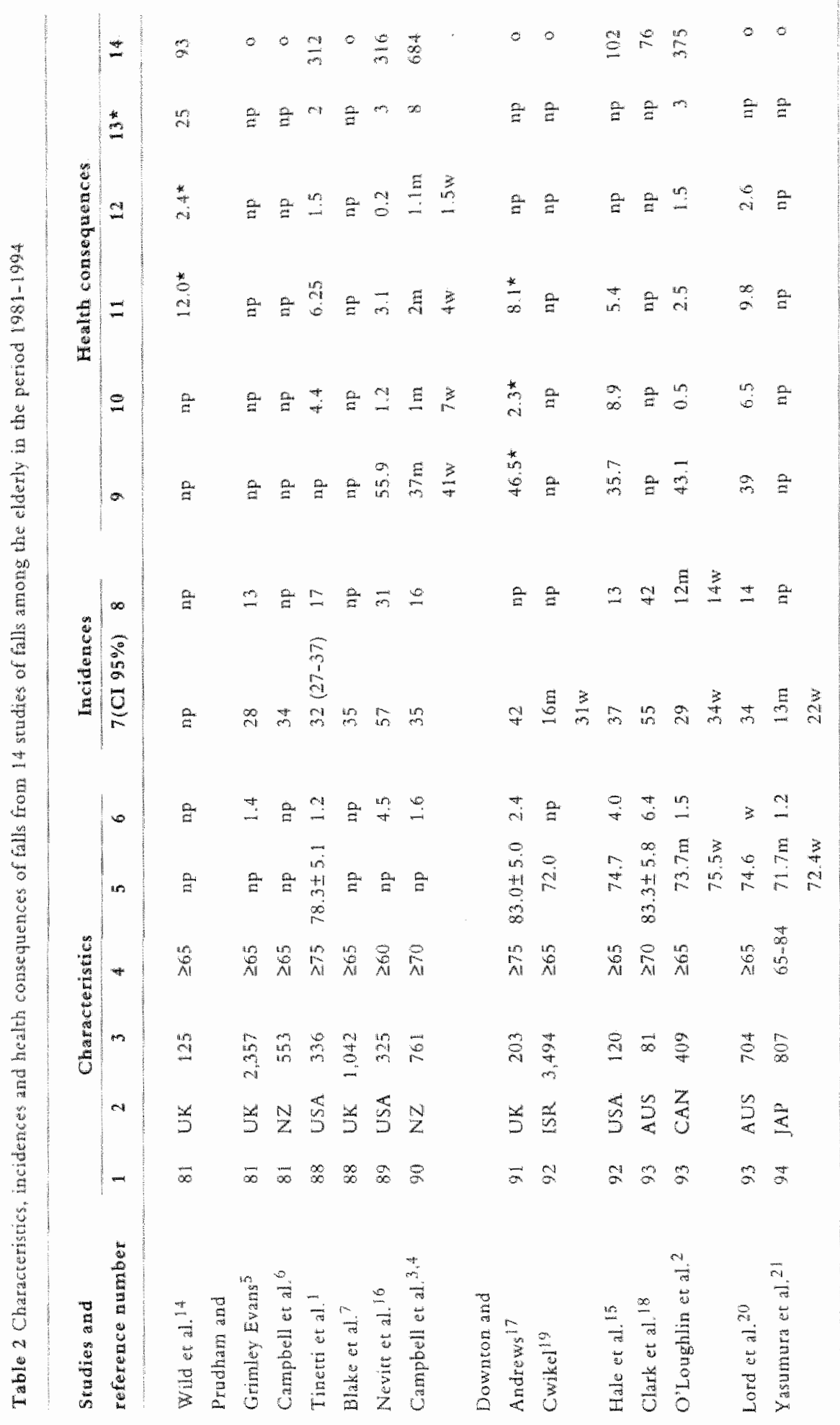




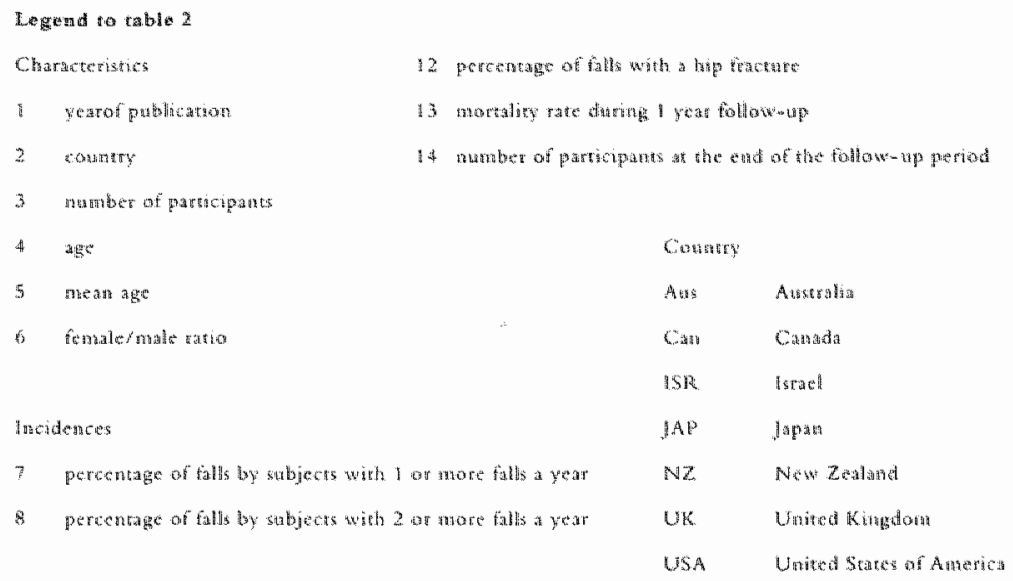

Wealth consegueness

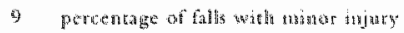

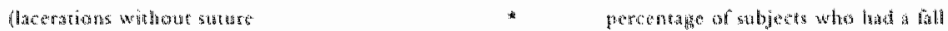

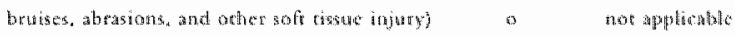

a relationship between the mean ages and incidences of falls.

- Risk factors and other determinants

We only included those risk factors and determinants which were labelled as significant by the authors themselves.

We clustered risk factors and determinants into the following groups: medication, mental functioning. mobility disorders, various complaints, symptoms and disotders, activity level, demographic determinants, dependence, various risk factors and determinants, fall history and envirommental risk factors (table 3). It is not possible to distil from the studies selected a complete picture of statistically significant risk factors and determinants, for several reasons: 1. not all studies included the same risk factors and determinants for investigation; 2. risk factors were expressed in different parameters, such as relative risks, odds ratios and incidence rate ratios and 3 . the statisticall method used was not always described and if it was there was a diversity of statistical techniques: a multivariate analysis, which is a valid instrument for the analysis of a multiple factor pthenomenon such as the risks of falling among the elderly, was not carried out in all the studies. Risk factors and 


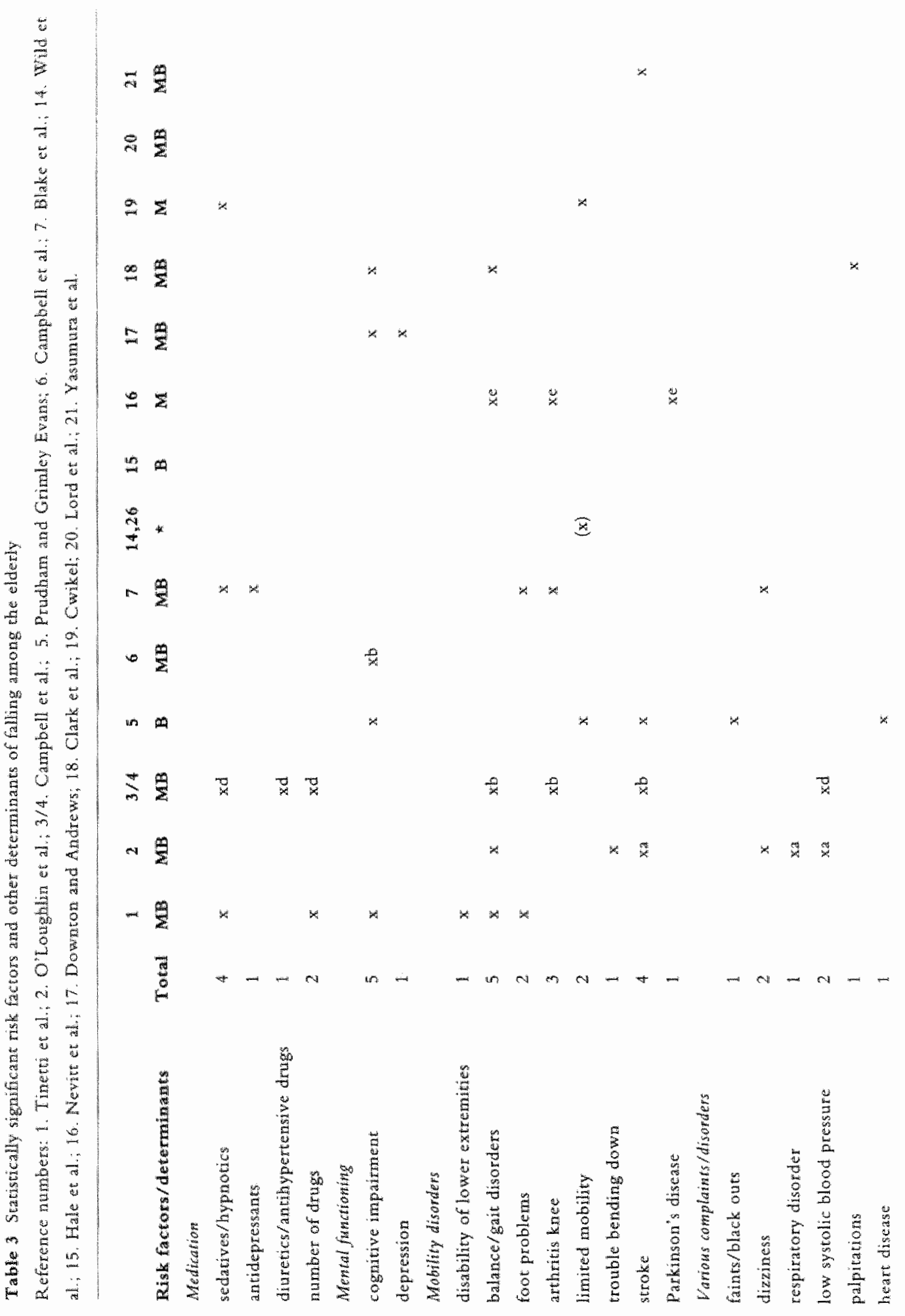


$\vec{x}$

埚

$\times \times$

च.

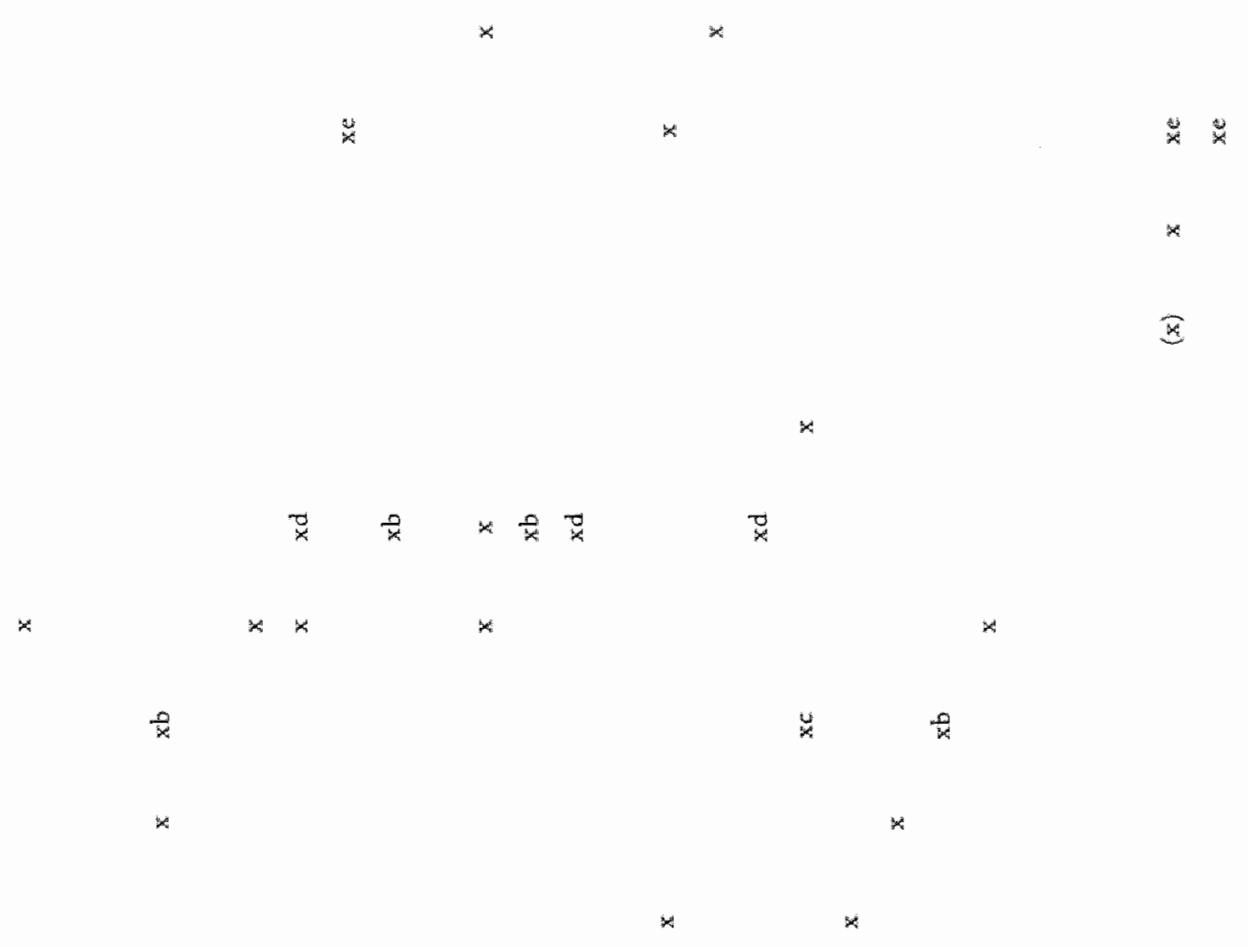

N $-\infty$ $+-+m-$

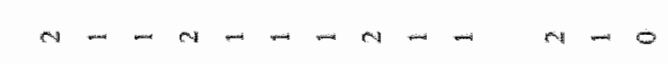

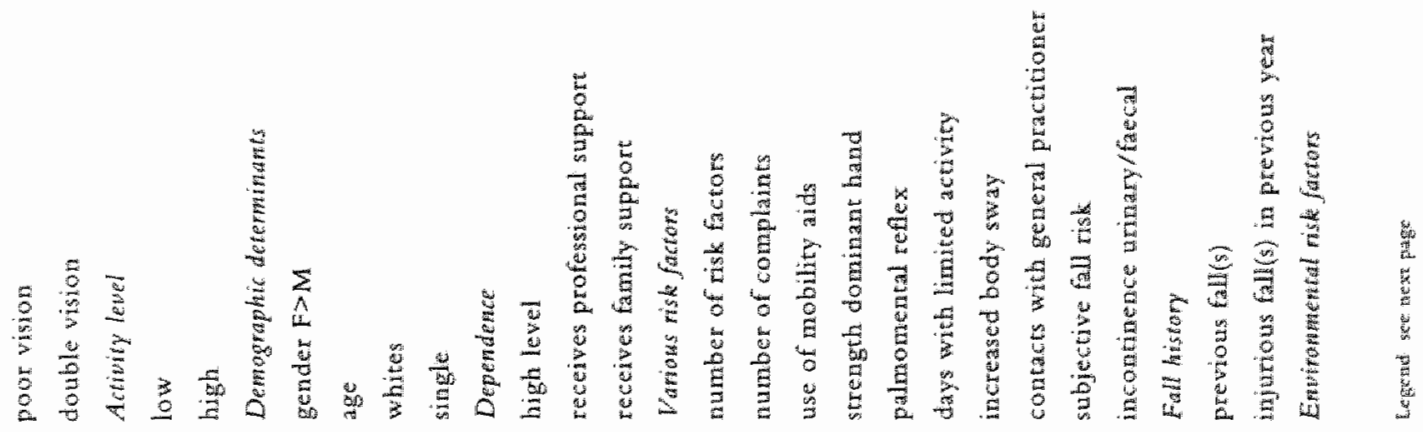




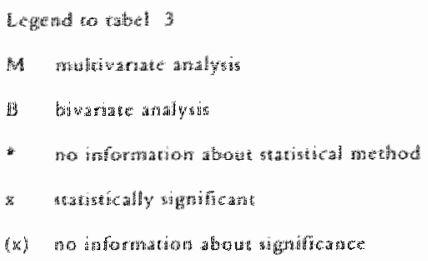

determinants most frequently mentioned as significant werc cognitive impairment $(1,5,6,17,18)$ and balance and gai disorders $(1,4,16,18)$ (five times), the use of sedatives and hypnotics $(1,3,4,7,19)$ a history of stroke $(2,5,21)$ and adwanced age $(5,6,19,21)$ (fout times) arthritic knee(3,4,7,16) and high level of dependence $(5,6,17)$ (three times) and the number of drugs, $(1,3,4)$, foot problems, $(1,7)$, limited mobility, $(5,19)$, dizziness, $(2,7)$, low systolic blood pressure, $(2-4)$, poor vision, $(20,21)$, high lewel of activity, $(2-4)$, number of risk factors, $(1,16)$, strength of the dominant hand, $(3,4,7)$ contacts with general practitioner, $(5,21)$, and a history of previous falls $(14,15)$ (two times).

Not a single study found extrinsic risk factors to be significant risk factors for falls among the elderly.

Health consequences of falls

Not all studies investigated the health consequences of falls. Five studies, all with a retrospective design $(5,7,19,21)$ and one prospective study (18) provided no information about the health consequences of falls. In the other studies selected, we compared the percentages of falls with minor and major injuries, fractures, particulatly hip fractures and mortality during a one year follow-up (table 2).

Major injurtes, if provided, like laceration needing suture, dislocations and sprains as results of falls were reported in $0.5 \%(2)$ $8.9 \%(15)$ of falls. The percentage of falls resulting in fractures also showed a considerable divergence: $2.5 \%(2)-12 \%(14,26)$ Hip fractures resulting from falls showed percentages of $0.2 \%(16)$ $2.6 \%(20)$.

The mortality rates during a one year follow-up were not confined to mortality directly caused by falls but comprised all mortality during the follow-up. Mortality rates varied from $2 \%(1)$ $25 \%(1,4,26)$.

Finally, the loss to follow-up is registered in table 2: only wild et al. 's (14) study (22\%) exceeded $20 \%$. 
partly by differences between the populations and partly by the methods of investigation used. The consequence of missing data. differences in the definition of injury and the use of different methods of investigation is that it is not possible to give a vallid survey of these outcomes. The data reported by Tineti et al.(1), O'Loughlin et al. (2), Campbell et al. $(3,4)$ and Nevitt et $1 .(16)$ are comparable.

\section{Discussion}

\section{Methodological quality}

Empirical investigations of elderly subjects living in the community encounter various limitations and are complicated in their nature as well as in the management of practical problems. Studies in this area should be viewed with this in mind otherwise results would seem disappointing.

In the presented criteria-based review we used ten criteria for quality. The weighing of these criteria is difficult. To avoid arbitrariness we did not use a weighing with points, but preferred a dichotomization into 'yes' or 'no' which has its limutations in not taking into account the differences in weight of the several criteria. We found a great diversity of methodological quality among the 14 studies selected. It is noticeable, that two studies $(5,19)$ friled to provide a definition of a fall. The other studies used various definitions mostly excluding major intrinsic events such as stroke and syncope and accidents as well. Not all studies gave a clear description of the sampling procedure used, or used a sufficient sample size and not all samples were representative of the elderly population living in the community. One study(16) was confined to fallers, recruited from seniot centres, semior residents, churches or university out-patient clinics. Another study(14), a case-control study of fallers only, had an insufficient statistical analysis. One study was an office-based study of ambulatory patients of a family practice with an insufficient sample size(15) and one study was confined to women(20). Other studies recruited their participants from populations such as à community surwey $(1,7,19)$, a regional area $(2,5,6)$, records and registers of general practices $(3,17)$, a municipal electoral list(21) or a hostel for elderly people(18). Samplle sizes differed considerably.

Retrospective studies have the disadvantages of recall bias due to memory loss and potential selection bias resulting in lower incidence rates. However, it is surprising that the incidence rates found in the retrospective studies hardly differed from those found 


\section{Literature review}

in prospective studies. Two studies reported high incidenc rates $(16,18)$. In one study participants wh a history of falling of least one fall during the previous 12 months were recruited fron senior centres and clinics(16). This probably concerns a population with more intrinsic risk factors. In the other study(18) the higl incidence of falls can be explained from the fact that it concerns: population from a hostel for the aged, with a high mean age $183:$ \pm 5.8 years), undoubtedly a population with many intrinsic risl factors.

The lack of a clear description of the statistical methods in many studies makes it difficult to judge theit quality. Most investigators $(1,2,6,7,16,21)$ analysed factors using a multiple, logistic, stepwise model to obtain a weighing of the different, independent risk factors. Data from studies using only a bivariate analysis $(3,5,15)$ are not always comparable, because parameters are different.

Another problem is that two studies $(14,15)$, with a small study sample lacked the statistical power to detect potentially important differences in the data.

Pooling of data was not performed because of major differences between the studies selected.

With all these shortcomings and differences of methodology in mind it must be concluded, that a definitive methodological assesment can hardly be made. Four studies with a good methodological quality may be given some degree of preference with regard to the outcomes: Tinetti et al.(1), O'Loughlin et al.(2), Campbell et al. $(3,4)$ and Nevitt et al. (16). All four had a prospective design with a one year follow-up. gave sufficient and clear descriptions of the methods and results and offered a more complete view of the subject of falls among the elderly. Nevitt et al. "s(16) study, however, suffered from selection deficiencies and the ontcomes of Campbell et all. $\$(3,4)$ study were described in two different publications, which gave a disadvantage in comparing data.

\section{Charateristics and outcomes}

If we confine this discussion to the four above-mentioned studies we can try to summarize data to obtain the essentials with regard to the incidences of, risk factors for and health consequences of falls among the elderly. The yearly incidence rates in the studies by Tinetti et al. (1), O'Loughlin et al.(2) and Campbell et al $(3,4)$ were similar: $32 \%, 29 \%(\mathrm{~m}) / 34 \%(\mathrm{w})$ and $35 \%$ respectively. In Nevitt et al.'s(16) study, however, the incidence rates were considerably higher: $57 \%$, presumably due to the selection of the study 
population, which consusted of subjects with a previous fall record, recruted from selected settings such as senior centres and clinics.

As for risk factors, there is hardly any similaricy between the data in the four studies. Balance and gait problems are the only risk factors mentioned as significant in all four studies and a history of stroke is mentioned as being a significant risk factor by $Q^{\prime}$ Loughlin et al. (2) and Campbell et $a 1,(3,4)$ although in Campbell et al. $3(3,4)$ sndy the significance was only with regard to men. Timetti et al.(1) emphasized the importance of the use of sedatives and hypnotics as an important risk factor, which was confirmed by Campbell et al $(3,4)$ for women, an outcome on which preventive strategies can be based. It is striking that only Tinetti et al.(1) found evidence for cognitive impaiment as a statistically significant risk factor for falling. It must be taken into account, however, that Nevitt et al.'s(16) study excluded people who were unable to respond to questions and cognitively impaired persons probably belong to this group. It seems plausible that persons with Parkinson's disease have a higher risk of falling. Only Nevitt et al.(16) found statistically significant evidence for this in subjects with multiple falls. Low blood pressure, resulting in orthostatic disturbances, was mentioned as a risk factor by $O^{\prime}$ Loughlin et al.(2) for both sexes and by Campbell et al, $(3,4)$ for women only. Both Tinetri et al. (1) and Nevitt et al.(16) found that the number of risk factors is an additional, statistically significant risk factor.

Summarizing the health consequences of the 14 studies selected we found that only eight studies gave information about the health consequences of falls. We differentiated minor and major injuries, fractures and specifically hip fractures. Here again outcomes differed considerably.

\section{Significance of our findirgs}

Several questions remain after the present review. In view of the high incidences, the many risk factors for falls among the ellerly and the high risk of injury caused by a fall, efforts should be made in general practice to prevent falls among the elderly as much as possible. Preventive strategies should be based on the outcomes of investigations. The present review found a considerable incidence of falls in old age in all studies selected: per year each subject aged 65 years or over has a probability of at least one fall of approximately $30 \%$, with a probability of recurrent falling of approximately $15 \%$ and a major injury from a fall of approximately $5 \%$. The great diversity of significant risk factors presents a problem in selecting risk factors for preventive strategies. We would prefer 
Literature review to choose the risk factors found to be significant in the studies by Tineti et al.(1), O'Loughlin et all.(2), Campbell et all. $(3,4)$ and Nevitt et al.(16), on the basis of their methodological quality. Confining ourselves to these four studies we conclude that preventive programmes should be directed at least at medication, in particular the use of sedatives and hypnotics and the use of drugs in general, cognitive imparment, mobility disorders such as disabilities of the lower extremities, gait disorders due to a stroke, arthritis of the knee, foot problems and Parkinson's disease, the level of activities, low blood pressure, dizziness and insufficient muscle strength. It is a noticeable outcome of the present review that none of the studies selected found a basis for significance of environmental risk factors. It may be questioned which place efforts to improve enviromental. risks should have in preventive programmes.

Returning to our aims, formulated in the three questions in the introduction to this paper, we cautiously conclude that we have gained more insight into the incidences of, risk factors for and health consequences of falls among the elderly, taking the methodological quality into account. However, as a basis for an intervention programme for community-dwelling elderly people, we need more specific knowledge about intrinsic and extrinsic risk factors. We have therefore decided to set up a combined retrospective and prospective study as a basis for prevention. Our aim is to develop a prevention programme, based on data obtained from a retrospective study, followed by a clinical assessment performed in a randomly selected population with a systematical follow-up. Data from this study will be linked with data from registrations by general practitioners(25).

\section{Acknowledgments}

We are indebed to René Lenoir for his assistance in the initial phase of this study and this check of the 14 studies selected against the criteria list.

This study was supported by a grant from the Praeventie Fonds. 


\section{References}

1. Tineti $M E$, Speehly $M$, Ginter SF. Risk factors for falls among elderly persons living in the community. $N$ Engt I Med $1988 ; 319: 1701-7$.

2. Oloughlin JL, Robraine $Y$, Bowin J-F, Swisa S. Incidence of and risk factors for falls and injurions falls among the communitydwelling elderly. Am J Epidemid 1993;137:342-54.

3. Campbell AJ, Borrie MJ, Spears GF. Risk factors for talls in a communitybased prospective study of people 70 years and older.

J Geront: Med Sci 1989;44:112-17.

4. Campbell AJ, Borrie MJ, Spears GF et al. Circumstances and consequences of falls experienced by a community population 70 years and over during a prospective study. Age Ageing 1990;19:13641 .

5. Prudham D, Grimley Evans J. Factors associated with falls in the elderly: a community study. Age Ageing 1981;10:141-6.

6. Campbell AJ, Reinken J, Allan BC, Martinez GS. Falls in old age: a study of frequency and related clinical factors. Age Ageing $1981 ; 10: 264-70$.

7. Blake AJ, Morgan K, Bendall MJ at al. Falls by elderly people at home: prevalence and associated factors. Age Ageing 1988:17:36572 .

8. Soomer-Thrings JMSJG, Crebolder HFJM, Bensmans GHMI, Bal RM. Het vallen van ouderen. Een exploratieve studie in de huisartspraktijk. (Falls by the elderly. An exploratory study in general practice.) Huisarts Wet 1992;35:57-60.

9. Province MA, Hadley EC, Hornbrook MC et al. The effects of exercise on falls in elderly patients. A preplanined meta-analysis of the FICSIT trials. JAMA 1995;273:1341-7.

10. Fiatarone $M A$, O'Nell EF, Doyle Ryan $N$ et al. Exercise training and nutritional supplementation for physical trailty in wery elderly people. N Engl J Med 1994;330:1769-75.

11. Tineti ME, Baker DI, McAvay G, Claus EB et al. A multifactorial intervention to reduce the risk of falling among elderly people living in the community. N Engl J Med 1994; 331:821-7.

12. Hormbrook MC, Stewems VJ, Winglield DJ, Hollis JF, Greenlick MR, Ory MG. Preventing falls among community-dwelling older persons: results from a randomized trial. Gerontology 1994;34:16-23.

13. Sackett DL, Haynes RB, Guyatt GH, Thizull P. Clinical epidemiology: a basic science for ctinical medicine. Boston: Little, Brown and Company, 1985.

14. Wild D. Nayak USL, Isades B. How dangerous are falls in old people at home? BMJ 1981:282:266-8. 
15. Hale WA, Delaney MJ, McGaghie WC. Characteristics an predictors of alls in elderly patients. J Family Pract 1992;34:557. 81.

16. Nevith $M C$, Cummings $S R$, Kidd $S$, Black $D$. Risk factors fol recurrent nonsycopal falls. A prospective study. JAMA 1989 261:2663-8.

17. Downton $J H_{*}$ Andrews $K$. Prevalence, characteristics and factor associated with falls among the elderly living at home. Aging $3: 219-27$.

18. Clapk RD, Lord SR, Webser IW. Clinical parameters associated with falls in an elderly population. Gerontology 1993;39:117-23.

19. Cwikel J. Falls among elderly people living at home: medical and social factors in a national sample. Israel J Med Sci 1992; $28: 446-53$.

20. Lord SR, Ward JA, Willams Ph, Anstey KJ. An epidemiological study of falls in older community-dwelling women: the Randwick falls and fractures study. Aus J Public Hlth 1993;17:240-5.

21. Yastmura $S$, Haga $H$, Nagai $H$, Suzuki $T$, Amano $H$, Shibata $H$. Rate of falls and the correlates among elderly people living in an urban community in Japan. Age Ageing 1994:23:323-7.

22. Jenniceck $M$. Meta-amalysis in medicine: where we are and where we want to go. J Clin Epidemiol 1989:42:35-44.

23. Buntinx $F$. De afnamekwaliteit wan cerwixuitstrijkjes. (The quality of cervical smears.) Diss.1992:Chapt. 3, part 1:73-82.

24. Ter Riet $G$, Kleymen J, Knipschild $P$. De meta-analyse als reviewmethode. (Meta-analysis: a method for reviewing.) Huisarts Wer $1989: 32: 176-81$.

25. Metsemakers JFM, Höppener $P$, Knotherws JA, Kocken RD, Limanard $C B G$. Computerised health information in The Netherlands: a registration network of family practices. Br J Gen Pract 1992;42:102-6.

26. Wild D, Nayak USL, lsaats B. Prognosis of falls in old people at home. J Epidemid Commun Hlth 1981;35:200-4.

27. Cuikel J. Kaplan $G$, Barell V. Falls and subjectiwe health rating among the elderly: evidence from two Israeli samples. Soc Sci Med $1990 ; 31: 485-90$. 
CHAPTER 5

Design and methods of the surveys 


\section{Population}

Design and methods of the surveys
The study is communicy-based and consists of two cross-sectiona surveys and one prospective study (1-3). Participants were recruited from two different community-based study populations ( $A$ and $B$ ). The prospective study was performed among a stratified random sample from the respondentz on a mail survey in population $(4,5)$. Figure 1 presents an overview of characteristics and popularions.

Population A: A mail survey on gait problems and falls (Chapter 6) was carried out among a random sample of 655 persons from the population of persons aged 55 years or over on the list of a rural primary health care centre.

Population $B$ : The second mail survey (Chapters 7 and 10 ) concerns a cross-sectional study on incidence of, risk factors for and consequences of falls in the elderly living in the community. A mail questionnaire was sent to all 2744 included persons 70 years or over, registered in three urban and semi-urban health care centres and one rural duo general practice (Population B1). The subsequent prospective study (Chapters 8 and 9) was conducted in a random sample of 311 persons from the 1238 respondents on this mail questionatire who gave written consent (Population B2). In addition, among the 16 general practitioners (GP's) of these elderly participants a mail survey on their involvement with falls and fallers was conducted (Chapter 11).

The participating GPs are members of the Registration Network Family Practices, a registration network, developed with the objective to provida data for scientific programmes of Maastricht University $(6)$.

\section{Data collection}

For the survey on gait problems and falls (Chapter 6) in a population of persons 55 years and over (Population A), a questionnaire was constructed, containing 61 questions on demographic situation, falls and injuries in the previous year. including near-falls and fear of falling, mobility, physical and mental health indicators, functioning and quality of life $(7-10)$.

A similar questionnaire was used in a second survey on incidence of, risk factors for and consequences of falls in a larger elderly population of 70 years and over (Population B; Chapter 7). Data from this questionnaire regarding self-perceived gait problems and causes were analysed separately (Chapter 10 ). 


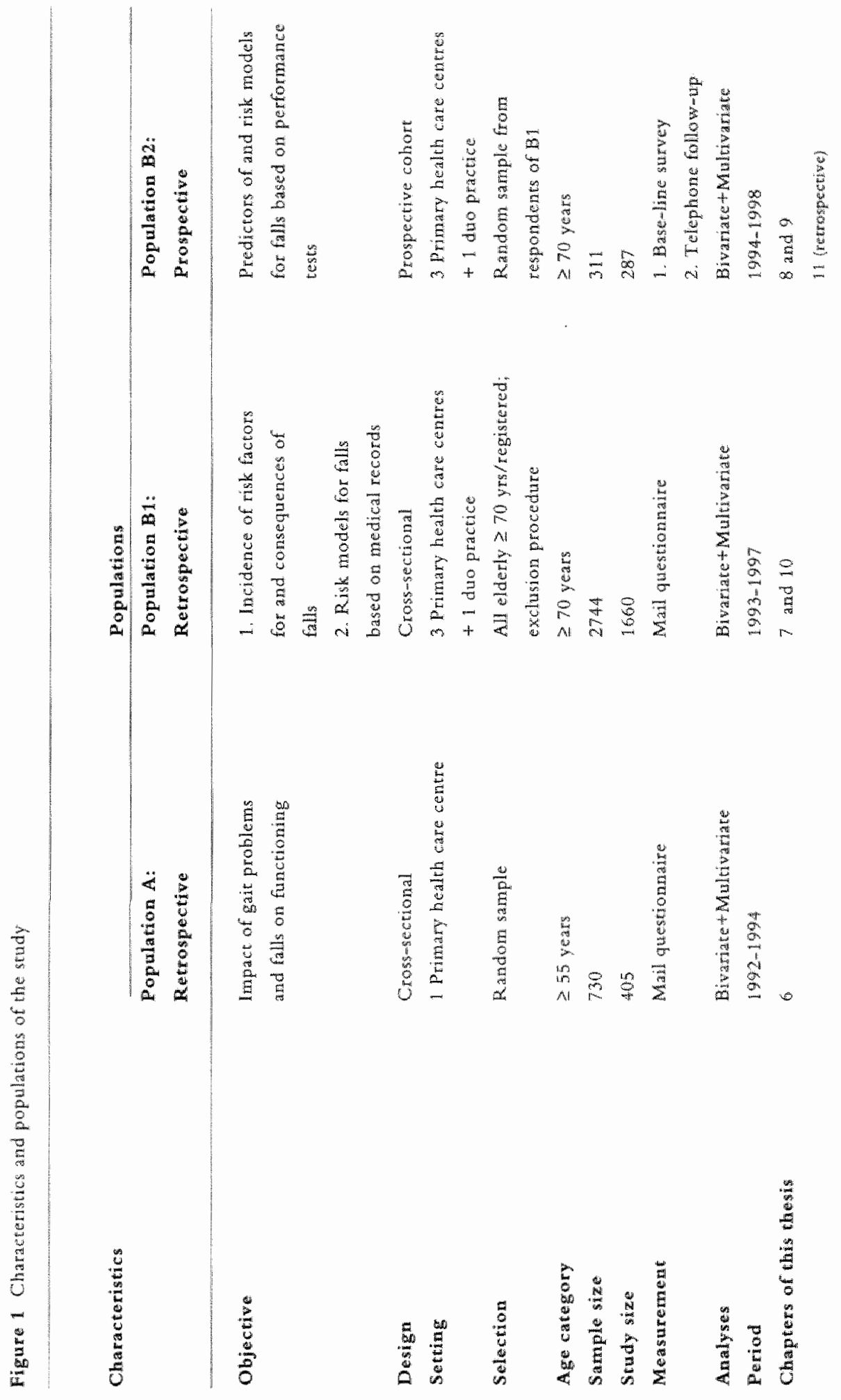


Design and methods of the surveys
Prior to the prospective cohort study two comsensus procedures were carried out: a nominal group procedure to construct an assesment on fall risk (Chapter 8) and a Delphi procedure to construct a home-safery checklist on indoor fall risk (Chapter 9) (11-14). In home visits a baseline assessment with a standardized procedure was performed by three specifically trained physicians. A subsequent standardized method of telephone calls every six weeks in a 36-week follow-up was conducted by five interviewers, also specifically trained. The telephone interviews contained questions on the occurrence of falls and injuries due to falls, perceived causes and changes in life and living conditions, related to falls. A mail questionnaire was sent to the $16 \mathrm{GPs}$ of the participating elderly persons about their involvement regarding reported falls and injurious falls, the diagnostic and therapeutic management and the estimation of fall risk and potential risk factors (Chapter 11).

\section{Chronology}

Community survey 1 in population A was carried out in 1992. The preparation of the community survey 2 in population $B$ started in the autumn of 1992 and the operationalization in the autumn of 1993. The mail questionmaire of community survey 2 was sent in February 1994. The subsequent baseline assessment between June and September 1994 and the 36-week follow-up, linked to the baseline assessment, was conducted till June 1995. The questionnaire to the GPs about their involvement was carried out between June and September 1995.

The design of the project was approved by the Ethical Board of the University Hospital Mastricht 


\section{References}

1. Mietrinen OS. Theoretical epidemiology. Principles of occurence research in medicine. New York; John Wiley \& Sons, Inc., 1985.

2. Bonter LM, wan Dongen MCJM. Epidemialogisch onderzock. Opzet en interpretatie. Houten/Diegem; Bohn, Stafleu Van Loghum, 1995.

3. Van Eijk JThM, Gubbels JW. Wetenschappelijk onderzock in de huisartsgeneeskunde. Lelystad; Meditekst, 1987.

4. Knotnerus JA, Volovics A. Medische statistiek en onderzoek in de huisartsgeneeskunde. Utrecht; NHG, 1990.

5. Fletcher RH, Flether SW, Wagner EH. Clinical epideniology. Baltimore; Williams \& Wilkins, 1988.

6. Mersemakers JFM, Hoppener P, Knotherus JA, Kocken RJI, Limonard CBG. The Registration Network Family Practices: a computerized health information system in the Netherlands. Br J Gen Prac 1992;42:102-6.

7. Meyboom-de Jong B. Bejarde patienten. Thesis. Groningen: Rijksuniversiteit Groningen., 1989.

8. wan Weel $C$, Rosser WW. Measuring functional status in family practice. Fam Pract 1991;8:394-43.

9. Applegate WB, Blass JP, Whliams TF. Instruments for the functional assessment of older patients. New Eng J Med $1990 ; 322: 1207-13$.

10. Vermeulen CA, Bosma AMM. De gezondheid van ouderen. Epidemiologie en beleid. Thesis University Amsterdam; CIPGegevens Koninklijke Bibliotheek Den Haag, 1992.

11. Fink $A$, Kosecoff J, Chassin M, Brook RH. Consensus methods: characteristics and guidelines for use. Am J Publ Health $1984,74: 979-83$.

12. Van der Ven $A H$, Delbeq $A L$. The nominal group as a resentch instrument for exploratory thealth studies. Am J Publ Health $1972 ; 62: 337-42$.

13. Linsione HA, Turoff $M$. The Delphi method. Techniques and applications. Massachusetts (USA), Addison-Wesley Publ, 1975.

14. Koch $M$, Gottschalk M, Baker DI, Palumbo S, Tinetri ME. An impairment and disability assessment and treatment protocol for community-living elderly persons. Phys Ther, 1994;74:286-96. 



\section{CHAPTER 6 \\ Community survey 1}

The impact op gat problews and falls on functioning in independent living persons of 55 years and aper: a connunity survey.

Published as:

Paul A. Stalenhoef, Jos P.M. Diederiks, Lue P. de Witte, Karin H. Schiricke, Harry FJ.M. Crebolder. The impact of gait problems and falls on functioning in independent living persons of 55 years and over: a community survey. Pat Educ Conns 1999:36:23-31 


\section{Community}

survey

\section{Abstract}

In a cross-sectional, population-based study among communitydwelling persons of 55 years and over the incidence of falls, risk indicators for falls, specifically age, and the impact of gait problems, falls and ather risk factors on functioning were determined. A randomly age-stratified sample ( $N=730$ ) was taken from all independant living persons of 55 years and over $(N=2269)$ and registered in a primary health care centre. They received a mail questionnaire concerning demographic data, history of falls and injuries due to falls, physical and mental health status, gait problems, functional status, including social activities. The net sample was 655 , with a response from 405 persons (response rate: $62 \%)$. Of the subjects aged 55 years and over and of those aged 65 years and over, $25 \%$ and $31 \%$ respectively fell at least one time in the prewious year. Half of the people reporting falls fell more than once. Serious injury occurred in $9 \%$ of the fallers, with $4 \%$ fractures. There is a significant association between falling and age and even more clearly, between gait problems and age. The main risk factors of single and recurrent falls were femalle gender, physical health status and gait problems. Logistic regression analysis reveals that the main determinants of falling in general are gait problems and female gender and, of recurrent falling female gender, physical complaints and gait problems. Falls have some negative effect on functioning, i.e. mobility range and social activities, but this is overshadowed by mental status indicators and gait problems.

Key words: gait problems, falls, elderly, risk factors, functioning. 


\section{Introduction}

Gait problems and falls, as well as fear of falling, result in important disabilities and morbidity in old age. About $6 \%$ of falls in the elderly result in fractures and about $5 \%$ in other injuries, like soft tissue damage, requing immobilisation or hospitalisation (1). "The year-incidence of falling in community-dwelling people of 65 years of age and over is 25 to $40 \%$ (1-4). Fifty percent of elderly people who fall are recurrent fallers $(1-3,10)$. Only a small percentage of falls is reported to the general practitioner $(5,6,7)$.

There is a growing consensus of the significance of risk factors for falls. Women fall more frequently than men and incidences increase by age $(8,9,10)$. Persons with multiple falls in general have a worse health status and significantly more risk factors than persons with a single fall $(2,8,11,12)$. Several authors divide risk factors of falls into intrinsic (individual), extrinsic (environmental) and activityrelated factors $(1,11)$. Particularly intrinsic risk factors play an important role: mobility disorders, medication, cognitive impairment and lower extremity disability seem to be the main risk factors $(1-3,11)$. In a criteria-based analysis of studies of incidences of risk factors for and consequences of falls among communitydwelling elderly, no single study appeared to report extrinsic risk factors playing a significant role (13). The risk of falling increases the more risk factors are present (1,11). Drugs are important risk factors, but in the available literature no consensus exists about the distinct relative risks of the different drugs (13). Anyhow, there is a cumulative risk of drugs: the more drugs are taken, the higher the risk of falling, independent of the type of drugs $(1,6,13)$.

Most studies of falls in the elderly include persons of adwanced age. mostly 65 years or 70 years and over, but it remains unclear if and to what extent age in categories of middle and adwanced age is an independent risk factor for falls and recurrent falls $(2,9,10,14)$. Disorders of mobility disability, particulatly gait problems increase by age, but it has to be explicited at which age the role as a risk factor for falls begins (15).

Balance and gait problerns are important risk factors for falls among elderly persons in many studies $(1-3,11,12)$. However in the clderly living in the community the contribution of balance and gait problems and falls to decrease of functioning. particularly to impaired mobility and social activities, in relation to other risk factors is not yet very clear $(16,17)$. Single falls do not appear to be associated with increased functionall disability, but multiple falls are predictors for functional decline (18). With regard to designing 
Community

survey 1 preventive programmes in primary health care it is important to gan more insight into these relationships in an cxtended age range. High-risk groups should be identified on the basis of uncterstanding of risk factors and personal knowledge of the patients and their living conditions (19). Wh the community the general practitioner has the opportunity to detect possibie high-risk groups and should regard any fall from a preventive point of wiew (20).

We therefore decided to study the following three interrelated questions in a cross-sectional study in a group of elderly with an extended age range.

1. What are the incidences of and risk factors for falls in elderly people aged 55 years and over living in the community?

2. Is age in all advanced age categories an independent risk indicator for falls in general and for recurrent falls in particular?

3. Ate balance and gait problems and fallis independent risk indicators for decreased functioning?

As we studied these questions in a cross-sectional design most associations found have not to be considered as causal relations, but as causal hypotheses. However, certain relations may be labelled as causal if there is a strong plausibility.

\section{Methods}

\section{Subjects}

A sample of 730 persons, living in the community, aged 55 years and over was taken from the population registered in a primary health care centre in a small town in the south of the Netherlands $(\mathrm{N}=2269)$. The sample was disproportionally stratified for age: from each 5-year age group a sample of 110 persons was taken. In the cohores above 80 years, however, this was not possible due to an insuficient number of persons.

\section{The quesfonthate}

The 730 persons selected were sent a prestructured mail questionnare. This included questions on the following variables:

- socio-demographic; age, gender and marital status;

- three physical health indicators as potential risk factors for falls: the presence or absence of a number of physical complaints and chronic diseases and regularly taken medication (21);

- two mental health indicators as potential risk factors for falls: the subscales Psychological Autonomy and Emotional Stability from the

- gait problems as potential risk factors for falls, measured with the 
subscale Mobility Control (SIP68) $(22,23,24)$;

- two variables conceming potential envirommental risk factors for falls: the presence of stairs in the home and adjusted footwear $(25,26)$;

- the occurence of falls $(\geq 1$ fall) and recurrent falls $(\geq 2$ falls $)$ in the previous year;

- the occurrence of injuries due to falls in the previous year, divided into major injuries fractures and other injury needing hospitalisation) and minor injuries (skin lacerations, contusions and other soft tissue injury);

- two variables on functioning: the range of mobility and social activities, measured by the subscales Mobility $\mathbb{R}$ ange and Social Behaviour (SIP68), respectively $(22-24)$.

Table 1 presents an overview of these selected variables with their operationalisation, minimum and maximum of the scores and, if applicable, reliability of the measurement (Cronbach's alpha).

\section{Data analysis}

Incidence of falls was calculated by frequency connts. Weighing for age distrubution tesulted in an estimation of yearly incidence.

Bivariate analysis was performed to study the association of risk indicators and falls in general as well as recurrent falls (odds ratios and their $95 \%$ confidence interval). Next, in logistic regression analyses, entry mode, the independent contribution of each determinant was investigated. In these analyses age was controlled for, regardless of its statistical significance. Age was introduced in the analyses as indicator variable, with the youngest age group as the reference category. In the analysis the following cut-off points as median values were used : physical complaints and chronic diseases: 2 or more; Mobility Control: 1 or more: Psychological Autonomy and Emotional Stability: 2 or more. For the risk factors of decreased functioning (notably physical and mental health indicators, gait and ballance problems and falls), the continuous variables which were applicable were analysed by pearson correlation coefficients. Finally, the independert contribution of the risk factors for daly functioning, operationalized by Mobility Range and Social Behaviour (SIP68), was assessed by multiple regression analysis. For this analysis falls in general (one fall or more) and recurrent falls (two falls or more) were introduced separately. 
rable 1 Vardales and ther measurement

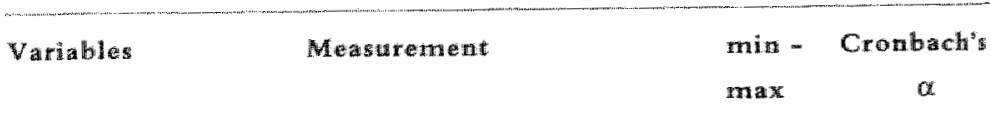

\section{Community}

Survey

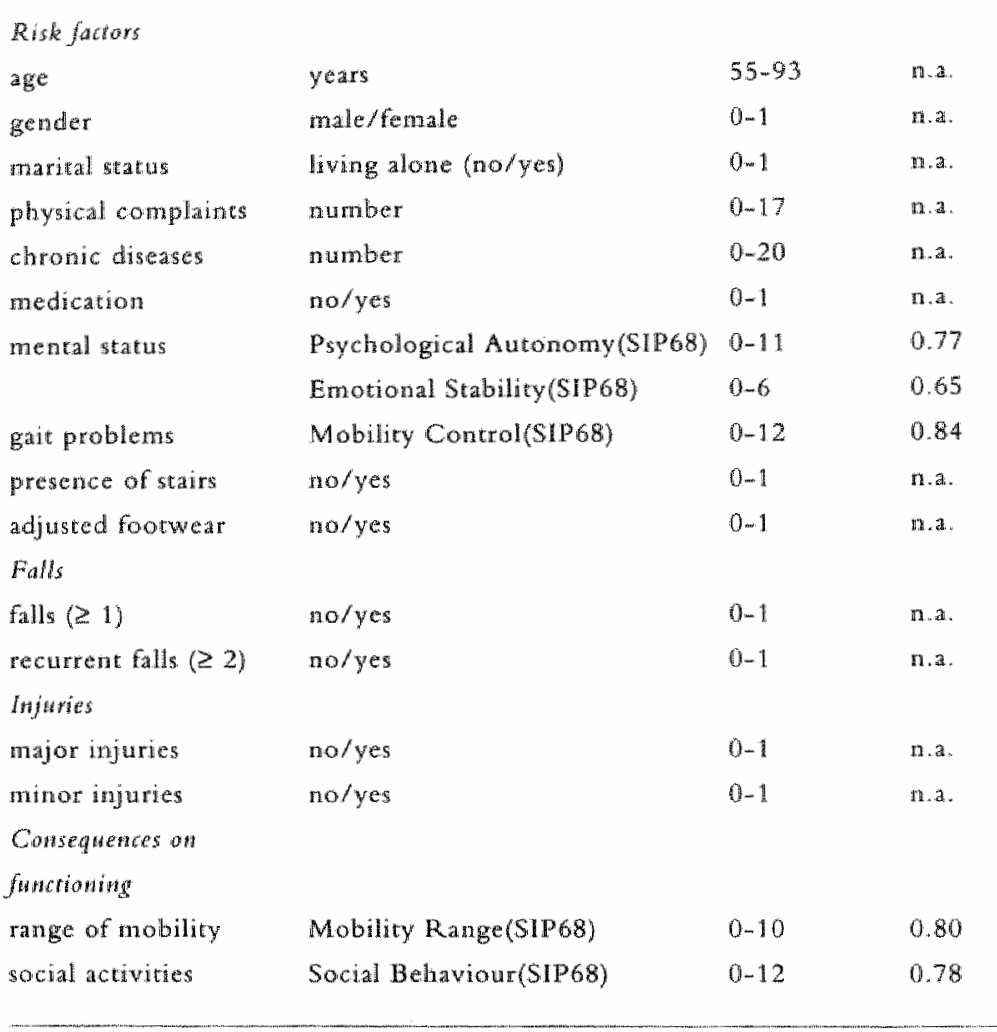

near mot applicable

\section{Results}

\section{Population}

Table 2 presents the age distribution of the 55 t population in the health centre, the gross sample of 730 persons, the net sample of 655 persons, the response and the response rates.

Of the 730 persons of 55 years and over approached, 59 appeared to have moved to another address. had died or were too ill to participate and 16 persons lived in a home for the elderly. The net sample therefore was 655 persons. After two mail reminders the response was 405 persons (response rate $61.8 \%$ ). Non-response increased strongly with age. People of 80 years and over are 
Table 2 Age distribution of the $55+$ centre population, the gross atmple. the net sample, the response (study) population and the response tate.

\begin{tabular}{lccccc}
\hline Age & $\begin{array}{l}\text { Health } \\
\text { centre }\end{array}$ & $\begin{array}{l}\text { Gross } \\
\text { sample }\end{array}$ & $\begin{array}{l}\text { Net } \\
\text { sample }\end{array}$ & $\begin{array}{c}\text { Response } \\
(\mathrm{N})\end{array}$ & $\begin{array}{c}\text { Response } \\
\text { rate (\%) }\end{array}$ \\
\hline $55-59$ & 526 & 110 & 108 & 77 & 71.3 \\
$60-64$ & 525 & 110 & 108 & 73 & 67.6 \\
$65-69$ & 435 & 110 & 108 & 73 & 67.6 \\
$70-74$ & 287 & 110 & 107 & 67 & 62.6 \\
$75-79$ & 207 & 110 & 95 & 62 & 65.3 \\
$80-84$ & 168 & 108 & 85 & 35 & 41.2 \\
$\geq 85$ & 121 & 72 & 44 & 18 & 40.9 \\
\hline \multirow{2}{*}{ Total } & 2269 & 730 & 655 & 405 & 61.8 \\
\hline
\end{tabular}

underrepresented in the study population. For this reason the higher age categories were united into one: 75 years and over. According to the general practitioners the reasons for nonresponse, checked in a random sample, were inability to read or write $(20$ percent), a poor health status ( 14 percent), the study is irrelevant (14 percent), and having no interest (11 percent).

Incidence of and risk factors for falls

Of the respondents of 55 years and over $25 \%$ reported to have had at least one fall in the previous year. In the group of 65 years and over the percentage rises to $31 \%$. Weighing of age distribution in the total population in the health centre leads to an estimated yearly incidence of $23 \%$ among the people of 55 years and over. Half of the people reporting falls had fallen more than once in the previous year.

The direct consequence of a fall is the occurrence of injury. In the group of fallers, $32 \%$ did not have any injury and $59 \%$ had minor injury, such as skin lacerations, contusions and other soft tissue injury. Major injury occurred in $9 \%$ of the fallers: fractures in $4 \%$ and other serious injury like concussion of the brain or injuries of vertebrae in $5 \%$.

There is a significant association of falling with age: in the age group 55-59 years $14 \%$ reported one or more falls, while in the group $\geq 75$ this percentage tose to $34 \%$ (Figure 1). Recurrent falls increase from $4 \%$ in the youngest to $18 \%$ in the oldest age group. Figure 1 also shows that the percentage of the people with one or 


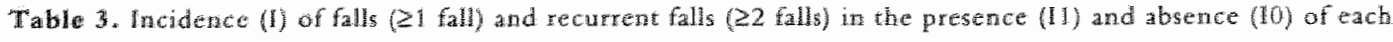
risk factor wh their odds ratos for fus and recurren falls $(\mathrm{N}=40 \mathrm{~s})$.

\begin{tabular}{|c|c|c|c|c|c|c|c|c|}
\hline \multirow{2}{*}{$\begin{array}{l}\text { Rish } \\
\text { Pecor }\end{array}$} & \multicolumn{4}{|c|}{ Finds $(\geq 1)^{3}$} & \multicolumn{4}{|c|}{ Recurrent Falls $(\geq 2)$} \\
\hline & $\mathbb{1 1}(0)$ & $10(\theta / b)$ & $\mathrm{OR}$ & $95 \% \mathrm{Cl}$ & $\mathbf{I}(1 / 0)$ & $10(\%)$ & $\mathrm{OR}$ & $95 \% \mathrm{Cl}$ \\
\hline Age (270 years) & 33 & 19 & 2.1 & $1.3-3.5$ & 18 & 10 & 2.0 & $1.5-2.8$ \\
\hline Gonder $(f)$ & 33 & 17 & 2.5 & $1.5-4.0$ & 18 & 7 & 2.9 & $1.5-5.7$ \\
\hline Living alone (yes) & 3.5 & 21 & 2.0 & $11.2-3.3$ & 18 & 1 & 1.8 & $0.9-1.2$ \\
\hline Chronic distases $(\geq 2)$ & 32 & 18 & 2.2 & $1.3-3.5$ & 19 & 6 & 3.6 & $1.8-7.2$ \\
\hline Physicall complaints $\geq 2$ & 38 & 20 & 2.5 & $1.5 \times 4.0$ & 23 & 8 & 3.5 & $1.9-6.6$ \\
\hline Medication (yes) & 29 & 18 & 1.8 & $1.1-3.0$ & 17 & 7 & 2.7 & $1.3-5.5$ \\
\hline Psychol. Autonomy (z2) & 41 & 23 & 2.4 & $1,3-4,4$ & 24 & 11 & 2.7 & $1.3-5.4$ \\
\hline Emot. Scability $(22)$ & 34 & 23 & 1.7 & $0.9-3.0$ & 21 & 11 & 2.2 & $1.1-4.3$ \\
\hline Gait problems (21) & 36 & 19 & 2.5 & $1.5-4.1$ & 21 & 7 & 3.4 & $1.8-6.6$ \\
\hline Presence of stars (yes) & 24 & 26 & 0.9 & $0.7-1.5$ & 14 & 11 & 0.8 & $0.4-2.4$ \\
\hline Adjusted footwear (yes) & 41 & 2 .4 & 2.3 & $1.0-1.6$ & 28 & 11 & 3.0 & $1.2-7.2$ \\
\hline
\end{tabular}

\begin{tabular}{|c|c|}
\hline * & 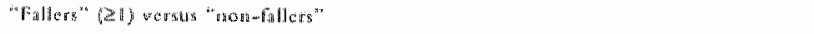 \\
\hline$\neq *$ & 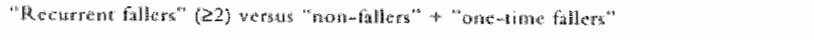 \\
\hline 11 & 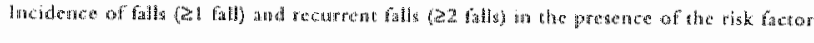 \\
\hline 10 & 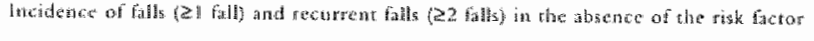 \\
\hline Cyld & nodidis rutizy \\
\hline 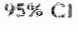 & 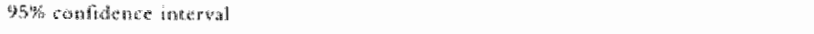 \\
\hline (r) & Pemale \\
\hline
\end{tabular}

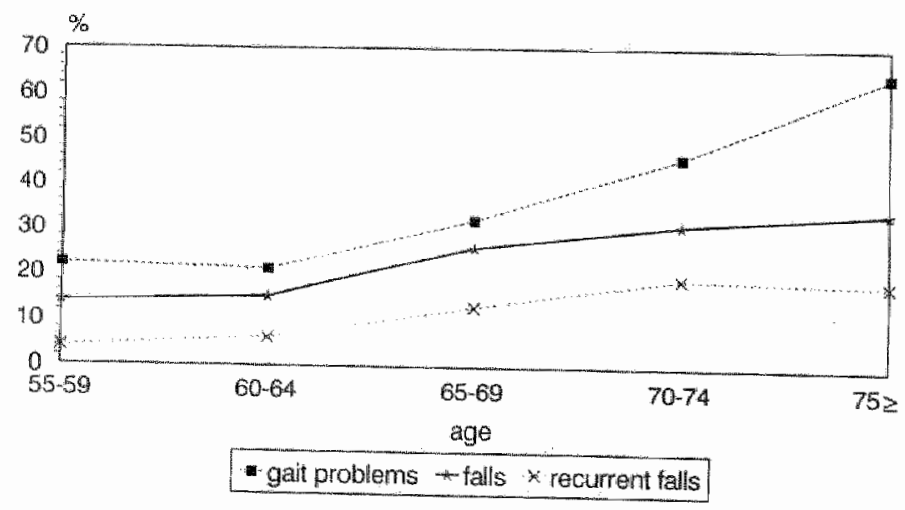


Table 4 Logistic regression analywed by "fallers" (21) versus "non-alliers"

\begin{tabular}{lllll}
\hline Variable & B & (s.e) & OR & $95 \% \mathrm{Cr}$ \\
\hline Gender (F) & 0.87 & 0.26 & 2.4 & $1.5-3.9$ \\
Gait problems (MC $\geq 1)$ & 0.74 & 0.27 & 2.1 & $1.2-3.6$ \\
Age & & & & \\
$60-64$ & 0.20 & 0.50 & 1.2 & $0.5-2.1$ \\
$65-69$ & 0.76 & 0.46 & 2.1 & $0.9-5.3$ \\
$70-74$ & 0.89 & 0.48 & 2.4 & $0.9-6.2$ \\
$\geq 75$ & 0.83 & 0.44 & 2.3 & $0.9-5.4$
\end{tabular}

Table 5 Logistic regression analysed by "recurent fallers" (¿ 2) wersus "nonfallers"s

\begin{tabular}{|c|c|c|c|c|c|}
\hline \multicolumn{2}{|c|}{ Variable } & B & (s.e) & OR & $95 \% \mathrm{Cr}$ \\
\hline \multicolumn{2}{|c|}{ Gender $(\mathrm{F})$} & 1.12 & 0.38 & 3.1 & $1.5-6.4$ \\
\hline \multicolumn{2}{|c|}{ Complaints $(\geq 2)$} & 0.97 & 0.37 & 2.6 & $1.3-5.4$ \\
\hline \multicolumn{2}{|c|}{ Gait problems $(\geq 1)$} & 0.85 & 0.38 & 2.3 & $1.1-5,0$ \\
\hline \multicolumn{2}{|l|}{ Age } & & . & & \\
\hline \multicolumn{2}{|c|}{$.60-64$} & 0.11 & 0.81 & 1.1 & $0.2-5.4$ \\
\hline \multicolumn{2}{|c|}{$65-69$} & 0.92 & 0.71 & 2.5 & $0.6-10.2$ \\
\hline \multicolumn{2}{|c|}{$.70-74$} & 1.36 & 0.71 & 3.9 & $0.9-15.8$ \\
\hline \multicolumn{2}{|c|}{.$\geq 75$} & 0.81 & 0.68 & 2.3 & $0.6-8.5$ \\
\hline B & regression coefhecicht & & $55 \% \mathrm{Cl}$ & 05 st confindence : & \\
\hline$(s, c)$ & standarath erior & & $(\mathrm{F})$ & fintalex & \\
\hline & oxdlds ratite & & $\mathrm{MO}$ & Mostoinsty Conerat & \\
\hline
\end{tabular}

more gait problems increases sharply with age: from $22 \%$ at the age of 55 years to $66 \%$ at 75 years and over.

The association of the risk factors with falls and recurrent falls, as shown in Table 3 , reveals that age, gender, physical health status indicators, decreased Psychological Autonomy and gait problems increase the risk of both falls and recurrent falls. Living alone is associated only with falls in general and decreased Emotional Stability (SIP68) only with recurrent falls. The presence of stairs in the home is not associated with increased risk of neither falls nor recurrent falls. As to be expected, the odds ratios for recurrent falls are higher than for fallis in general. 


\section{Community} survey 1
Table 6 Risk factors for negatwe conseques for functoning (Peares correlarions]

Risikfactor

Mobility Range

Social Befuation

Gender $(\mathrm{ro})$

0.03

0.06

Age

$035 *$

$0.27 \times$

Medication

$0.26 k$

$0.30 \%$

Plysical complánts

0. 35

1). $38 *$

Chronic diseases

1. $26 *$

$0.32 *$

Psychological Automomy

$0.52 * *$

0.48 th

Emotional stability

$0.38 * *$

$0.43 *$

Gat problems

$0.48 *$

$0.49 *$

Adjusted footwear

$0.18 *$

0.06

Fallig $(\geq 1)$

(1). $24 *$

$0.14 *$

Recturent falls $(\geq 1)$

$0.23 *$

0.22 *

lojuries due to folls (yes)

Table 7 Consequences in fumctioning: multiple regresion analysis on Mobility Range and Social Behaviour $\left(\beta^{*} \mathrm{~s}\right)$

\begin{tabular}{|c|c|c|}
\hline Risk factor & Mobility Range & Social Belnavion: \\
\hline Mge & $0.18 *$ & $0.08 *$ \\
\hline Medication & - & $0.12 *$ \\
\hline Gait problens & $0.24 *$ & 0.26 \\
\hline Psychological Autonomy & $0.32 *$ & $0.27 *$ \\
\hline Emotional Stablitity & $0.22 *$ & $0.26 *$ \\
\hline Falls $(21) /$ & 0.091 & $\infty /$ \\
\hline \multirow[t]{2}{*}{ Recuntent fals $(\geq 2)$} & $0.09 *$ & - \\
\hline & $R^{2} a d j=0.43$ & $\mathrm{R}^{2} \mathrm{dj}=0.43$ \\
\hline \multicolumn{3}{|l|}{ (b) tomale } \\
\hline \multicolumn{3}{|l|}{$* \quad 0<0.895$} \\
\hline \multicolumn{3}{|l|}{$* * \quad \quad \quad 0<00$} \\
\hline 2 mubsequena analyes: & $(\geq 1$, second recurrenir fatlic $(\geq 2)$ & \\
\hline
\end{tabular}


In the logistic regression analysis of falls, only women and persons with gait problems have an increased risk of falls in general (Table 4).

The risk of recurrent falls is, in addition, influenced by the presence of physical complaints of two or more (Table 5). In both analyses, the age category of 75 years and over excepted, there seems to be a tendency of an increasing risk with age, although none of the odds ratios is significant.

\section{Consequences on functioning}

The next question to be addressed is whether gait problems and falls have to be regarded as independent risk indicators for decreased functioning. Table 6 presents the correlations of several risk factors with functioning, operationalized in the subscales Mobility Range and Social Behaviour of SIP68.

Here, gender does not play a role as a risk factor. The most important factors associated with decreased functioning are the indicators of mental status and gait problems. Also, to a lesser degree, both falls in general and recurrent falls, are associated with a decrease of functioning. The occurrence of an injury due to falling is related to a decrease of the Mobility $\mathbb{R}$ ange only. In the multiple regression analyses on Mobility Range and Social Behaviour, a small independent effect of falls on the Mobility Range is still present, while the effect of injuries on the Mobility Range, present in the Pearson correlations, disappears (Table 7). However, the prediction of functioning is dominated by mental status indicators and gait problems. Medication has a negative influence on social acivities only.

\section{Discussion}

There is an overall congruence between the results of the present study and the literature on incidence of falls and potential risk factors. The incidence of injuries due to falls is also in accotance with the literature: some $9 \%$ of the falls are related to serious injury. Particularly, poor physical and mental health status and gait problems are consistent risk factors for falling. Recurrent falling is, in addition, more likely to occur when there are more physical complaints present. The most important and consistemt independent risk factor for both falls and recurrent falls, however, is female gender. As age and gait problems are accounted for in the analysis one is tempted to believe that there should be a sex specific explanation. Perhaps the striking difference in muscle strength 
Community

survey berwen males and females is a candidate factor in this matter (27). In our seudy there was no independent contribution of extrinsic risk factors like the presence of stairs in the home and adjusted footwear. This finding is in accordance with earlier research (1). In a criteriambased analysis, no single study displayed evidence for an independent contribution of extrinsic factors to the total risk of falling $(13)$.

Our results suggest that preventive measures should be directed to the elderly with gait problems, particularly the female elderly. The persistent negative findings on extrinsic risk factors, raises serious doubi about the priority of preventive measures in this area.

Although advanced age of 70 years and over and the distinct age categories show bivariately an association with falls and recurtent falls, in the logistic regression analysis the age categories from 60 to 75 years only show a tendency of significance in increasing risk by age.

In the present study mentall status indicators and gait problems appeared to be the most important predictors of decreased functioning. Falls in general and recurrent falls, on the contrary, seem not to have serious independent impact on functioning, what provides some new insights. Some authors had supposed a functional decline as consequence of falls, and particularly recurrent and injurious falls, but our data did not reveal this $(18,28)$. It still remains to be determined whether falls directly cause a decline of functions in old age or only serve as a marker for them (16).

From methodological point of view this study has some important limitations. In consequence of the cross-sectional design it is not possible to make sharp distinctions between risk factors for and consequences of falls, due to a lack of information about the timesequence of risk factors, falls and consequences of falls. We marked some variables as potential risk factors for falls and some as consequences if there were reasons for plausibility. Therefore. certain results have to be considered as associations more than clear causal relations between risk factors and falls. In this respect we comsidered physical and mental health indicators, and gait problems as potential risk factors for falls, but the range of mobility and sociall activities, operationalized in the Mobility Range and Social Behaviour, respectively, as variables of functioning.

The non-response rate may seem high and may have caused confounding in the higher age categories, which were underrepresented. However, we regard the response of 62 percent as satisfactory, taken into accoumt the mean response rate of 60 percent among mail surveys published in medical journals (29). 
Our results suggest that poor physical healh, unfavourable mental status and gait problems are the more important deteminants of decline of functioning. This agrin emphasises that poor physical and mental health and gait problems belong to the most importane risk factors for functional decline in the elderly. With regard to preventive measures, directed at functional decline, prevention of gait problems and its determinants, are strongly recommended. A fair amount of published evidence about the benefits of physical activity and exercise in preventing falls is awailable $(30-34)$. In general practice the early identification and treatment of elderly patients with and at risk for gait problems is important.

\section{Acknowledgements}

We wish to thank Mignon Vloet for her initiative in cooperation with one of the authors, Karin Schiricke, to start this study and to write the first draft of the article.

We are indebted to the general practitioners P.B.N. Hulshof, R.A.M. Panhuysen and $\mathbb{E} . T$.I.M. Guldemond-Hecker and their assistants in the Voerendal Primary Health Care Centre, Voerendaal, The Netherlands, for their contribution and support in the introduction of this study to their patients.

\section{References}

1. Tinetif $M E$, Spechley M, Giner SF, Risk factots for falls among elderly persons living in the community. $\mathbb{N}$ Eng J Med $1988 ; 26: 1701-7$.

2. Campbell $A J$, Borrie $M J$, Spears GF. Risk factors for falls in at communitymased prospective study of people 70 years and older. I Gerome:Med Sici 1989;44:112-7.

3. O'Loughlin JL, Robitaille $Y$, Boivin $J-F$, Suissa S. Incidence of and risk factors for falls and injurious falls among the communitydwelling elderly. Am J Epid 1993:1137:342-54.

4. Cranam, Helen J. Firth, Juha. Home accidents in older people. Br Med J 1992;305:30-2.

5. Wild D, Nayak USL. How dangerous are falls in old people at home? $\mathrm{Br}$ Med J 1981:282:266-8.

6. Soomers-Turlings JMSJG, Crebolder HFM, Beusmans GHMI, Bal $R M$. Het vallen van ouderen; een exploratieve studie in de 


\section{Community}

surey 1

hutsatspraktik. Huisarts Wet 1992;35:57-60 (Falls by the elderly. An exploratory study in geveral practice).

7. Stalenhoef PA, Busse van der S, Knottmerws JA, Crebolder HFJM Vallen van ouderen: het horen, zien, doen en laten van de huisarts. (Falls in the elderly: the involvement of the general practitionery. Huisare Wet 1998:41(5):241-5.

8. Blake AJ, Morgan K, Bendall MJ, Dalasso H, Ebrahim SBJ. Arit THD. Fentem PH, Bassey EJ. Falls by elderly people at home: prevalence and associated factors. Age Ageing 1988;17:365-72.

9. Prudham D, Grimley Evars J. Factors associated with falls in the alderly: a community study. Age Ageing 1981;10:141-6.

10. Yasumara $S$, Haga $H$, Nagai $H$, Suzuki $T$, Amano $H$, Shibata $H$. Rate of falls and the correlates among elderly people living in an urban community in Japan. Age Ageing 1994;23:323-7.

11. Nevitt $M C$, Cummings $S R$, Kidd $S$, Black D. Risk factors for recurrent non-syncopal falls; a prospective study. JAMA $1989 ; 261: 2663-8$.

12. Grafmans WC, Oons ME, Hofstee HMA, Bezener PD, Bonter $L M$, Lips $P$. Falls in the elderly: a prospective study of risk factors and risk profiles. Am J Epidemiol 1996:143:1129-1136.

13. Stalenhoef PA, Crebolder HFJM, Knotnerus JA, Horst, wan der $G E M$. Incidence, risk factors and consequences of falls among elderly subjects living in the community: a criteria-based analysis. Eur J Public Health 2997;7:328-34.

14. Cwikel J. Falls among eldelry people living at home: medical and social factors in a national sample. Israel J Med Sci $1992 ; 28: 446-53$

15. Lundgren-Lindquist $B$, Jette $A M$. Mobility disability among elderly men and women in Sweden. Int Disabil Studies 1990:12:15.

16. Timeti ME. Prevention of falls and fall injuries in elderly persons: a research agenda. Prev Med 1994;23:756-62.

17. King MB, Tineth $M E$. Falls in community-dwelling older persons. JAGS 1995:43:1146-54.

18. Dunn JE, Rudberg MA, Furner SE, Cassel CK. Mortality. disability, and falls in older persons: the role of underlying disease and disability. Am J Publ Health 1992:82:395-400.

19. Cwikel J. Fried $A W$. The social epidemiology of falls among community-dwelling elderly: guidelines for prevention. Disab Rehab 1992;3:113-21.

20. Weel wan $C$, Werweulen $H$, Bosch wan den $W$. Falls, a community care perspective. Lancet $1995 ; 345: 1549-51$.

21. Bos van dev GAM. Zorgen van. en voor chronisch 
zieken. Thesis. Bohn, Schelteman Holkema, 1989.

22. Bntw, de AF, Diederiks JPM, de Witte LP, Stevens FCJ, Philipsent $H$. The development of a short generic version of the Sickness Impar Profile. ] Clin Epidemiol 1994:47:407-18.

23. Bergner M, Bobbitt RA, Carter WB, Cilson BS. The Sickness Impact Profle: development and final revision of a health status measure. Med Care 1981:19:787-805.

24. Brain de AF, Diederiks JPM, Witte de LP, Stewers FQJ, Philipson $H$. Assessing the responsiviness of a functional status measure; the Sickness Impact Profile versus SIP68. J Clin Epidemiol $1997 ; 50(5): 529-40$.

25. Arhed JC. Environmental factors associated with stair accidents in the elderly. Clin Geriatr Med 1985;1:555-68.

26. Walker JE, Howland $J$. Falls and fear of falling among elderly persons living in the community: accupational therapy intervention. Am J Occup Ther 1991;45(2):119-22.

27. Judge JO, Whipple RH, Wolfon LI. Efrects of resistive and balance exercises on isokinetic strength in older persons. JAGS $1994 ; 42(9): 937-46$

28. Rubenstein LZ, Robbins $A S$, Schulnan $B L$, Rasado J, Osterweil $D$, Josephsom $K R$. Falls and instability in the elderly. JAGS $1988 ; 36: 26,6-78$.

29. Asch DA, Jedrzieuski MK, Christakis NA. Response rates to mail surveys published in medical journals. J Clin Epideniol 1997,50:1129-36.

30. Province MA, Hadley EC, Hotmbrook MC, Lipsitz LAQ, Miller IP, Mulrow CD, Ory $M G$, Sattin $R W$, Tineth ME. The effects of exercise on falls in elderly patients. A preplanned meta-analysis of the FICSIT trials. JAMA 1995:273(17):1341-7.

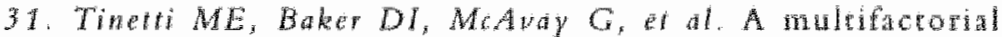
intervention to reduce the risk of falling among elderly peoplo living in the conmunity. N Engl J Mad 194;31:821-7.

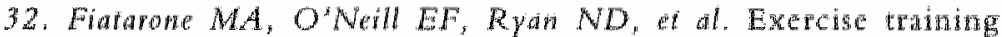
and nutritional supplementation for plasicat fally in wery alderly people. N Engl J Med 1994:330:1769-75.

33. Fiatarone MA, Marks EC, Ryari ND, el at. High-inedestry strength traming in nonagenarian. JAMA 1990,263:3029-34.

34. Lord SR, Ward JA, Williams Ph, Strudwoth $M$. The eftect of a 12-month exercise trial on balace, strength, and falls in older women: a tandomized controlled tral. I Am Geriats Soc $1995 ; 43: 1198-1206$ 

CHAPTER 7

Community survey 2

A patient record-based risk model for falls in community-dwelling elderly

Submitted as:

Stalenhoef PA, Dicderiks JPM, Knottnerus JA, Witte

LPM de, Crebolder HFIM. A patient record-based risk

model for falls in community-dwelling elderly. 
Community

survey 2

\section{Abstract}

Objedives To investigate incidence, determinants and consequences of falls in a community-dwelling elderly population and the contribution of data from patient records to a risk model of recurrent falls.

Design Population survey using a mail questionnaire.

Seting Four general practices $(\mathrm{N}=27,000)$

Methods A mail questionnaire on occurrence of, risk factors for and consequences of falls was sent to 2744 community-dwelling elderly of 70 years and over, registered in four general practices. Data were analysed by bivariate techniques and logistic regression, resulting in a logistic model.

Results $1660(60 \%)$ responded. Falls $(\geq 1$ fall $)$ in the previous year were reported by $25 \%$ and recurrent falls $(\geq 2$ falls) by $19 \%$. Women had significantly more falls than men. Major injury was reported by $8 \%$ of the fallers (1\% hip fractures; $7 \%$ other fractures); minor injury by $49 \%$. Treatment of injuries was done by the general practitioner in $67 \%$. Logistic regression revealed that the main risk factors for falls and recurrent falls were similar, although risk factors for recurrent falls had higher odds ratios. A risk model for recurrent falls consisting of 6 risk factors: female gender, age 80 years or over, presence of a chronic neurological disorder, use of antidepressants, problems of balance and sense organs and complaints of muscles and joints was developed. The addition of a 7 th risk factor (Mobility Control SIP68 $\geq 3$ ) did not result in an essential improvement of the model. The Receiver Operator Characteristic (ROC) analysis of the model yielded an Area under the Curve (AUC) of $0.73(0.75$ if $M C$ SIP68 $\geq 3$ is added).

Condusion A risk model consisting of 6 wariables (7 if MC SIP68 $\geq 3$ is added) from the patients' records predict recurrent falls with a sensitivity of $64 \%$ ( $65 \%$ with $\mathrm{MC}$ ), a specificity of $71 \%(74 \%$ with $\mathrm{MC}$ ), a positive predictive value of $42 \%$ ( $45 \%$ with $\mathrm{MC}$ ) and a negative predictive value of $86 \%$ ( $86 \%$ with $\mathrm{MC})$.

Keywords: falls, elderly, general practice, population survey, risk factors, risk model, patient records. 


\section{Introduction}

Falls in the elderly belong to the major problems in health care, because of their high incidence and severe consequences $(1-4)$. From earlier studies it is known that $25-40 \%$ of community dwelling elderly people of 65 years and ower have at least one fall each year and half of them fall two or more times $(4-6)$. The incidence of falls increases with age and reaches $40 \%$ at the age of 80 years or over and in institutionalized elderly persons even $100 \%$ $(4,7)$. Women fall more often than men, but the sex difference in fall incidence disappears in the higher age categories $(4,5,7)$. Falls may have important consequences for health and functionimg (810). Fractures are the most common serious injuries resulting from falls in elderly persons. Hip fractures have an incidence of a half to one percent a year and a mortality of around 30 percent in the first 3 months (4,11-13). Other consequences are head tramas and wrist or hand fractures, which occur in about another five percent (14). The inability to get up after a fall may result in scrious morbidity and "long lies" after falls have a bad prognosis and a high mortality $(15,16)$. Also psychological and social consequences, such as fear of falls and social isolation, may occur, sometimes resulting in a "post-fall syndrome" $(17-19)$.

Many determinants and risk factors are associated with falls in the elderly $(4,5,20-24)$. Falls are usually classified on the basis of the type of risk factors such as intrinsic (individual), extrinsic (envirommental) and risk factors related to hazardous behaviour $(4,25)$. The predominant role of intrinsic risk factors in the eriology of falls is generally accepted (26). The most important intrinsic risk factors are mobility imparment, cognitive decerioration, wse of medication, especially sedarives, quantity of regularly taken medication, a history of stroke and orthostatic hypotension $(4,5,20$ 24). However, there is a great diversity in number and kind of risk factors $(4,5)$. In an earlier study physical health indicators, such as the number of complaints and disorders, appeared to have strong associations with falls and recurrent falls (27). In some studies the difference in the risk profile between one-time and recurrent fallers is emphasized $(2,11)$. For the general practitioner (GP), the question of the occurrence of a single fall should be: is it an accasional event or the beginning of a series of falls leading to general deterioration and impaiment?

Based on the results of a criteria-based analysis of studies on falls in community-dwelling elderly, risk factors can be classified, apart from the classification into intrinsic and extrinsic risk factors, into 
Community

survey 2

tour main areas (5): 1. socio-demographic determinants; 2 . physical and 3 . mental health indicators, and 4. risk factors concerning and influencing mobility, including environmental hazards. Many of these risk factors can be deduced from the medical history, patient records and assessments at the disposal of the GP. It is of great interest to operationalize these data for the identification of the community-dwelling elderly at risk for falling in wiew of preventive strategies. In this respect a foasible risk model based on data easily and directly available from patient records could be very helpful to the GP (22). We therefore decided to set up a community survey with the following two study questions:

- What are the incidence, determinants and health consequences of falls and recurrent falls in a community-dwelling elderly population?

- Do data from patient records contribute to a risk madel for recurrent falls?

\section{Methods}

\section{Subjects}

All elderly persons of 70 years or over $(N=2946)$, registered in three primary health care centres and one duo practice $(\mathrm{N}=27,000)$. were selected for this study. Of these, 202 individuals were excluded by the general practitioners. Exclusion criteria wer wheelchair dependence, advanced cognitive impaiment, illiteracy and severe somatic or psychiatric disease, which would hamper participation. Furthermore, persons living in or planned for admission into a hospital or nursing clinic were excluded, but those independently living in residential homes and aparments for the elderly were included. Practices are members of the Registration Network Family Practices (RNH) (28)

The study design was approved by the Ethical Review Board of the University Hospital Mastricht.

\section{Meastrements}

A questionnaire was sent to the study population $(N=2744)$, including the following fall-related items:

- Socio-demographic data: age, gender, educational level, marital status and the presence of stairs in the dwelling.

- Fall history and injuries due to falls: falls and near-falls in the previous year, perceived causes of falls, injuries due to falls, treatment, and fear of falling

- Physical health status: complaints and disorders, the number of 
medicines taken, the regular use of prescribad medication beng considered to increase the risk of falling, perceived health status and alcohol consumption $(29,30)$.

- Mental health status: the Psychological Autonomy and Communication and the Emotional Behaviout scales from the Sickness Impact Profile (SIP68) (31-33).

- Mobility impaiment: a 5-point rating scalle regarding perceived gait problems and the Mobility Control (MC) scale from the (SIP68) (31-33).

- Dependence and activities of daily life (ADL) and household activities ( $H D L$ ): a 5 -point rating scale on need for professional aid and sumscores of six 3-point scales on ADL/HDL for the determination of the level of independent functioning (34).

A "fall" is defined as any unintentional coming down on the ground or to a lower level. "Ever fallers" were defined sts participants with at least one fall in the previous year; "one-time fallers" with only one fall and "recurrent tallers" with two falls or more in the previous year.

Data analysis

Differences of socio-demographic characteristics between study population and up-dated RNH population of the participating practices were tested by Chi-square test. Potential determinants were analysed by odds ratios with $95 \%$ confidence intervals. Three outcome variables concerning falls in the previous year were defined: "ever fallers" ( $\geq 1$ fall), "one-time fallers" and "recurrent fallers" ( 22 falls), all contrasted to "non-fallers".

Age was dichotomized into 2 categories: $<80$ years and $\geq 80$ years. Cut-off values for dichotomization of orher variables were used as recommended in the relevant literature or in case of the SIP68 scores, median values were used.

Factor analysis (Principle Components analysis, followed by Varimax $\mathbb{R}$ otation) of complaints was performed to obtain a reduction of the number of complants and to determine coherence between variables. Three relevant factors were extracted factor 1 related to complaints of rnobility such as pain and stiffness of joints and muscles, backache and foot problems; factor 2 related to problems of balance, dizziness and impaiment of vision and hearing, and factor 3 related to chest complaints such as chest pain, palpitations and dyspnoca.

Forward stepwise logistic regression analysis of age gender; variables reaching significance in the bivariate analysis and factors 1 and 2 from the factor analysis of complaints, was performed. 
Community

survey 2

Variables were selected that had independent significant associations with outcome, taking their contribution into account simultaneously. From logistic regresion analysis, a risk model containing the strongest independent risk factors was derived. The threshold for significance was $\alpha=0.05$. The fit of the logistic model was assersed using the goodness-of-fit test according to Hosmer Lemeshow (35).

A Receiver Operator Characteristic (ROC) analysis was performed to describe the relationship between sensitivity and specificity at different cut-off values and to determine the maximal sum of sennitivity and specificity as the statistically optimal cut-off value. The predictive power of the logistic model was determined using the Area Under the ROC Curve (AUC) $(36,37)$. Finally, positive and negative predictive values ( $P V+$ and $P V-$ ) of the model were calculated.

\section{Results}

\section{Subjects}

After one mall reminder, completed questionnaires were received from 1660 persons, 642 men (39\%) and 1018 women (61\%) (response rate: $60 \%$ ). Table 1 presents the main socio-demographic characteristics of the study population compared to the $70+$ population registered in the RNH practices. Respondents were similar to the $\mathbb{R N H} 70+$ population regarding sex, but not regarding age: in the study population the percentage of subjects of 80 years or over as lower than in the RNH population. Percentages of widowed and single persons were similar in both populations. In the study population the percentage of persons living independently was 89 percent. The level of education was subdivided into low (63 percent), medium (20 percent), high (13 percent) and not classifiable ( 4 percent). The presence of stairs was reported by 57 percent.

\section{Falls}

Seven hundred and twenty-three subjects (44 percent) had at least one fall in the previous year. One fall was reported by 413,25 percent) and recurrent falls ( 22 falls) by 310 persons (19 percent). Women had significantly more one-time falls (29 percent versus 19 percent) and recurrent falls (22 percent versus 12 percent) than men. Indoor falls were reported by 41 percent, outdoor falls by 42 percent and both indoor and outdoor falls by 17 percent. Near-falls were reported by 37 percent and fear of falling by 48 percent of the 


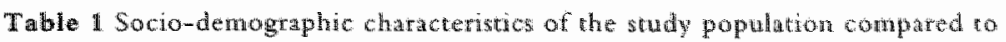
the RH population (columan percentases)

\begin{tabular}{|c|c|c|c|c|c|}
\hline \multirow[t]{2}{*}{$\begin{array}{l}\text { Socio-demographic } \\
\text { characteristics }\end{array}$} & \multicolumn{2}{|c|}{$\begin{array}{l}\text { Situdy population } \\
\qquad N=1660\end{array}$} & \multicolumn{2}{|c|}{$\begin{array}{c}\text { RNI population } \\
N=2170\end{array}$} & \multirow[t]{2}{*}{ Silg } \\
\hline & $\mathbb{N}$ & $\%$ & $N$ & Fa & \\
\hline \multicolumn{6}{|l|}{$\operatorname{Set} x$} \\
\hline Male & 642 & 39 & 829 & 38 & \multirow[t]{2}{*}{$\mathbb{N} . S$} \\
\hline Female & 1018 & 61 & 1341 & 62 & \\
\hline \multicolumn{6}{|l|}{$A g$} \\
\hline$<80$ years & 1279 & 77 & 1556 & 72 & \multirow[t]{2}{*}{$*$} \\
\hline$\geq 80$ years & 381 & 23 & 614 & 28 & \\
\hline \multicolumn{6}{|l|}{ sex by a d } \\
\hline \multicolumn{6}{|l|}{ Male } \\
\hline$<80$ years & 521 & 81 & 636 & 77 & \multirow[t]{2}{*}{$*$} \\
\hline$\geq 80$ years & 121 & 19 & 193 & 23 & \\
\hline \multicolumn{6}{|l|}{ Female } \\
\hline$<80$ years & 758 & 74 & 920 & 69 & \multirow[t]{2}{*}{$*$} \\
\hline$\geq 80$ years & 260 & 26 & 421 & 31 & \\
\hline \multicolumn{6}{|l|}{ Marital status } \\
\hline \multicolumn{6}{|l|}{ Married living } \\
\hline together & 876 & 53 & 1062 & 49 & \multirow[t]{2}{*}{ N.S. } \\
\hline Widowed/single & 778 & 47 & 1039 & 48 & \\
\hline
\end{tabular}

* level of mighticance; Chi sathate

N.5. That significant

* $p<0,0,0$

**: $\quad p<a, 0$ !

respondents. Generally, fallers have a higher mean age chan nonfallers: mean age of non-fallers was 75.4 years (SD 4.8), of onetime fallers: 76.4 years (SD 5.4) and of recurrent fallers: 77.4 years (SD 5.3).

Table 2 presents major and minor injuries duc to falls in the previous year with type of injury, the proportion of subjects needing treatment and the location of treatment.

\section{Determinants}

Table 3 lists prevalences of and odds ratios for potential determinants of ever falls ( $\geq 1$ fall), one-time falls and recurrent falls ( $\geq 2$ falls). Comparison of the odds ratios in the three outcome 
Table 2 Injures due co fills in the previous year

Injury

Percentage of fallers

$(\mathrm{N}=723)$

\section{Community}

survey 2

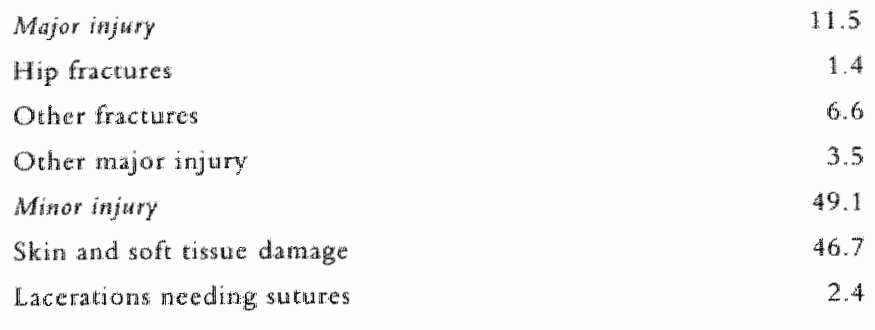

Treatment

Percentage of

injured fallers

$(\mathbb{N}=438)$

Treathe rat by GP

40.9

Treatment in hospical

16.6

Treatment by others

2.1

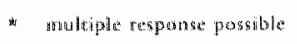

groups reveals a spectrum of increasing odds ratios for one-time fallers, ever fallers and recurrent fallers. Variables which showed associations with falls in all fall groups are age 80 years or older, female gender, living alone (widowed or single), gait problems, mobility impaiment, more than two complaints and disorders, theumatoid discase, use of anti-depressants and decreased Psychological Autonomy and Communication according to SIP68. Variables which did not show any associations with falls are the presence of stairs in the dwelling. use of anti-hypertensives and catdiac agents and alcohol consumption of five or more units a week. The strongest associations are shown in the recurrent fall group, particularly for impaired mobility, the presence of more than two complants, chronic neurological disease, use of antidepressants and a poor perceived health, all reaching odds ratios above 3. It has to be noted that the prevalence of chronic neurological disorder and the use of anti-depressants is low: 3 and 2 percent, respectively. About 73 percent of all respondents regularly wsed prescribed medication. Some 32 percent were regularly using other prescribed medication. Comparison in all fall groups of 6 


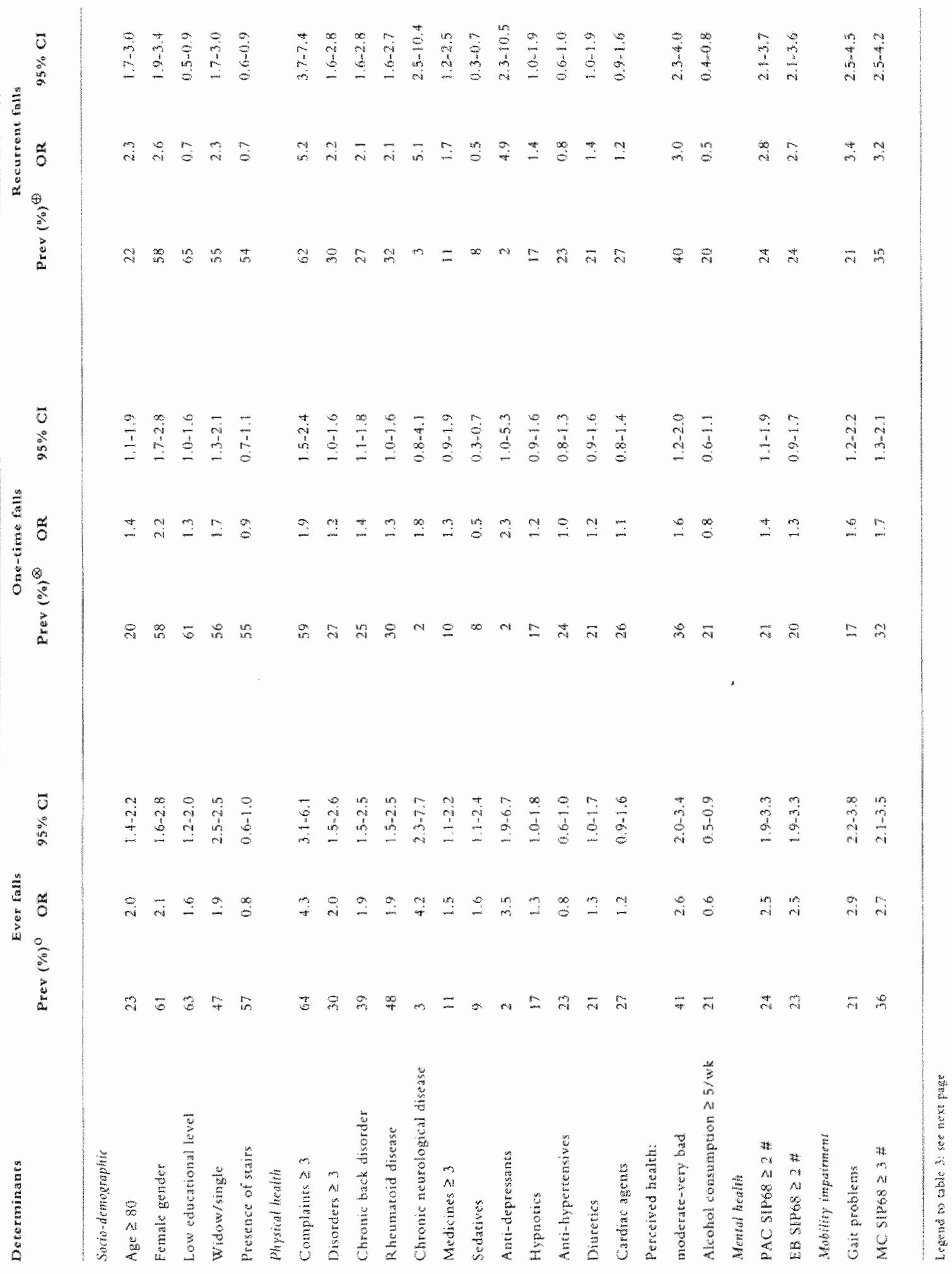


Community

survey 2
Legends iog thate 3

解

8

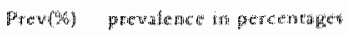

od

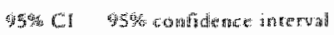

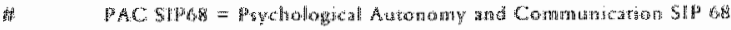

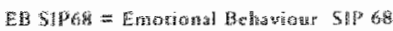

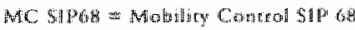

categories of medicines, adjusted for age and sex, revealed that only anti-depressants in all fall groups, and hypnotics and diuretics in the ever falls and the recurrent falls groups were significantly associated.

\section{Logistic regression}

Variables showing strong associations with recurrent falls in the bivariate analysis, included two factors from the factor analysis reaching significance (factor 1: pain and stiffness of muscles and joints, backache and footproblems and factor 2: balance problems, dizziness and impairment of vision and hearing) were retained into a logistic regression analysis. Six variables appeared to give an independent statistically significant contribution to the prediction of recurrent falls. To this logistic model, a seventh variable from the section Mobility impairment, MC SIP68 $\geq 3$, was added, resulting in two variants of the logistic model, Models 1 and 2 , respectively. Table 4 reveals that female gender, the presence of a chronic neurologicall disease and the use of anti-depressants are the strongest independent risk factors for recurrent falls in both models. In at calculation of probabilities for recurrent falls three examples of the application of the model are given.

Table 5 presents the predected probability of modell 1 and model 2 for predictions of recurrent falls according to the goodness-of-fit test of Hosmer Lemeshow. Both Models 1 and 2 had satisfactorily scores for the fit test, i.e. there is no difference between expected and observed number of recurrent fallers. Calculation of the Area Under the Curve (AUC) revealed about equal walues for the model variants: 0.73 and 0.75 , respectively.

Table 6 reveals that the statistically optimal cut-off value in both models is reached at 0.26 , being the maximum sum of the sensitivity and the specificity. The positive predictive values (PV+) 
Table 4 Logistic regression analysis of Model 1 and Model 2 for recurrent fallers $(22$ [a]lis; $\mathbb{N}=1226$ *

\begin{tabular}{|c|c|c|c|c|}
\hline \multirow[b]{2}{*}{ Variables } & \multicolumn{2}{|c|}{ Model 1} & \multicolumn{2}{|c|}{ Model 2} \\
\hline & OR & $95 \% \mathrm{CI}$ & OR & $95 \% \mathrm{CL}$ \\
\hline Age: $\geq 80$ years & 1.7 & $1.3-2.4$ & 1.5 & $1.1-2.1$ \\
\hline Gender: female & 24 & $1.7-3.2$ & 2.3 & $1.7-3.2$ \\
\hline \multicolumn{5}{|l|}{ Pain/stiftness in } \\
\hline muxles and joints & 2.2 & $1.7-3.0$ & 1.9 & 14.26 \\
\hline Balance/senses. & 2.0 & $1.5-2.7$ & 1.8 & $1.3-2.4$ \\
\hline \multicolumn{5}{|c|}{ Chromic me urological } \\
\hline disortier & 4.0 & $1.8-8.9$ & 3.5 & $1.6-7.9$ \\
\hline Anti-depressants & 2.0 & $1.5-6.6$ & 2.6 & $1.1-6.0$ \\
\hline \multicolumn{5}{|l|}{ Mobility impairment } \\
\hline$(\mathrm{MC} \operatorname{SIP68} \geq 3)$ & $\mathrm{n}, \mathrm{a}$ & nia & 1.8 & $1.3-2.5$ \\
\hline Congeant & & -2.6 & & -2.7 \\
\hline
\end{tabular}

\begin{tabular}{|c|c|}
\hline OR & odds rint to \\
\hline $55 \% \mathrm{Cl}$ & confiftence interyat \\
\hline
\end{tabular}

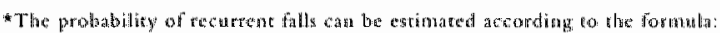

$$
p=1 /\left\{1+e^{-k}\right\}
$$

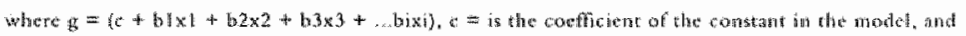

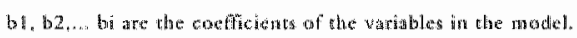

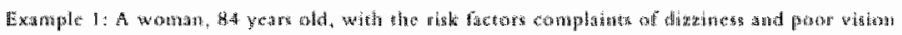

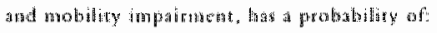

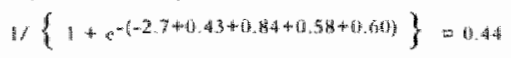

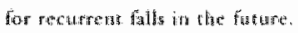

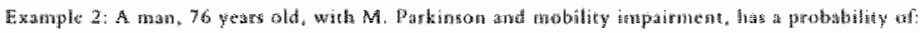

$$
1 /\{1+2-(-2,7+1.26+1.60\}\}=0.54
$$

for racurrent bills in the fiture.

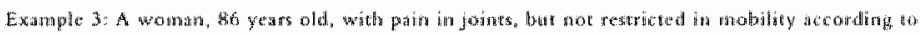

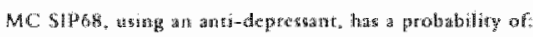

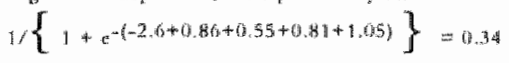

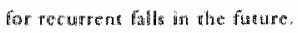


Table 5 Predicted probabily of Model 1 and Model 2 for predierion recurrent falls $(22$ fills): $N=1226$

Community survey 2

\section{Predicted probability}

$0-10 \%$
$10-20 \%$
$20-30 \%$
$30-40 \%$
$40-50 \%$
$50-60 \%$
$60-70 \%$
$70-80 \%$
$\geq 80 \%$

Model 1

Observed

$\%$

\begin{tabular}{rrrr}
178 & 5.1 & 178 & 6.2 \\
386 & 13.7 & 430 & 12.6 \\
362 & 26.5 & 225 & 27.1 \\
6.7 & 44.8 & 190 & 38.4 \\
133 & 45.1 & 117 & 47.9 \\
77 & 48.1 & 5 & 80.0 \\
9 & 66.6 & 64 & 46.9 \\
7 & 71.4 & 10 & 80.0 \\
7 & 85.7 & 5 & 80.0 \\
& & \multicolumn{2}{c}{3.04} \\
& 5.53 & \multicolumn{2}{c}{0.6} \\
& 0.6 & \multicolumn{2}{c}{0.75}
\end{tabular}

* AUC = Area Under the Receiver Opperater Charactersedic (ROC), curve

at this cut-off point are tather low ( 42 and 45 percent), but the negative predictive values are high ( 86 percent both). 
Tabel 6 Predictis value of the lowiste models for recurrent falls (22 alls) at differene cut-of points for predieted probabiluty.

Modell

Catit-of

point for

predicted

probability
Sengitvity Specincity $\& \quad P V+P V-$

gio

\begin{tabular}{|c|c|}
\hline & \\
\hline & $\%$ \\
\hline
\end{tabular}

$\begin{array}{llllll}0.10 & 97 & 18 & 115 & 28 & 95 \\ 0.20 & 79 & 54 & 133 & 36 & 89 \\ 0.26 & 64 & 71 & 135 & 42 & 86 \\ 0.30 & 48 & 83 & 131 & 48 & 83 \\ 0.40 & 38 & 87 & 125 & 49 & 81 \\ 0.50 & 18 & 95 & 113 & 54 & 78 \\ 0.60 & 6 & 99 & 105 & 74 & 76 \\ 0.70 & 4 & 99.6 & 104 & 79 & 76 \\ 0.80 & 2 & 99.8 & 102 & 86 & 76\end{array}$

\section{Model 2}

$\begin{array}{llllll}0.10 & 96 & 18 & 114 & 29 & 95 \\ 0.20 & 78 & 59 & 137 & 38 & 89 \\ 0.26 & 65 & 74 & 139 * & 45 & 86 \\ 0.30 & 58 & 76 & 134 & 45 & 85 \\ 0.40 & 34 & 89 & 123 & 51 & 81 \\ 0.50 & 16 & 96 & 112 & 55 & 78 \\ 0.60 & 15 & 96 & 111 & 54 & 77 \\ 0.70 & 5 & 99.7 & 105 & 92 & 76 \\ 0.80 & 2 & 99.9 & 102 & 86 & 76 \\ 0.90 & 0.7 & 100 & 101 & 100 & 75\end{array}$

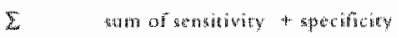

* maximition

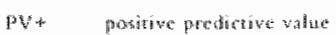

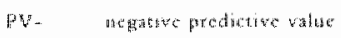




\section{Discussion}

Community survey 2

\section{Main results}

The reported incidences of falls and mean ages of the fallers, onetime and recurrent fallers do not essentially differ from other, comparable retrospective and prospective studies $(2,4,5,6,8,20-24)$. The proportion of fallers with major and minor injury $(8 \%$ and $49 \%$ ) is also in accordance with other investigations (5). In our study two-thirds of all fall-related injuries were treated by the GP and about one third in an emergency ward of a hospital, which emphasizes the important contribution of the GP to the mamagement of fall-related injuries in community-dwelling elderly (38). The relevant contribution of complaints and disorders to fall risk, already revealed in an earlier study (27), is confrmed in this study. In some studies on falls in the elderly the regular use of medication appeared to be a significant risk factor and in other studies the risk of falling is positively associated with the quantity of medication taken $(4,22-24)$. In our data only the use of sedatives, hypnotics and anti-depressants appeared to be associated with ever falls and recurrent falls $(4,8,23,24)$. However, in the regression analysis only the use of anti-depressants had a significant, independent contribution to the risk of ever falls and recurrent falls (8). Alcohol consumption of five or more units a week does not play a significant role, a finding already known from other studies $(4,11,21)$.

The logistic regression analysis yuelds a risk model for recurrent falls consisting of six variables, which are usually known to the GP from the patients" medical records. "The addition of a seventh variable, a performance test on mobility, the Mobility Control (MC) from the SIP68, cut-off value 3, offers no fundamentally better performance in the diagnostic and predictive applicarion (Tables 5 and 6 ). The consequence of this finding is that the short variant of the risk nodel is preferable to the variant with an extra test.

With regard to the $\mathrm{PV}+$ and $\mathrm{PV}$ - the models are apparently mor appropriate to predict no falls in the absence of risk factors than the occurrences of falls in the presence of them.

\section{Meihodological considerations}

A limitation of this study is that because of the cross-sectional design no definitive conclusions can be drawn about the timesequence of risk factors, falls and consequences of falls. As a consequence of this, determinants and outcomes are not always conceptually distinguishable. Therefore, observed associations have 
to be considered as indicators for risk, supported by plausibility, and can be the basis for further prospective investigations. Examples of interpretation problems in this cross-sectional study regarding the direction of the associations concern near-falls, fear of falling, certain complaints and impaiments of functioning. such as mobility imparment, which can be considered as causes and consequences of falls as well.

The study population had a similar sex distribution as the community population of persons of 70 years or over, registered in the practices belonging to the Registration Network Family Practices (RNH). However, the $80+$ population in this study is somewhat under-represented: 23 versus 28 percent. This means that overall results from this study have to be considered as relatively flattered, the age-dependence of incidence of and risk factors tor falls taken into account. In the regression analysis, however, we have controlled for age.

In clinical studies a response tate of $60 \%$ may not seem to be high, but in mail surveys published in medical journals the mean response rate appeared to be $60 \%$ (39). We consider the response from our mail survey in a community-dwelling elderly population of 70 years and over acceptable. There is no evidence of selection bias due to non-response. Retrospective studies may suffer from recall bias, due to short-term memory loss, but we tried to avoid this by prestructuring the questions on falls into two separate, sequential petiods of a half year each $(40,41)$. Data on incidence from this retrospective study are comparable to other prospective studies $(4,20-24)$. This is in accordance with our finding in an carlier criteria-based analysis in which we did not find significant differences of incidence rates of falls between selected retrospective and prospective studies $(5)$.

\section{Implications for general practice}

For the GP the main outcome of this study is that all six independent and significant risk factors for recurrent falls of the risk model are usually known to the GP or easy to extract from the patient's medical record. In order to obtain more detalled information about the impaiment of the mobility, the addition of a seventh risk factor to the model, the MC SIP68, a self-rating scalle on mobility impaiment and consistimg of 12 items, offers no particular advantage. Depending on the variant of the model used, recurrent falls can be predicted with positive predichive values of $42 \%$ and $45 \%$ with a risk model variant of six or seven variables. respectively; these values are rather low. The sensitivity walues are 
Community

survey 2 satisfactorily, but in the application of the model a bighes sensitivity is of interest from a prevention point of wiew. The choice of a cut-aff value at $0.20 \mathrm{may}$ be preferable to the statistically optimal cut-off value at 0.26 . reaching a sensitivity of nearly 80 percent. However, the positive predictive value is lowet at that cut off point ( 38 percent).

Our conclusion is that a useful risk model to predict recurrent falls can be based on variables which are usually known to the GP or directly derivable from parient records.

\section{Acknowledgements}

We thank the GPS of the participating elderly in this study for their cooperation and support: G. Castermans, Th. Govaert, R. Helmers, L. Huynen, R. Leclercq, M. Maakant, A. Muysken-du Saar, M. van Nunen, J. Paas, M. Peeters, G.J. van Schendel (†). B. Schilte, M. wan Venrooy, F. Vissers and P. Voorhoeve.

We also thank Jos Hamers, research assistant, for his help in the analyses and Lilian Hesemans, secretary, for her contribution to the data collection.

This study was supported by a grant from ZON (ZorgOnderzoek Nederland; formerly the Praeventie Fonds).

\section{References}

1. Kellogg Intemational Work Group on the Prevention of falls by the elderly. The prevention of falls in later life. Danish Medical Bulletira $1987 \cdot 34: 1-24$.

2. Campbell AJ, Renken J, Allan BC, Matinex GS. Falls in old age: a study of frequency and related clinical factors. Age Ageing $1981 ; 10: 264-70$.

3. Wan Weel $C$, Vermenten $H_{n}$ wan den Bosch $W$. Falls, a community care perspective. The Lancet, 1995;345:1549-51.

4. Tinetti ME, Spechley M, Ginter SF. Risk factors for falls among elderly persons living in the communty. N EngJ Med

$1988: 319: 1701-7$.

5. Statenhof PA, Crebolder HFM, Knotmerus JA, Horst vam der FGEM. Incidence, risk factors and consequences of falls anong elderly subjects living in the community.: a criteria-based analysis. Eur \Publ Health 1997,7:328-34. 6. Pyndham D, Grimley Evans J. Factors associated with falls in the elderly: a community study. Age Ageing 1981;10:141-6. 
7. Rubinstein LZ, Robbins AS, Sdumban BL, Rosado J, Ostantwit D, Josephson KR. Falls and instability in the elderly. I Am Ger Soc $1988 ; 36(3): 266-78$.

8. Blake Al, Morgan K, Bendall MD, et al. Falls by elderly people at home: prevalence and associated factors. Age Ageing 1988:17:36572.

9. Wild D, Nayak USL, Isads B. How dangerous are falls in old people at home? BMJ 1981;282:266-8.

10. Tinetri ME. Prevention of falls and fall injuries in elderly persons: a research agenda. Prev Med 1994:23:756-62.

11. Nevitt CN, Cummings SR, Hudes ES. Risk factors for falls among elderly persons living in the community. N Engl $J$ Med $1988 ; 319: 1701-7$.

12. Grisso JA, Kelsey JL, Strom BL, ot al. Risk factors for falls as a cause of hip fracture in women. N Engl IMed $1991 ; 324: 1326-31$.

13. Boereboom FTJ, Raymakers JA, Faber JAJ, Dunrsme SA. Survival following hip fractures and total hip arthroplasty for osteoarthritis of the hip, in The Netherlands. In: Hip fractures: a public health problem. PhD Thesis, Rijksuniversteit Utrecht, The Netherlands, 1991.

14. Satin $R W$, Lambert Huber DA, DeVito CA, et al. The incidence of fall injury events among the elderly in a defined population. Am J Epidemiol 1990;131:1028-37.

15. Tinetio ME, Lin AL, Claus E. Predictors and prognosis of inability to get ap after falls among elderly persons. IAMA $1993 ; 265: 269-70$.

16. Ryymänen O-P, Kivelä $S-L$, Honkanen $R$, Laippala $P$. Falls and lying helpless in the elderly. Zeitschr Gerontol 1992:25:278-82.

17. Timeti ME, Richman D, Powell La Falls efficacy as a mearunc of fear of falling. J Gerontoll Psy Sci 1990:45:239-43.

18. Vellas BJ, Waye SJ, Romero LJ. Fear of falling and restriction of mobility in elderly fallers. Age Ageing 1997:26:189-93.

19. Murphy $J$, laats $B$. The post-fall syndrome: a study of 36 elderly patients. Gerontology 1.982:28:265-70.

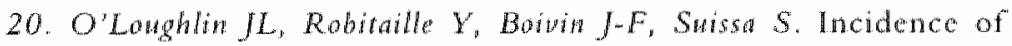
and risk factors for falls and injurious falls among the communitydwelling elderly. Am J Epidemiol 1993;137:342-54.

21. Neyift $M C$, Cummings SR, Kidd S, Black D. Risk factors for recurrent nonsyncopal talls: a prospective study. JAMA 1989;

261:2663-8.

22. Gradmans WC, Ooms ME, Hofstee HMA, Bezemer PD, Bouter LM, Lips P. Falls in the elderly: a prospective study on risk factors 
Community

survey 2

atad risk profiles. An J Epidemiol 1996:143:1129-36.

23. Camplell Al, Borme MJ. Spears GF. Risk factors for falls in a community-based prospective study of people 70 years and older. I Geront Med Sci 1989:44:112-7.

24. Campbell Al, Borric MJ, Speats GF, et al. Circumstances and consequences of falls experienced by a community population 70 years and over during a prospective study. Age Ageing $1990 ; 19: 136-41$.

25. Lach HW, Reed TR, Arfeen CL, Miller Ph, Paige GD, Birge Si, Peck $W A$. Falls in the elderly: reliability of a classification system. JAGS 1991:39:197-202.

26. Tinetti ME, Speechley M. Prevention of falls among the elderly. N Eng J Med 1989;320:1055-9.

27. Stalenhof PA, Diederiks JPM, Witte de LP, Schiricke KH, Crebolder HFJM. The impact of gait problems and falls on functioning in independent living persons of 55 years and over: community survey. Patient Educ Couns 1999;36:23-31.

28. Metsemakers JFM, Hoppener P, Knotherus JA, Kocken RJ. Limonard CBG. The Registration Network Family Practices: a computerized health information system in the Netherlands. Br ) Gen Prac, 1992; 42:102-106.

29. Bos van den GAM. Zorgen van en voor chronisch zieken (Care of and for chronic ill persons). Thesis. Bohn, Scheltema en Holkema, Amsterdam, 1989.

30. Meyboom-de Jong B. Bejaarde patienten: een onderzoek in twalf huisartspraktijken (Elderly patients: a study in twelve general practices). Thesis, 1989. Meditekst, Lelystad, The Netherlands.

31. Bergner $M$, Bobbitt RA, Carter WB, Gilson BS. The Sickness Impact Profile: development and final revision of a health status measure. Med Care 1981;19:787-805.

32. Brin de AF, Diederiks JPM, Witte de LP, Stewens FC, Philipsent H. The devellopment of a short generic version of the Sickness Impact Profile. J Clin Epidemiol 1994;47:407-18.

33. Brwin de AF, Diederiks JPM, Witte de LP, Stevens FCJ, Philipsen H. Assessing the responsiveness of a functional status measure: the Sickness Impact Profile versus SIP68. I Clin Epidemiol $1997,50(5): 529-40$.

34. Meenan RF, Gertwan PM, Mason JH. Measuring health status in arthritis: the arthritis impact measurement scales. Arthritis and Rheurn 1980;23:146-52.

35. Hosmer DW, Leweshow $S$. Assessing the fit of the model. In: Applied logistic regression. 1st Ed. New York: John Wiley and Sons, 1989. 
36. Vat der Schow YT, Verbed ALM, Rwys JHC. ROC curves for the initial assessment of new diagnostic tests. Fam Prant $1992,9.506-11$.

37. Kuornerts JA. Diagnostic prediction rules: principles, requirements, and pitalls. In: Med Decis Making 1995:22(2):34163.

38. Stalenhef PA, Busce van der S, Crebolder HEJM. Falls in the elderly: the involvement of the general practioner. (Vallen vam ouderen: het horen, zien, doen en laten van de huisarts.) Huisats Wetensch 1998; 11(5):241-5.

39. Asch DA, Jedrziewski MK, Christakis NA. Response rates to mail surveys published in medical journals. I Glin Epidemiol $1997,50: 1129-36$.

40. Cummings SR, Newit MC, Kidd S. Forgettimg falls. The limited accuracy of recall of falls in the elderly. JAGS 1988:36:613-6.

41. Hale WA, Delaney MJ, Cable T. Accuracy of patient recall and chart documentation of falls. $』$ Am Board Fam Pract $1993: 6: 239-242$. 

CHAPTER 8

Prospective cohort scudy

Predictors of falls in commwnity-dwelling elderly: a prospective cohort stady.

Submitted as:

Stalenhoef PA, Diederiks JPM, Knottnerus JA, Kester A,

Crebolder HFJM. Predictors of falls in community-dwelling elderly: a prospective cohort study. 


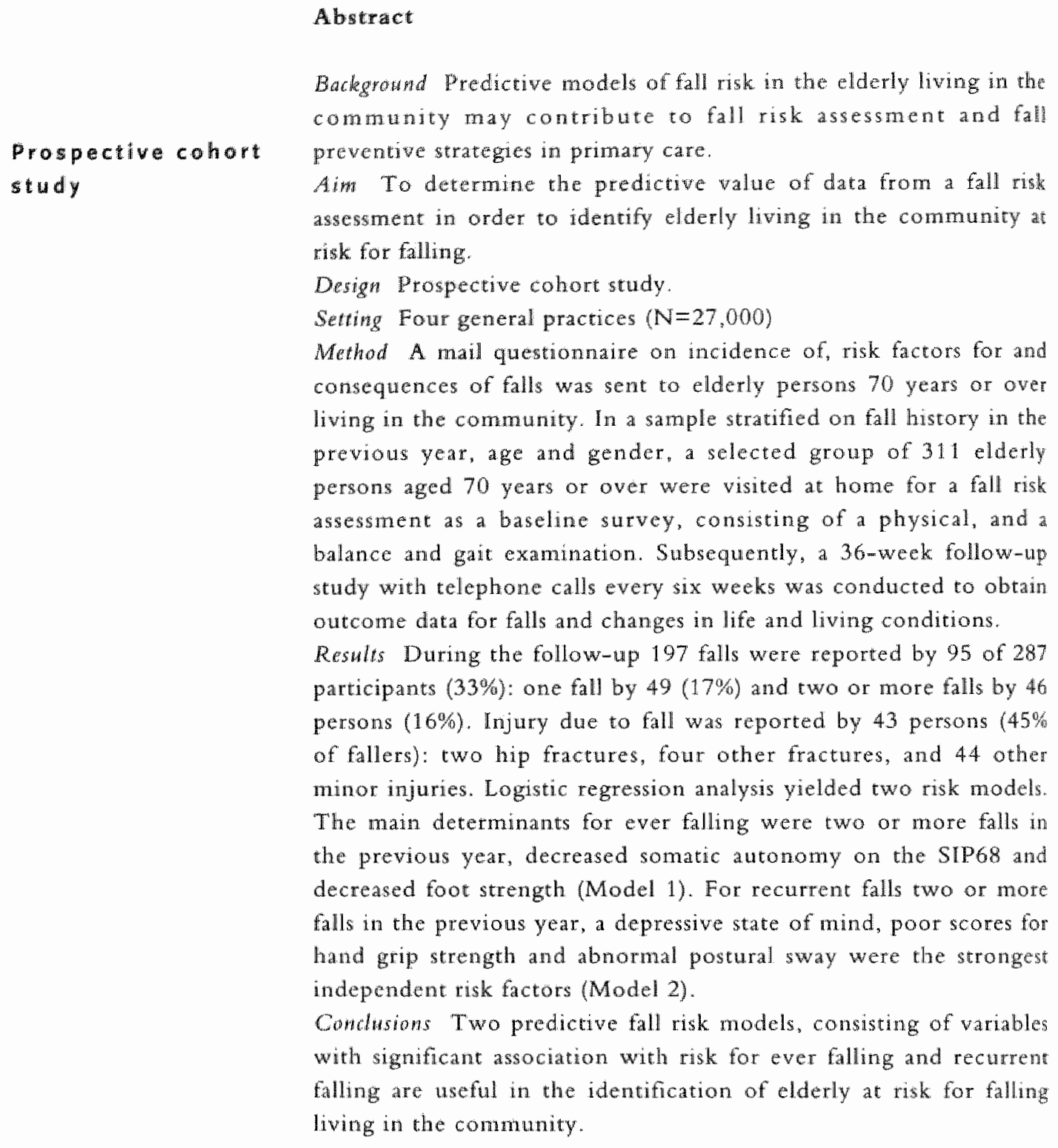

Keywords: elderly, falls, community-dwelling, general practice, predictors, assessment. 


\section{Introduction}

Falls in the elderly represent a major problem in general practice, because of their high incidence, the involvement of many risk factors and the considerable post-fall morbidity and mortality (1-8). In community-dwelling elderly of 65 years of age and over lifetime cumulative incidence of falls ranges berween 25 and 40 percent $(9,10)$. Major injury caused by falls account for about 10 percent, of which one percent concern hip fractures and five percent other fractures $(5,7,10,11)$. By far most hip fractures are caused by falls $(5,7,12)$. Hip fracture represents an important health problem, because of the high mortality in the first three months, decline in the level of functioning, threat to independence and the need for cost-consuming clinical care and rehabilitation facilities (13-16). Other consequences of falls are psychosocial: fear of falling. "postfall syndrome" and social isolation party due to fear of talling and partly to mobility impaiment $(16-20)$.

Falls in the elderly are multifactorial: intrimsic (patient-related), extrinsic (environment-related) and activity-related (hatardous behaviour) risk factors contribute to risk $(5-7,21)$. Earlier studics have reported that, particularly in recurrent falls, intrinsic risk factors play a dominant role and excrinsic risk factors mainly an additional role (5-8). However, the distinction between intrinsic and extrinsic risk factors is often not very clear (22). In a criteriabased analysis on falls in the elderly, no study provided information about the independent contribution of extrinsic risk factors to falling (8). Therefore, at this moment it is not clear to which particular risk factors preventive strategies of falls in communitydwelling elderly should be addressed and where accents have to be laid (23).

In general practice, falls and fall-related injury in the eldorly, particularly the increase of age-adjusted incidence of hip fracture. have become a prominent problem with the growth of the number of disabled elderly people as al consequence of the increase of life expectancy and better survival for the frail elderly (24). An average general practice $(N=2300)$ can expect ach year about 120 clderly persons with at least one fall. Of these about 45 persons will experience more than one fall and approximately 12 will have major injury due to a fall (5-8). However, only about 20 percent of all, manly injurious, falls are reported to the general practitioner $(25-27)$.

Because of the high incidence, important consequences and the fact that many falls are potentially preventable, efforts to develop a 


\section{Prospective cohort study}

strategy to prevent falls should be made (28-31). To set up and to promote fall preventive acrivities in primary care, particularly secondary and tertiary prevention, the availabilty of a validated and feasible fall assesment protocol is of great interest (31). In a crosssectional study we already found indications that in the first identification of the elderly at risk, the patient register provider sufficient data to estimate fall risk (32). However, to complete this information a more detaled assessment by use of performance test on health and mobility indicators, particularly balance, gait and muscle strength, may be needed and useful. Several tests and assessments of mobility problems have already been recommended by nany authors, but generally without an evidence-base and/or without staficient feasibility in general practice (33-37). A fall risk assessment from physical examination should preferably be developed using a prospective design, because of the possibility to draw conclusions regarding causal associations.

Therefore we set up a prospective study to answer the following questions:

- What are the diagnostic values (sensitivity and specificity) and predictive values (positive and negative predictive values) of data from physical examination tests on risk factors for falls in a community-based elderly population?

- Which predictive models can be recommended to general practitioners for the assessment of the elderly at risk for falling with regard to daily care preventive programmes?

\section{Methods}

\section{Subjects}

The potential participants were the respondents to a mail questionnaire on the occurrence of, risk factors for and consequences of falls in the elderly, sent to all persons aged 70 yoars or over registered in four primary health care centres $(N=2744)$. Criteria for exclusion applied by the general practitioners were wheelchair dependency, serious cognitive imparment, illiteracy and serious somatic or psychatric disease. After one mail reminder a complete questionnaire was received from 1660 respondents (response: 60\%). Written permission for further investigation was obtained from 1238 respondents, who were classified into three groups, according to self-reported number of falls in the previous year: "non-fallers", "one-time fallers" and "recurrent fallers" ( $\geq 2$ falls). Stratification on fall history, age and gender in these groups was 
performed co obtain more balanced distribution of persons regarding fall history in relation to the ariables age and gender in order to avoid under-representation of importint subgroups. A random sample was taken from 1 in 5 of the persons in the group of 70-80 years and from 1 in 2.5 from the group of 80 years and over, resulting in an overall sample of 1 in 4 . Generally, compared to the study poptlation, stratification resulted in more fallers, more men and more persons of advanced age in the stratified samples.

By calculated guess a minimum required number of 300 participants was determined. The 392 persons selected were randomly contacted by telephone as a reminder for writcen consent arlier given, until a cohort of 311 persons was reached for a follow-up study.

The study design was approved by the Medical Ethical Board of the University Hospital Maastricht.

\section{Baseline data}

In a panel of five experts, a rehabilitation specialist, a neurologist, a geriatrician and two general practitioners, with special interest and experience in this subject, a nominal group proces consensus procedure was performed and resulted in a protocol for a baseline assessment $(38-40)$. Criteria for inclusion of proposed tests were their clinical relevance, reliability, validity and feasibility in general practice. Consensus was reached if four members of the panel agreed ( 80 percent consensus). The protocol for a baseline assessment consisted of an interview, scales on functioning and tests on general health, cognitive functioning and mobility impaiment. All 311 persons selected were visited by one of three physicians, specifically trained in performance, interpectation and reliability of the tests. In a one-hour home visut each participant was assessed on potential risk factors for falls as a baseline survey for the subsequent follow-up study.

The interview. The pre-structured interview yielded infomation supplementary to the prior mail questionnaire. It was focused on the interval between mail questionnaire and baseline examination and concerned the occurrence, the circumstances and self-perceived causes of falls, injuries, treatment and fear of falling. Data about changes in morbidity, functioning, medication, living conditions and life events were registered as weil.

Scales on functioning. Physical, mental and social functioning were tested by the short version of the Sickness Impact Profile (SIP68) $(41-43)$, the activities of dally life and household activities by the Barthel index (BII) (scores 0-20) $(44,45)$, the cognitive functioning 


\section{Prospective cohort study}

by the Mini Mental State Examination (MMSE) (scores 0-30) $(46,47)$ and the depressive state of mind by the depression subscalit of the Symptom Checklist (SCL90) (containing 16 items on a 5 point scale, total score 0-80) (48).

physical examination. Tests on body weight and height to obtain Quetelet indices, blood pressure in sitting and lying position, pulse regularity and frequency, distant vision using Snellen"s chart, hearing of speech at a distance of 2 metres with or without hearing aid inspection of the feet to detect skin lesions, deformities and callus, senso-motorical examination of the feet (strength, propriocepsis, measured by reduced toe position sense, and sengibilty) and a handgrip dynamometry using the My Gripper dynamometer1*, testing the strength in the dominant hand with a mean of three attempts as a measure for the total body muscle strength, in particular of the lower extremities $(4,49-56)$.

Mobility was tested using six validated independent performance tests.

- The "Get-Up and Go Test" (GUGT): a test on ballance and gait comprising the ability to rise from a chair, standing in upright position for 5 seconds, walking three metres, turning, walking three metres back, and sitting again. Scoring on a 3-point rating scale for all the seven performances: normal, doubtrul and abnormal. The scores were transformed subsequently into a 5 -point scale for the whole test, following the original description, with a cut-off point set on $3(57-59)$.

- The Romberg Test (RT): a test on the sense of position by standing in upright posicion for 10 seconds, feet with shoes on together, arms at 90 degree ventral flexion and eyes frrst open and then closed. The test is positive if a person is nor able to reman standing stable with eyes closed (60).

- The Postural Sway Test (PST): a test of propulsion and retropulsion. It gives an indication of the presence of a disorder of the central nervous system and differentiates between accidental falls and recurrent falls. Scores: nomal or abnormal (61-63).

- The Trendelenburg Test (TT): a test of balance standing on one leg. It tests the ability to stand on one leg for 5 seconds without support. Scores: normal or abnormal (64).

- The "Bending Down Test" (BDT): the person is asked to pick up a small object from the floor. The test is positive if a person is unable to resume upright position after bending down or takes multiple attempts to get upright. Scores on a 3-point scalle: normal, doubtful and abnormal (64).

- The Functional Reach Test (FRT): a test to assess the balance by

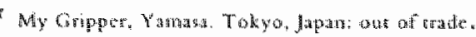


measuring the maximal reach of the elevated. dominant arm in 90 degree position, in three attempts. Scoring on a 4-point scale: $0=$ not able at all to reach; 1 = reach of 1 to $15 \mathrm{~cm} ; 2=$ reach of 15 to $25 \mathrm{~cm} ; 3=$ reach of $25 \mathrm{~cm}$ or more $(65,66)$.

Cognitive behaviow was tested wh the "Double Task Test" (DTT). Participants were asked to walk three metres and at the same time to solve two simple calculations. Scoring on a 3-point scale: normal if the test is performed without any problem; doubtful if there is any hesitation or delay in the performance; and abnormal if the participant is not able to perform both tasks in the same time (67).

A home-safety checklist of indoor fall risk was developed in a separare Delphi procedure among occupational therapy experts. The evaluation is described alsewhere $(68,69)$.

\section{Definitions, ontcome and follow-mp}

A "fall" was defined as an unintentional coning down on the floor or to a lower level. "Ever fallers" were defined as participants with at least one fall, "one-time fallers" with only one fall, "recurrent fallers" with two or more falls and "non-fallers" with no falls during the follow-up period.

Three dependent variables were defined as outcome parameters: "ever fallers" ( $\geq 1$ fall), "one-time fallers" and "recurrent fallers" $(22$ falls), all contrasted to "non-fallers".

Subsequent to the baseline assessment, a 36-week telephone follow-up with standardized telephone calls after each 6-week interval was performed by trained interviewers. The occurrence, circumstances and self-perceived causes of falls, and changes in living conditions and life events were registered. To avoid recall bias, all answers were compared to answers front the previous call and checked for possible mistakes due to memory deficits (70).

\section{Data analysis}

Independent variables were inicially analysed using bivariate techniques, resulting in odds ratios with their $95 \%$ confidence intervals. All variables were dichotomous. Cut-off points are listed in Table 1 . For hand dynamometry sex-specific cut-off points were chosen because of striking differences in performances between men and women; cut-off point for women: $12 \mathrm{~kg}$ and for men: 22 $\mathrm{kg}$. For the Barthel Index (BI) ( $\$ 19)$, the Mini Mental State Examination (MMSE) ( $\leq 24)$, the Get-Up and Go Test (GUGT) (23) and the Functional Reach Test (FRT) $(515 \mathrm{~cm})$ cut-off points were chosen as recommended in the avajlable literature $(44,46,57,65)$. In the SIP68 scores median values were used 
Prospective cohort study
$(42,43)$

Variables showing statistically significant associations in the bivariate analysis were entered into a forward stepwise logistic regrestion analysis with $\mathrm{p}<0.05$ both as an entry and remowe critcrion. Two logistic models for the prediction of ever falls and recurrent falls were obtained. The odds ratios with their $95 \%$ confidence intervals of the variables in the models were determined. In addition, the observed and predicted probability of the models were calculated. Next, the fit of the logistic models was determined by the goodness-of-fit test according to Hosmer Lemeshow (71). The predictive power of the models were tested by the Area under the Receiver Operator Characteristic ( $R O C$ ) Curve (AUC) (72,73). Finally, in a Receiver Operator Characteristic (ROC) analysis, the data from logistic regression were evaluated at different cur-off values to determine the maximum sum of sensitivity and specificity as the optimal cut-off value and the positive and negative predictive values.

\section{Results}

Sinbjects

After the stratification and random selection procedure, 311 subjects were contacted and visited at home for a baseline assessment. The baseline procedure was completed by 302 and the follow-up by 287 participants: $115 \mathrm{men}$ ( 40 percent) and 172 women (60 percent) with a mean age of 77.2 (SD 4.9) and 78.5 (SD 5.2) years, respectively. The proportion of individuals of 80 years and over was 37 percent. About 50 percent were widowed or single.

In all 24 persons did not complete participation: nine persons dtring the baseline period and 15 in the subsequent follow-up period. The following reasons were registered: ten participants died, three refused further participation for personal reasons, thee were not physically and one not cognitively able, two were admitted into a hospital or nursing clinic, one moved to another town and four did not respond for unknown reasons.

\section{Falls and ingries}

During the 36-week follow-up period, 197 falls were reported by 95 of the 287 participants who completed follow-up (33 percent: 56 women and 39 men) and no falls by 192 participants $(67$ percent). One fall was reported by 49 (17 percent) and two falls or more by 46 persons ( 16 percent). Twenty-three subjects of them ( 8 
percent had three falls or more, with a maximum of eight falls by one participant. Of the 95 individuals who reported falls, 63 (66 percent) had indoor falls. The infuence of the season on the fall pattem appeared to be negligible.

Altogether 54 injuries due to fills $(27$ percent of all falls during follow-up) were reported by 43 individuals ( 45 percent of the fallers): two persons had a hip fracture and four other fractures 2 and 4 percent of the fallers, respectively). Contusions were reported by 12 , other soft tissue damage by 32 persons and wounds needing sutures by five persons $(13,33$ and 5 percent of the tallers; respectively).

\section{Risk}

\section{Bitnatate analysis}

Table 1 presents results from bivariate analysis. Comparing odds ratios for potential risk factors for ever falls, one-time falls and recurrent falls, it appeared that age 80 years or over, female sex. living alone and all physical health parameters, excluding feet qualities, did not have any significant association with falls. Falls in the previous year show association with ever falls and recurrent falls, but not with one-time falls. Variables like poor handgrip strength scores, mental health status, and particularly mobility and functioning are associated with ever falls, but even more so with recurrent falls.

\section{Logistic regression analysis}

In a forward stepwise logistic regression analysis, 18 variables, with bivariately significant associations with ever falls and recurrent falls, including age and sex were retained. Two logistic models resulted: Model 1 for the prediction of ever falls and Model 2 for the prediction of recurent falls. In a next step, method enter, the selected variables in the two models were analysed to calculate the adds ratios and their $95 \%$ confidence intervals (Table 2 ). The wariables in Model 1 which showed independent significant associations with ever falls are a score on the Somatic Autonomy SMP68 $\geq 1$, two or more falls in the previous yoar and decreased foot strength. The variables of Model 2 which showed independent assoctations with recurrent falls are: a band dynamometry score of $\leq 12 \mathrm{~kg}$ for women and $522 \mathrm{~kg}$ for men, two or more falls in the previous year, a $S C L 90$ depression score of $\geq 22$ and an abnormal postural sway. 


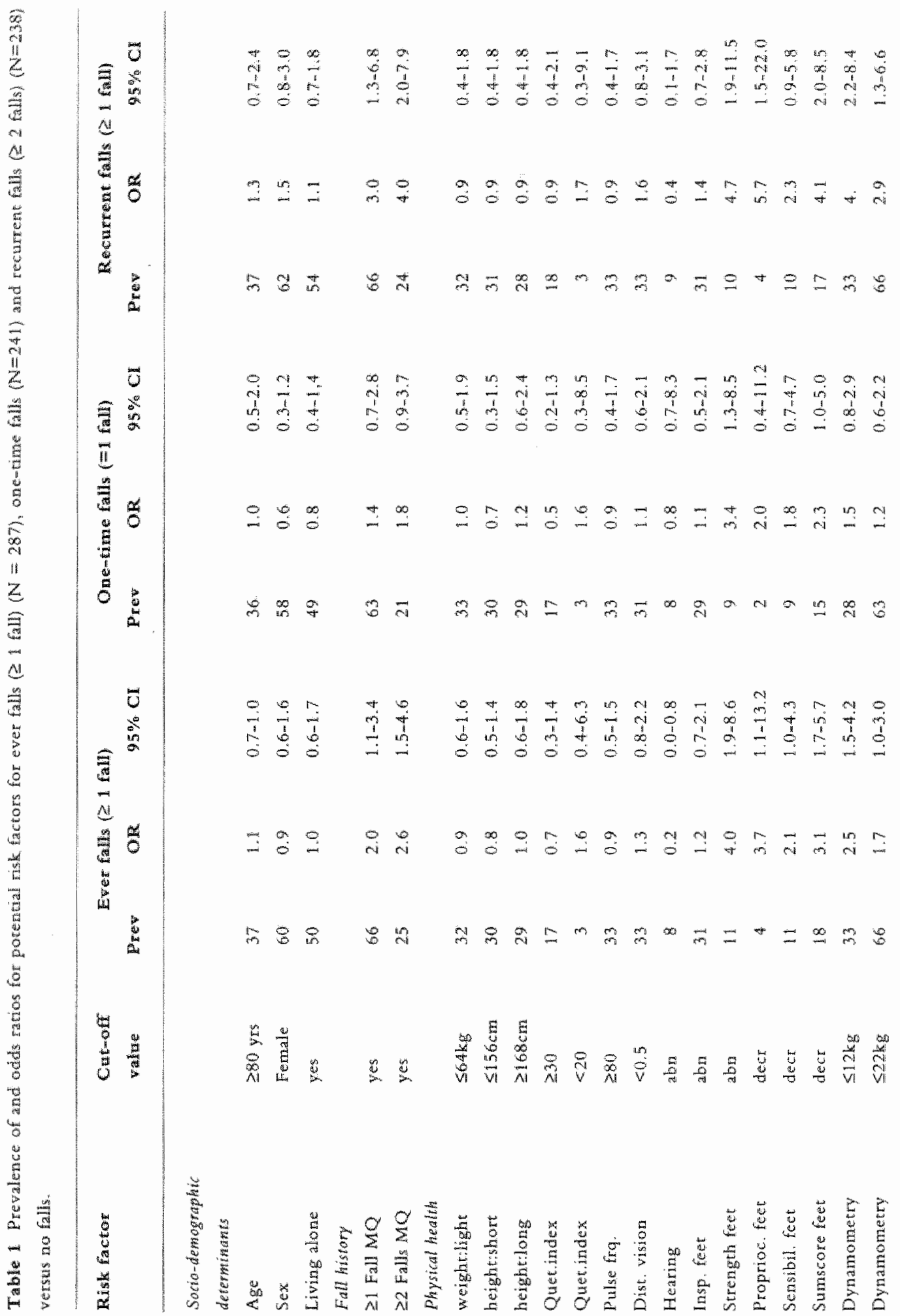




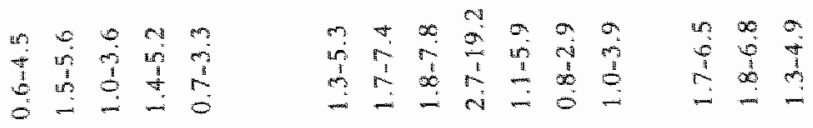

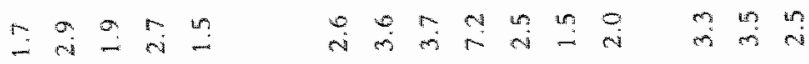

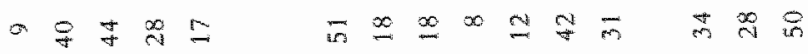

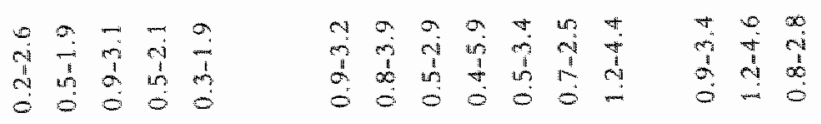

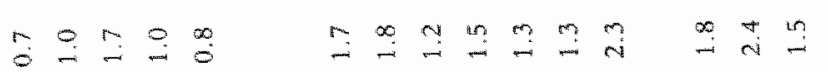

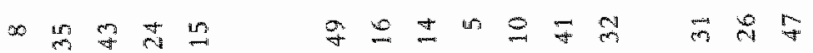

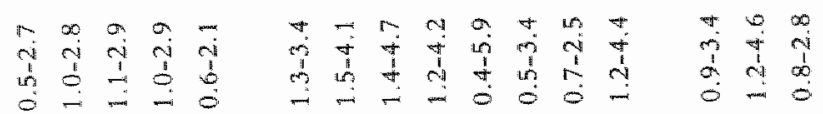

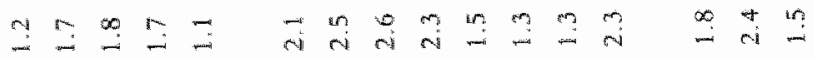

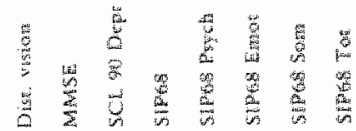

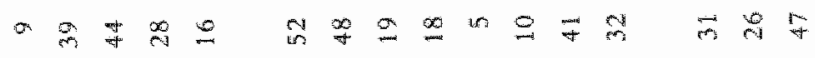

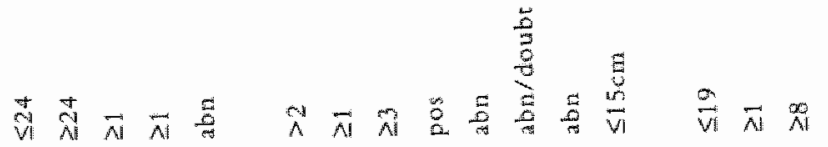

5 घ

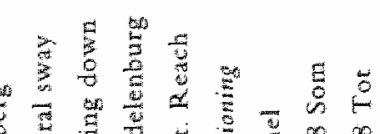

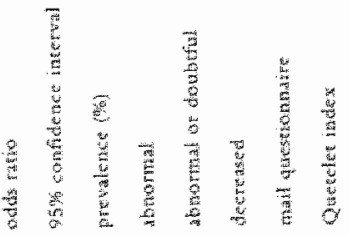

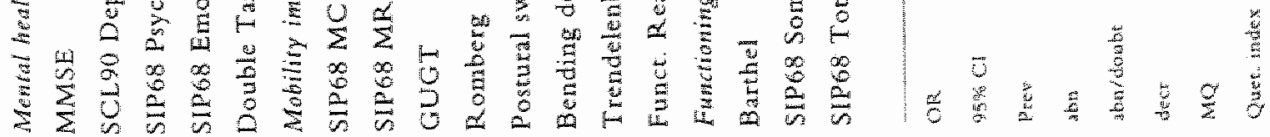




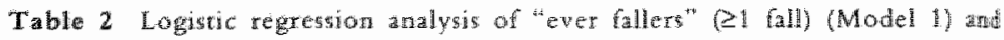
"tecurent fallers" $(22$ falls) (Model 2 ) versus "nortallers"

\section{Model i}

Prospective cohort sudy

\begin{tabular}{|c|c|c|c|}
\hline Variable & Cut-off value & $\mathbf{O R}$ & $95 \% \mathrm{CH}$ \\
\hline Gender & Female & 1.3 & $0.8-2.3$ \\
\hline Age & $\geq 80$ years & 0.9 & $0.5-1.9$ \\
\hline \multicolumn{4}{|l|}{ Recurrent falls } \\
\hline in previous year & $\geq 2$ falls & 2.4 & $1.3-4.3$ \\
\hline \multicolumn{4}{|c|}{ Somatic Autonomy } \\
\hline $\operatorname{sip} 68$ & $\geq 1$ & 2.2 & $1.2 \mathrm{~m} .9$ \\
\hline Strength teet & abnormall & 3.7 & $1.6-8.5$ \\
\hline
\end{tabular}

\section{Modal 2}

\begin{tabular}{|c|c|c|c|}
\hline Gender & Fermalle & 0.7 & $0.3-1.5$ \\
\hline Age & $\geq 80$ years & 1.0 & $0.5-2.2$ \\
\hline \multicolumn{4}{|l|}{ Recurtent falls } \\
\hline in previous year & $\geq 2$ falls & 3.1 & $1.5-6.7$ \\
\hline \multicolumn{4}{|l|}{ Depression } \\
\hline $5 \mathrm{CL} 90$ & $\geq 22$ & 2.2 & $1.1-45$ \\
\hline \multirow[t]{2}{*}{ Hand dymamometry } & Men: $\leq 22 \mathrm{~kg}$ & & \\
\hline & Women: $512 \mathrm{~kg}$ & 3.1 & $1.5-6.6$ \\
\hline Poscumolsway & abnomal & 3.9 & $1.3 \times 1.2 .1$ \\
\hline
\end{tabular}

\begin{tabular}{|c|c|}
\hline ok & whaterath \\
\hline $455 x+1$ & 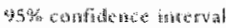 \\
\hline
\end{tabular}

probability of the models. It reweals a general congruence between the increase of predicted probability and percentage of observed cises in both models. The predicted values of both models. calcuated according to the Hosmer Lemeshow goodness-of-fit, showed good fits. The values of the Areas under the Receiver Operator Characteristic (ROC) Curves, the AUC for Model 1 was 0.69 and for Model 2: 0.79. The diagnostic values of the logistic models at different cut-off values in a $\mathrm{ROC}$ analysis are listed in Table 4. The statistically optimal cut-off value, the maximum sum of the sensitivity and specificity, was found at $0.3 \mathrm{in}$ both models. 


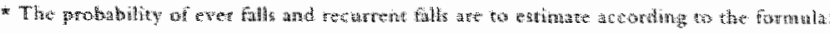

$$
p=1,1+k\}
$$

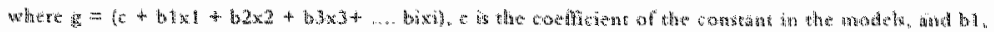

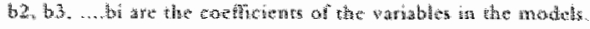

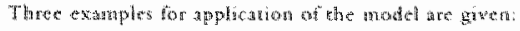

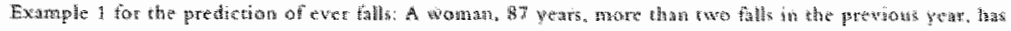

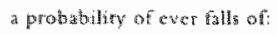

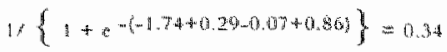

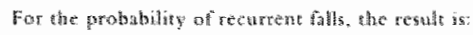

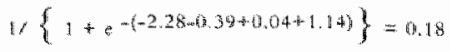

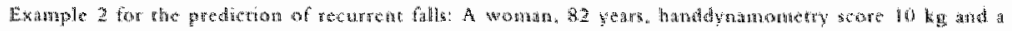

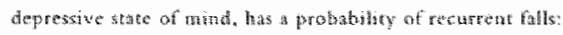

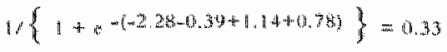

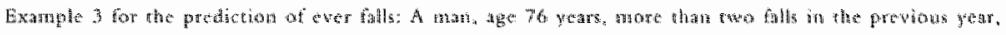

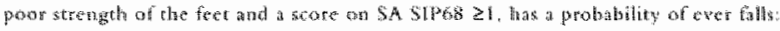

\begin{tabular}{|c|c|c|c|c|}
\hline \multirow[b]{2}{*}{$\begin{array}{l}\text { Predicted } \\
\text { probability }\end{array}$} & \multicolumn{2}{|c|}{ Model } & \multicolumn{2}{|c|}{ Model 2} \\
\hline & $\mathbf{N}$ & $\begin{array}{c}\text { Observed } \\
\%\end{array}$ & $\mathbf{N}$ & $\begin{array}{c}\text { Observed } \\
\mathrm{g} / \mathrm{m}\end{array}$ \\
\hline $0-10 \%$ & 0 & 0 & 99 & 8.1 \\
\hline $10-20 \%$ & 84 & 7.1 & 68 & 13.2 \\
\hline $20-30 \%$ & 67 & 23.9 & 19 & 10.5 \\
\hline $30-40 \%$ & 53 & 32.1 & 25 & 36.0 \\
\hline $40-50 \%$ & 30 & 43.3 & 11 & 63.6 \\
\hline $50-60 \%$ & 27 & 63,0 & 5 & 600 \\
\hline $60-70 \%$ & 18 & 61.1 & 4 & 750 \\
\hline $70-80 \%$ & 0 & 0 & 1 & 100 \\
\hline$-\geq 80 \%$ & 7 & 71.4 & 6 & 66.6 \\
\hline Chi-square & \multicolumn{2}{|c|}{$0.51 \mathrm{dr}(5)$} & \multicolumn{2}{|c|}{$3.41 \mathrm{df}(7)$} \\
\hline$p$-vallue & \multicolumn{2}{|c|}{$>0.5$} & \multicolumn{2}{|c|}{$>0.5$} \\
\hline AUI * & \multicolumn{2}{|c|}{0.69} & \multicolumn{2}{|c|}{0.79} \\
\hline
\end{tabular}

$$
1 /\left\{1+n^{2}-1-7.7+6.86+0.78+1.32\right\}=0.77
$$

Table 3 Predicted and observed probability of Model 1 for the prediction of ever falls ( $\geq 1$ fall) and Model 2 for the prediction of recurrent falls ( 22 falls)

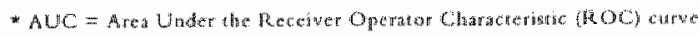


Table 4 Diaghostic and predictive values of the logistic models for ever fall (21 fall) (Model 1/) and recurent falls (22 falls) (Model 2) as different cut-of values for predicted probability.

Prospective cohort study

\section{Model 1}

\begin{tabular}{lccccc}
$\begin{array}{l}\text { Cut-wf value } \\
\text { of the model }\end{array}$ & $\begin{array}{c}\text { Sensitivity } \\
\%\end{array}$ & $\begin{array}{c}\text { Specificity } \\
\%\end{array}$ & $\begin{array}{c}\Sigma \\
\%\end{array}$ & $\begin{array}{c}\text { PV+ } \\
\%\end{array}$ & $\begin{array}{c}\text { PV- } \\
\%\end{array}$ \\
\hline 0.10 & 100 & 0 & 100 & 33 & 0 \\
0.20 & 84 & 36 & 120 & 39 & 82 \\
0.30 & 67 & 63 & $130 *$ & 47 & 79 \\
0.40 & 49 & 81 & $130 *$ & 56 & 76 \\
0.50 & 35 & 90 & 125 & 63 & 74 \\
0.60 & 17 & 9 & 112 & 64 & 70 \\
0.70 & 5 & 99 & 104 & 71 & 68 \\
\hline
\end{tabular}

Model 2

\begin{tabular}{llllll}
\hline 0.10 & 83 & 47 & 130 & 27 & 92 \\
0.20 & 63 & 78 & 141 & 41 & 90 \\
0.30 & 59 & 87 & $146 *$ & 52 & 90 \\
0.40 & 39 & 95 & 134 & 67 & 87 \\
0.50 & 24 & 97 & 121 & 69 & 84 \\
0.60 & 17 & 98 & 115 & 73 & 83 \\
0.70 & 11 & 99 & 110 & 71 & 82 \\
\hline
\end{tabular}

\begin{tabular}{|c|c|}
\hline$\Sigma$ & Sum of semsitivity and specifficty \\
\hline הi" & maximal 2 \\
\hline put & positare predictive nallo \\
\hline pl: & regative predicase ralue \\
\hline
\end{tabular}

At cut-off point 0.30 Model 1 has a positive predictive vallue (PV+) Chapter 8 these values are $52 \%$ and $90 \%$, respectively. 


\section{Discussion}

This prospective study revealed that data on incidence of falls and injuries are comparable with other prospective community studies $(5-13)$. To obtain andual incidence data actor 1.4 bas to be applicd.

In a bivariate analysis many risk factors showed a significant association with falls and recurrent falls, but only a few were included in the final risk models, because of dependence on other risk factors. Age and gender appeared not to have any significant association, not with ever falls, nor one-time falls not recurrent falls. This finding seems contrary to other studies, but our data may be explained by the influence of other variables with a strong age and gender dependence. Two or more falls in the previows year appeared to have strong associations with both ever falls and recurrent falls, but not with one-time falls. In this respect memory deficits have to be taken into account $(26,70)$.

In the baseline assessment only blood pressure measurements in lying and sitting position were performed, and not, contrary to many studies, in upright position. Low and high blood pressure rates in sitting and lying position did not show any association with fall risk. In the avalable literature there is no consensus about a standardized method of measuring orthostatic blood pressure (74). In addition, some authors admit the contribution of this factor only if orthostatic hypotension causes dizziness upon standing, which raises the question whether it is dizainess upon standing itself that is actually the true risk factor $(75-77)$. Also the actual contribution of orthostatic hypotension to falls in the elderly is controversial (78). The panel discussion about the inclusion of measurement of bllood pressure in upright position did not yield the required consensus of 80 percent. Therefore from our study no data on orthostatic hypotension as risk factor for falls are available.

Changes in medication were assessed in this study, but, because of a prevalence below five percent, were not further analysed. It is noticeable that in our data foot qualities like poor strength, reduced toe position sense (decreased propriocepsis) and to a lesser degree decreased sensibility showed significan associations with falls. Peripheral neuromuscular dysfunction plays an important role in falls in the elderly $(49,50)$. Although the systematic examination of feet in the elderly is not common practice, these findings merit a closer evaluation. Cognitive impairment, measured by the MMSE appeared not to be significantly associated with falling. Some authors regard the MMSE as insufficient to detect mild or moderate 
Prospective cohort study

cognicive impaiment and more appopriate to evaluate intervention $(45,46)$. Severely cognitively inpaired persons were excluded from this study. Therefore, cognitive impaiment may be an underestimated risk factor. A depressive state of mind, measured by the SCL90 depression subscale, appeared to be associated with ever falling and particularly with recurrent falling. The SIP68 scales for psychological and emotional functioning had moderate associations with falls.

Poor muscle strength is a strong predictor for ever and recurrent falls in the elderly, but showed strong sex differences $(4,53,54)$. Similarily, other tests on mobility showed stronger associations with falls in women than in men. An explanation for these sex differences could be the differences in muscle strength, which points to a strong relationship between maintaining balance and muscle strength (51). In women, particularly balance-related tests like the PST, the GUGT, the RT and the FRT had a strong association with ever falls and the PST and the $R T$ with recurrent falls. The RT, however, is disputed because of problems with is performance, interpretation and the notable number of falsepositive results (79). In men only the FRT appeared to have a clear association with ever falls and the GUGT with recurrent falls. The FRT is difficult to perform and to standardize and not very safe, and for these reasons cannot be recommended to the GP. Probably also sex differences in incidences of falls, although not apparent in our data, could be, at least for a part, explained by this phenomenon. The sex-related differences in mobility tests and the sex-specific approach in interpretation of the results deserves further examination.

To summarize, taking the sex differences into account, the hand dynmometry, the GUGT and the PST can be considered as walid and feasible rests on mobility, easily to perform and interpret, and for these reasons can be recommended in general practice.

The decline in functioning in our data can be regarded as a risk factor for falls. Impared level of activities of daily life, measured by $B I \leq 19$, and SIP68 Somatic Autonomy $\geq 1$ have associacions with ever falls and recurrent falls. A SIP68 total score $\geq 8$ is, in addition, positively associated with falls in all fall groups. However, even to consider daily functioning as a risk factor for falls more than as a consequence will meet criticism and can be defended only on the basis of clinical plausibility.

Logistic analysis resulted in risk models for ever falls and recurrent falls. The main independent significant risk factors for ever falls are two or more falls in the previous year, poor strength of the feet and 
a score on SIP68 Somatic Autonomy $\geq 1$. For recurrent falls these risk factors are two or more falls in the previons year, a depressive sate of mind, poor muscle strength and abnomal postural sway. The fit of both models is satisfactory. Risk models derived from logistic ragression, containing these risk factors, are evily to apply in general practice. In fall preventive activits a higher semsitivity would be prefered. A cut-of threshold of 0.3 or 0.4 in Model 1 offers values for sensitivity of $67 \%$ and $49 \%$ and for specificity $63 \%$ and $81 \%$, respectively, both offering a maximal sumscore of 130 . From clinical point of wew a cutoff value of 0.3 is preferable. Model 2 reaches its optimal cut-off point at 0.3 with walues for sensitivity of $59 \%$ and for specifiety $87 \%$. The predictive power of model 1 is moderate ( $\mathrm{UUC}=0.69$ ) and of model 2 acceptable ( $A \cup C=0.79$ ).

The main advantage of this study is the prospective design and the use of standardized procedures for data collection in bastine assessment and follow-up. This allows conclusions to be diawn about the significance of causal associations between risk fictors for falls and falling.

There are some methodological limitations, however. Stratification resulted in a study population consisting of more fallers, more men and more older persons compared to the response population to the mail questionnaire. Consequently, as a result of the dependence of falls on age and sex, there is some confounding in incidence rates of falls and injuries. Due to the lack of comsensus about the value of orthostatic hypotension as a risk factor for falls in the elderly no conclusive statements can be made. The duration of the followip was determined at 36 weeks for practical and budget reasons. A follow-up period of one year should have offered possibilities to differentiate in the analysis between the degree of recurrent falling This study has demonstrated that assessment of risk factors for falls in the elderly by the GP can be simplified into two risk models, which are complementary to a risk model derived from the patient's record. This study also revealed that the GP should mainly focus his attention on four groups of risk factors to identify the community-dwelling elderly at risk for falling. Firstly, the question of a history of two or more falls in the previous year. Secondly, the assessment of mobility imparment, particularly balance and gait disturbances, by wse of the GUGT, the PST, the hand dymamometry and the examination of feet qualities like muscle strength and sensibility. Thirdly, the application of the SIP68 Somatic Autonomy, an indicator of frailty and a predictor of ever falls. And fourth, the identification of the depressive elderly, having 
Prospective cohort study a particularly greater risk of recurrent falls, by use of the depression subscale of the SCL90. The implementation of these recommendations in general practice is easy and costs little time and money.

\section{Acknowledgements}

We are indebted to all clderly persons that participated in this study. We thank the assistants and general practitioners of the fout general practices, Heer, Hoensbroek, Stein and Dr. van Kleef for their supporting cooperation. We thank $W$. Bakx, rehabilitation specialist for his advice for the construction of the concept of the baseline assesment. The members of the consensus panel. $\mathbb{E}$. Lindeman, rehabilitation specialist, $\mathbb{F}$. Vreeling, neurologist, J. Fiollet, geriatrician, C. Ligthart-Schenk and J. Soomers-Turlings, general practitioners gave us important advice and support. We are grateful to the three physicians who carried out the baseline assessment: Hanneke Hamers, Djouke Bussemakers and Bert Schilte. F. Vreeling, nearologist gave expert comment upon the proposals and the results of the fall assessment, Lilian Hesemans assisted in the data collection and Jos Hamers was very helpful in the data analysis. Gregor Franssen was an important stand-by in matters on data collection and data processing. Through Mieke Witte we would like to thank the members of the interview team. that made about 1800 telephone calls during the follow-up.

This study was supported by a grant from the ZON (Zorg Onderzoek Nederland), formerly the Praeventie Fonds.

\section{References}

1. Sheldom JH. On the natural history of falls in old age. Br Med J 1960;11:1685-90.

2. Campbell AJ, Reinken J, Allan BC, Martinez GS. Falls in old age: a study of frequency and related clinical factors. Age Ageing $1981 ; 10: 264-70$.

3. Prudham D, Grimley Evans I. Factors associated with falls in the elderly: a community study. Age Ageing 1981;10:141-6.

4. Blake AJ, Morgan $K$, Bendall MJ, et al. Falls by elderly people at home: prevalence and associated factors. Age Ageing 1988;17:36572.

CHAPAE

5. Tinetti ME, Spechley $M$, Ginter SF. Risk factors for falls among elderly persons living in the community. N Engl I Med 
$1988: 319: 1701-7$

6. O'Loughtin JL, Robratle $Y$, Boimin $J-F$, Suissa $S$. Incidence of and risk factors for falls and injurious falls among the communitydwelling elderly. Am J Epidemiol 1993:137:342-54.

7. Newitt $M C$, Cummings $S R$, Kidd $S$, Black D. Risk factors for recurrent nonsyncopal falls: a prospective study. JAMA $1989 ; 261: 2663-8$.

8. Stalenhof PA, Crebolder HFM, Knotherus JA, Horst van der FGEM. Incidence, risk factors and consequences of falls among elderly subjects living in the community: a criteria-based andysis. Eur J Publ Health 1997:7:328-34.

9. Camplell AJ, Borrie MJ, Spears $G F$, Jacksom $S L$, Brown IS, Fitzgerald $J L$. Circumstances and consequences of falls experienced by a community population 70 years and over during a prospective study. Age Ageing 1990;19:136-41.

10. Kellogg Intematianal Health and Aging Program: Prevention of falls by the elderly. Dan Med Bull 1987;34(suppl 4)

11. Grisso JA, Kelstey JL, Strom BL, et al. Risk factors for falls a a cause of hip fracture in women. N Engl J Med 1991;324:1326-31.

12. King NB, Tinetti ME. Falls in community-dwelling older persons. J Am Geriatr Soc 1995;34:1146-1154.

13. Awnstrong $A L$, Wallace WA. The epidemiology of hip fractures and methods of prevention. Acta Otchopaed Belg 1994;60:85-101.

14. Riggs JE. Mortality from accidental falls among the elderly in the United States, 1962-1988: demonstrating the impact of improved trauma management. J Trauma 199;35:212-19.

15. Broos PLO, Van Haaften KIK, Van Leenwem PAM, Vandeputie JHNR, Stappaerts KH. Heupfracturen bij bejaarden; sterfte, functionele resultaten en kans op hwiswarts keren (Hip fractures in the aged; mortality, functional results and the probability of going back hone). Ned Tijdsche Geneskd 1990;134:957-61.

16. Vellas BJ, Wayne SJ, Romero LJ, Bawngarner RN, Garry PJ. Feat of falling and restriction of mobility in elderly fallers. Age Ageing 1.997:26:189-93.

17. Tineti ME, Richman $D$, Powell L. Falls efficacy as a measure of fear of falling. J Gerontol Psy Sci 1990;45:P239-43.

18. Tineth ME, Mendes de Leon CL, Doncene JT, Baker DI. Fear of falling and fall-related efficacy in relationship to functioning among community-living elders. J Gerontol Med Sci 1994:49:M 140-7.

19. Tineti ME, Powell $L$. Fear of falling and low self-efficacy: a cause of dependence in elderly persons. J Gerontol 1993;48:35-8.

20. Murphy J. Isacs $B$. The post-fall syndrome: a study of 36 elderly patients. Gerontolgy $1982 ; 28: 265-70$. 
21. Cradmans WC, Ooms ME, Hofstee HMA, Bezener PD, Batda $L M$, Lips $P$. Falls in the elderly: a prospective study on risk factors and risk profles. Am J Epidemiol 1996;143:1129-36.

22. Lach HW, Reed AT, Arket CL, et al. Falls in the elderly:

Prospective cohort study reliability of a classification system. J Am Geriatr Soc 1991;39:197202.

23. Thetti ME. Prevention of falls and fall injuries in elderly persons: a research agenda. Prev Med 1994:23:756-62.

24. Boereboon FTl, Raymakers JA, de Groot RRM, Dusrsma SA. Epidemiology of hip fractures in independent and institutionalized elderly people. Osteoporosis Int. 1992;2:285-9.

25. Graham HJ, Firth J. Home accidents in older people: role of primary health care team BMJ 1992;305:30-2.

26. Hale WA, Delaney MJ, Cable T. Accuracy of patient recall and chart documentation of falls. I Am Board Fam Prac 1993;6:239-42. 27. Sooners-Turlings JMSJG, Crebolder HFJM, Bewsmans GHMI, Bal $R M$. Het vallen van ouderen. Een exploratieve studie in de huisartspraktijk (Falls in the elderly. An exploratory study in general practice). Huisarts Wet 1992;35:57-60.

28. Tineti $M E$, Speechley $M$. Prevention of falls among the elderly. New Engl J Med 1989,320:1055-9.

29. Ward J. Preventing falls and fractures. Austr Fam Phys $1993 ; 23: 866-72$.

30. Oakley $A$, Dawson MF, Holland $J$, et al. Preventing falls and subsequent injury in older people. Quality Health Care $1996,5: 243-9$.

31. Cwikel $J$, Fried $A V$. The social epidemiology of falls among community-dwelling elderly: guidelines for prevention. Disabil Relabil 1992;14:113-21.

32. Stalenhoef PA, Diederiks JPM, Knotherus JA, De Witte LP, Crebolder HFIM. A patient record-based risk model for falls in community-dwelling elderly. Submitted.

33. Tineti ME. Performance-oriented assessment of mobillyt problems in elderly patients. IAGS 1986;34:119-26.

34. Heitmann DK, Gossman MR, Shaddeau SA, Jackson JR. Balance performance and step width in noninstitutionalized, elderly, female fallers and nonfallers. Phys Ther 1989;69:923-31.

35. Hale WA, Delaney MJ, MeCaghie WC. Predicting elderly patients" nobility using fall history and physician assessment. Fam Med 1990;22:383-7.

36. Studenski S, Duwan PW, Chandler J, Samsa G, Prescott B, Hogue $C$, Bearon $L B$. Predicting falls: the role of mobility and nonphysical factors: JAGS 1994;42:297-302. 
37. Fried AV, Curkel J, Ring $H$, Galinsky D. ELGAM-Extra laboratory gat assessment method: identification of risk factors for falls among the elderly at home. Int Disabil Stud 1990;12:161-4.

38. Fiwk A, Kosetoff J, Chrasin M, Brook RH. Consensus methods: characteristics and guidelines for use. An J Publ Health $1984: 74: 979-83$.

39. Vet wan der $A H, D e b e q A L$. The nominal group as a research instrument for exploratory health studies. Am $\mathbb{J}$ ubl Health $1972 ; 62: 337-42$.

40. Delbeg AL, Ven wan der AH. A group process model for problem identification and program plaming. I Appl Behav Sct $1971 ; 7: 466-92$.

41. Bergner $M$, Bobbit RA, Carter WB, Gibon BS. The Sickness Impact Profile: development and final revision of a health status measure. Med Care 1981;19:787-805.

42. Bruin de AF, Buys $M$, Witte de LP, Diederiks JPM. The Sickness Impact Profile: SIP68, a short generic version. First evaluation of the reliability and reproducibility. J Clin Epidemiol 1994:47:86371.

43. Bruin de AF, Diederiks JPM, Witte de LP, Stevens FCJ, Philpsen $H$. Assessing the responsiveness of a functional status measure: the Sickness Impact Profile versus the SIP68. J Clin Epidemiol 1997,50(5):529-40.

44. Mahoney FI, Barthel DW. Functional evaluation: the Barthel index. Maryland State Med J 1965;14(2):61-5.

45. Applegate WB, Blass JP, Williams TF. Instruments for the functional assessment of older patients. New E J Med 1990;

$17: 1207-14$

46. Folstein MF, Folstein SER, McHugh PR. "Mini-mental state": a practical method for grading the cognitive state of patients for the clinician. J Psychiatr Res 1975;12:189-98.

47. Niffe S, Booroff A, Galliwan S, Goldenberg E, Morgan P. Haines $A$. Screening for cognitive impaiment in the elderly using the mini-mental state examination. Br J Gen Pract 1990; 40:277-9.

48. Vermenten CA, Bosma AMM. De gezondheid van oudaren: epidemiologie en beleid (Health in elderly people: epidemiology and management). Thesis University of Amsterdam. CIP Gegevens Koninklijke Bibliotheek Den Hag 1992.

49. Sorock GS, Labiner DM. Peripheral neuromuscular dysfunction and falls in an elderly cohort. Am J Epidemiol 1992;136:584-91.

50. Richardson $J K$, Hurvitz EA. Peripheral neutopathy: a true risk factor for falls. J Gerontol 1995 50A;M211-15. 
Prospective cohort study

51. Judge JO, Whipple RH, Wolfson LI. Effects of resiseive and balance exercises on isokinetic strength in older persons. JAGs $1994 ; 42(9), 937-46$

52. Whipple RH, Wolfson LI, Ameman PI. The relationship of knec and ankle weakness to falls in nursing home residents. JAGS $1987 ; 35: 13-20$.

53. Wickham $C$, Cooper C, Margetts BM, Barker DJP. Murcle strength, activity, housing and the risk of falls in elderly people. Age Ageing 1989:18:47-51.

54. Coupland $C$, Wood $D$, Cooper $C$. Physical inactivity is an independent risk factor for hip fracture in the elderly. J Epidemiol Coomm Health 1993;47:441-443.

55. Bohanon RW, Lusardi MM. Modified sphygmomanometer wersus strain gauge hand-held dynamometer. Arch Phys Med Rehabil 1.991;72:911-1.4.

56. Ploeg wan der RJO, Oosterhuis HJGH. Het onderzock van spierkracht in de klinische praktijk (The examination of muscle strength in clinical practice). Ned Tijdschr Geneeskd $1995: 139: 2028-32$.

57. Mathias S, Nayak USL, Isaacs B. Balance in elderly patients: The "Get-up and Go" test. Arch Phys Med Rehabil 1986;67:387-9. 58. Anacker $S L$, Di Fabio RP. Influence of sensory inputs on standing balance in community-dwelling elders with a recent history of falling. Phys Ther 1992;72:575-84.

59. Casset $J-C$. Etude sur les chutes chez les sujets âgées. Essai de validation de "up and go test" (Study on falls in the elderly. Validity test of "the Get-up and go test"). Exercer, Numero special recherche 1994:21-22.

60. Vaerenbergh van I, Broos P. Positieve Romberg en het woorspellen wan vallen bij ouderen (Positive Romberg test and the prediction of falling in the elderly). Tijdschr Gerontol Geriatr $1990 ; 21: 71-4$.

61. Opersiall PW. Prevention of falls in the elderly. JAGS $1980 ; X X V I I I: 481-4$.

62. Maki BE, Holliday PJ. Topper AK. A prospective study of postural balance and risk of falling in an ambulacory and independent elderly population. J Gerontol Med Sci 1994;49:M72M84.

63. Lord SR, Sambrook PN, Gillbert $C$, et al. Postural stability, falls and fractures in the elderly: results from the Dubbo Osteoporosis Epidemiology Study. Med J Austr 1994;160:684-91. reach: a new clinical measure of balance. I Gerontol Med Sci 
$1990 ; 45: M 192-7$

65. Duknom PW, Stadenthi $S$, Chandley J. Prescour B. Functional reach: predictive validity in a sample of elderly male veterans. J Gerontol Med Sci 1992:47:93-98.

66. Weiner DK, Bongromi DR, Studenski SA, Duncan PW, Kochersberger GG. Does functional reach improve with rehabilitation? Arch Phys Med Rehabil 1993;74:796-800.

67. Lundin-Olsson $L$, Nyberg $L$, Gustafson $Y$. "Stops walking when talking' as a predictor of falls in elderly people. The Lancet $1997 ; 349: 617$

68. Linstone HA, Turoff $M$. The Delphi method. Technigues and applications. London: Addison-Wesley Publishing Company, Inc., 1975 .

69. Stalenhoef PA, Diederiks JPM, Knotnerus JA, De Witte LP, Crebolder HFJM. How predictive is a home-safety checklist of indoor fill risk for the elderly living in the communty? Eur J Gen Prac 1998;4:114-20.

70. Cumnings SR, Nevit MC, Kidd S. Forgetring falls. The limited accuracy of recall of falls in the elderly. JAGS 1988;36:613-6.

71. Hosmer DW, Lemestow S. Assessing the fit of the model. In: Applied logistic regression. 1st ed. New York: John Wiley and Sons, 1989.

72. Van der Schouw YT, Verbek ALM, Rays JHJ. ROC curves for the initial assessment of new diagnostic tests. Fam Pract 1992;9:506-11.

73. Knotnerus $J A$. Diagnostic prediction rulles: principles, requirements, and pitfalls. Med. Decis Making 1995;22(2):

$341-63$.

74. Lipsitz LA. Orthostatic hypotension in the clderly. N Eng J Med 1989;321:952-7.

75. Kwok $T$, Liddle J, Hastie IR. Postural hypotension and falls. Postgrad Med J 1995;71:278-83.

76. Lin BA, Topper AK, Reeves RA, Gryfe C, Maki BE. Falls among older people: relationship to medication use and orthostatic hypotension. JAGS 1995:43:1141-5.

77. Vogt TM. Falls, fallacies and hypertension. JAGS 1995;43:1169.

78. Lenders JWM, Hoefragels WHL, Thien Th, Orthostatische hypotensie bij bejarden (Orthostatic hypotension in the elderly). Ned Tijdschr Geneeskd 1990;134;26:1252-1254.

79. Keppel Hesselink JM. De test wan Romberg; een eeuw onenigheid over de uitwoering (The Romberg test: a century of disagreement about the implementation). Ned Tijdschr Genecskd $1995 ; 139: 2678-81$. 



\section{CHAPTER 9}

Home-safery checthlist

How predicnive is a howe-safery chedelist for indoor fall risk in the elderly living in the commonity?

Published as:

Paul Stalenhoef, Jos Diederiks, Andre Knottnerus, Luc de Witet, Harry Crebolder. How predictive is at home-safety checklist of indoor fall risk for the elderly living in the community? Eur J Gen Pract 1998;4:114-20. 
Home-safety checklist

\section{Abstract}

Objective Development and evaluation of a home-safety checklist of indoor fall risk for the elderly living in the community.

Methods A checklist of indoor fall risk was developed in a Delphi procedure as part of a base-line assessment of fall risk. Based on the number of falls in the previous year the 1238 respondents to a mall questionnaire on occurence of, risk factors for and consequences af falls in community-living elderly of 70 years or over, were divided into three groups: non-fallers, one-time fallers and recurrent fallers ( $\geq 2$ alls). Out of each group 130 subjects were randomly selected and stratified on age and gender $(\mathrm{N}=392)$, of which 311 subjects (79\%) were available for participation in a prospective study: a baseline assessment including a home-safety assessment of indoor fall risk, and a subsequent 36 week follow-up procedure with telephone calls every six weeks. Outcome variables were indoor falls and the number of subjects with indoor falls during follow-up. Prevalences of potential risk factors were determined. In addition, by bivariate analysis associations between potential risk factors for indoor falls risk and indoor falls during follow-up were calculated. Results Follow-up was completed by 293 subjects and data from 287 subjects were available for analysis. During follow-up 198 falls were reported by 96 participants (32\%). Two persons had a hip fracture $(1 \%)$ and four had other fractures (2\%). 135 Indoor falls were reported by 63 ( $21 \%$ ) and 63 outdoor falls by 45 persons $(15 \%)$. Potential risk factors for indoor falls equally belong to structural (immobile) and non-structural (mobile) risk factors. Stairs, bedrooms and bathrooms are the locations of the dwelling in which most potential risk factors are situated, but do not correspond with locations in which indoor falls actually occur. In bivariate analyses high scores on the checklist do not have a predictive value for indoor falls with an exception for indoor falls in the entrance.

Comclusions A checklist on indoor fall risk is useful in the identification of potential risk factors for indoor falls, but does not have a predictive value for indoor falls in the community-dwelling elderly with an exception for indoor falls in the entrance.

Keywords: falls, elderly, home-safety checklist, general practice 


\section{Introduction}

Falls are an important health problem and a threat to independence of elderly people. They are characterized by a high incidance, many risk factors and severe consequences (1-4). Moreover, they serve as markers for morbidity, frailty and functional decline (5). Fractures, particularly hip fractures belong to the najor fall-related injuries (6). About 90 percent of all hip fractures are caused by falls (4). Therefore a reduction of incidence of fractures and ocher fallrelated injuries should be an outcome measure of fall prevention programmes (7). Falls in the elderly are associated with both intrinsic (patient-related) and extrinsic (environment-related) risk factors $(3,8,9)$. About three-quarters of all falls occur indoors $(10,11)$. Generally, it is assumed that extrinsic risk factor play an additional role to intrinsic risk factors $(3,9)$. The main intrinsic risk factors identified as significant are balance and gait problems, cognitive impairment and medications $(3,4,12-14)$. Extrinsic risk factors for indoor falls can be classified into structural (immobile) risk factors like dangerous stairs or floors, insufficient lighting and high thresholds, and non-structural (mobile) risk factors such as absence of nightamps, absence of anti-slip material in the bathroom, too high or low storage, dangerous furmiture, loose carpets and objects or insufficient walking space (15). The presence of stairs is mentioned as an important hazard (16). It has been estimated that extrinsic risk factors contribute to beween one thind and a half of all falls by elderly people living in the community $(8,17)$. Until now extrinsic risk factors have appeared to be associated mainly with accidental falls and not with frailty and seem not to contribute independently to recurrent falls $(3,12,14,18-21)$. Hatards in the dwelling as risk factors for falls are rarely assessed in prospective studies $(3,4,22)$. In addition, it is difficult to define environmental hazards and to standardize methods for assessing then (18).

In wiew of prevention of falls and fractures it is important to gain more insight into the prevalence and significance of extrinsic risk factors for indoor falls. The assessment of indoor tall risk with a checklist is recommended by many authors, but an evidence-base is generally lacking $(19,22-26)$. To investigate the prevalence and signifucance of potential extrinsic risk factors for indoor falls, we developed and evaluated a home-safety checklist to assese potential risk factors for indoor falls as part of a prospective study on falls in the community-dwelling elderly.

The following questions were formulated: 
Home-safety checklist
1. Which potential risk factors for indoor falls in the communitydwelling elderly can be identified by use of a home-safecty checklist:

2. In which locations of the dwelling are these potential risk ractors situated?

3. What is the predictive value of this checklist?

\section{Material and Merhods}

\section{Construction of the measurements instrument}

A home-safety checklist of indoor fall risk was developed in a Delphi procedure (27-29). Members of the Delphi panel were fiwe occupational therapists, one district nurse and one social insurance expert. In three rounds consensus was reached. Figure 1 presents this checklist consisting of 23 potential risk factors subdivided into six categories (I. through VI.; rows) and eight locations of the dwelling (a, through h; columns), totally 116 cells for homes with stairs and 96 cells for homes without. Categories of potential risk factors are: I. Floors; II. Lighting; III. Walking Space; IV. Stairs; W. Obstacles and VI. Various. Locations of the dwelling in which risk factors are situated are: a. Entrance; b. Stairs; $c$. Kitchen; d. Bathroom; e. Toilet; f. Bedroom; g. Liwing room and h. Loft and Cellar. The assessment of the homes was performed by three physicians, specifically trained for this study. Each location of the dwelling was inspected and scored on the checklist for each allocated potential risk factor. An inter-observer test between two observers for the total checklist scores of ten randomly selected homes was performed to ensure inter-observer reliability, resulting in a Cohens" kappa of 0.66

The analysis was conducted in two steps: frequency counts and bivariate analyses. The frequency counts yielded for each participant a total checklist score and subscores of risk factors, rish categories and locations. The checklist was controlled for stairs and not applicable items. Means of checklist scores with their 95 吿 confidence intervals were calculated overall, and for fallers versus non-fallers and indoor fallers versus non-indoor fallers, both controlled for stairs, and analysed with analysis of variance (Oneway ANOVA).

An individual checklist score, compared to the overat mean score, offered a rough measure of potential indoor fall risk. To obtrin more insight into the prevalence of potential risk factors by their locations, from each checklist totals of rows and columns were taken, controlled for stairs and not applicable items and related to 


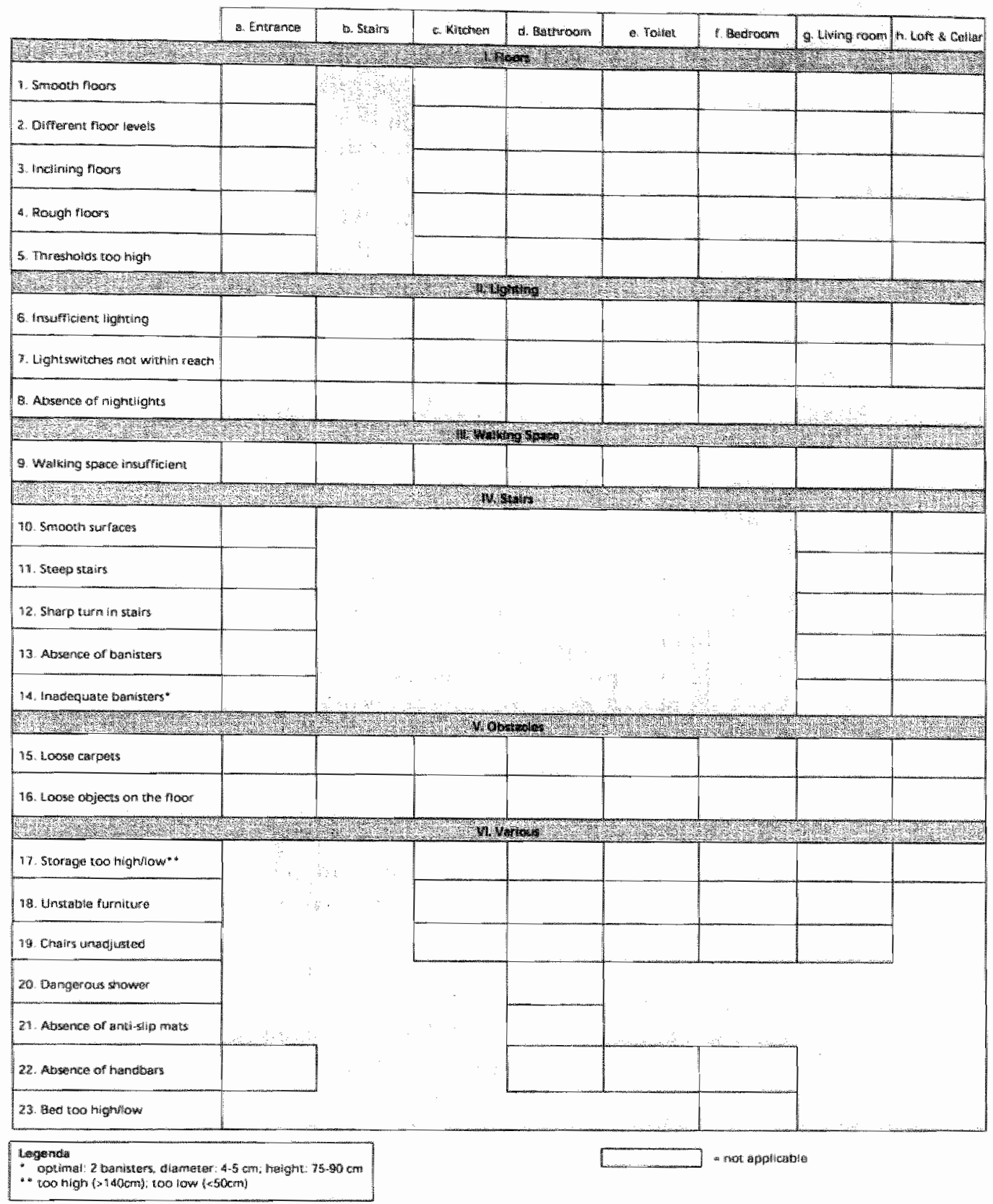

Figure 1 
Home-safety

checklist the possible maximum scores.

Subsequently, to perform bivariate analysis the means of checklin scores were trichotomized into three risk groups: $10 \mathrm{w}(<10)$. medium $(10-19)$ and high scores (19 and higher). Cut-of points were chosen on the basis of the distribution of all total checklist scores: 20 and 80 percent, respectively. Odds ratios (OR) and the $95 \%$ confidence intervals (Cl) for the risk groups with medium plus high ( $\geq 10)$ and high risk scores $(>19)$ for indoor falls during follow-up were calculated in the presence of stairs, representing potentially the highest risk. Finally, odds ratios and their $95 \% \mathrm{Cl}$ for the six risk categories and the eight locations were determined. A "fall" was defined as any unintentionally coming down on the floor or at a lower level. Outcome measures were falls $(\geq 1$ fall). indoor falls and number of subjects with or without falls or indoor falls during follow-up.

\section{Subjerts}

From the population of three primary health care centres and one duo general practice, all persons of 70 years and over were enrolled for participation in a survey on incidences, risk factors and health consequences of falls in the community-dwelling elderly ( $N=2946$ ). Persons living in residences for the elderly were included. A total of 202 subjects were excluded in accordance with the exclusion criteria applied by the general practioners (GPs). Exclusion criteria were: severe illness, severe dementia, illiteracy, blindness and wheelchair dependence. A mail questionnaire was sent to 2744 included persons, of whom 1660 responded (response rate: 60\%; one mail reminder). Written consent for further participation in a prospective study, consisting of a baseline assessment on potential risk factors for indoor falls and a 36-week telephone follow-up, was obtained from 1238 persons. To reach a more homogeneous distribution of the follow-up population regarding fall history in the previous year, age and gender, the respondents to the mail questionnaire were divided into three groups: non-fallers, onc-time fallers and recurrent fallers ( $\geq 2$ falls) and stratified on age and gender. Out of each group 130 persons were randomly selected and stratified to obtain at least 100 participants in each group, resulting in 311 participants for the follow-up study. The number of participants and the duration of the follow-up period was determined by calculated guess. The baseline assessment was performed in June till September 1994 and the subsequent followup from June 1994 till June 1995. 
University Hospital Masstricht.

\section{Results}

Population and falls

Out of the 311 subjects, 303 started and 293 completed the 36 week follow-up: eight persons died, six refused further participation for several reasons. two were institutionalised in a clinic, one moved to another address and one was not cognitively capable. At the end of the follow-up period data from 287 participants were avalable for further analysis. The proportion of

Table 1 Prevalence (\%) of porculal risk factors for indoor tall $(\mathbb{N}=311)$

\begin{tabular}{|c|c|c|c|}
\hline Rank & Potential risk factor & $\begin{array}{l}\text { Checkllist } \\
\text { notation }\end{array}$ & $\begin{array}{l}\text { Prevalence } \\
\qquad(\%)\end{array}$ \\
\hline 1 & Absence of aightiamps & 11.8 & 70 \\
\hline 2 & Absence of thandbars & $\mathrm{V} 1.22$ & 57 \\
\hline 3 & Storage too high/low & VI.17 & 51 \\
\hline 4 & Inadequate banisters* & IV.14 & 41 \\
\hline 5 & Dangerous shower & $V 1.20$ & 39 \\
\hline 6 & Absence of anti-slip mats & 11.21 & 36 \\
\hline 7 & Loose carpets & $V .15$ & 29 \\
\hline 8 & Steep stairs* & IV.11 & 18 \\
\hline 9 & Absence of banisters & IV.13 & 12 \\
\hline 10 & Sharp turn in stairs" & IV. 12 & 11 \\
\hline 11 & Thresholds too high & 1.5 & 10 \\
\hline 12 & Loose catpers on the flow & $\mathrm{V} .16$ & 6 \\
\hline 13 & Walluing space insufficient & 111.9 & 4 \\
\hline 14 & Smoorli surfaces stairs* & IV. 10 & 3 \\
\hline 15 & Smooth Aoors & 1.1 & 3 \\
\hline 16 & Bed roo high/low & $\mathrm{V} 1.23$ & 3 \\
\hline 17 & Chairs unadjusted & VI.19 & 2 \\
\hline 18 & Insufficient lighkiag & $\| 1.6$ & $i$ \\
\hline \multirow[t]{2}{*}{19} & Liglutw-switches not within & & \\
\hline & reach & 11.7 & 1 \\
\hline 20 & Unsable funiture & $V 1.18$ & 1 \\
\hline 21 & Different foor levels & 1.2 & 1 \\
\hline 22 & Rough floors & 1.4 & 1 \\
\hline 23 & Inclining floors & 1.3 & $<1$ \\
\hline
\end{tabular}


Home-safely

checklist

homes with stairs was $45 \%$.

During the 36-week follow-up period, 198 falls were reported by 96 of the 303 participants, who initially participated in the followup $(32 \%)$ : fifty people (17\%) reported one fall and 46 (15\%) recurrent falls. Sixty-three persons (21\%) reported 135 indoor falls and 45 participants (15\%) 63 outdoor falls. Totally, 54 fallorelated injuries were reported by 43 individuals ( 45 percent of the fallers). Two persons had a hip fracture and four other fractures $(2 \%$ and $4 \%$ of the fallers, respectively). Contusions were reported by $12(13 \%)$, other soft tissue damage by $32(33 \%)$ and wounds needing sutures by five persons ( $5 \%)$.

\section{Checklist}

The mean of the checklist scores of potential risk factors for indoor falls of the 287 analysed cases is 14.3 (SD:5.06) with a range of 2 to 32.

Table 1 presents the prevalence of 23 potential risk factors for indoor falls in the base-line population, adjusted for stairs $(N=311)$. Out of the ten potential risk factors with the highest scores, four are non-structural, mobile and more amenable to prevention: absence of nightlamps (70\%), storage too high/low (51\%), absence of anti-slip mats in bathroom (36\%) and loose carpets (29\%). The other six are structural, immobile risk factors: absence of handbars $(57 \%)$, inadequate and absence of banisters in stairways $(41 \%$ and

Table 2 Prevalence $\%$ of potemtinl risk factors for indoor falls by location $(N=311)$, compared to perentage of indoon fallers during follow-ap $(N=63)$

\begin{tabular}{|c|c|c|c|c|}
\hline Rank & Location & $\begin{array}{l}\text { Checklist } \\
\text { notation }\end{array}$ & $\begin{array}{c}\text { Prevalonce } \\
(\%)\end{array}$ & $\begin{array}{l}\text { Indoot fallers } \\
\text { in follow-up }\end{array}$ \\
\hline 1 & Stairway * & $\mathrm{b}$ & 24 & 7 \\
\hline 2 & Bedroom & $\mathrm{f}$ & 19 & 19 \\
\hline 3 & Bathrooda & $d$ & 18 & 7 \\
\hline 4 & Living roon & g. & 16 & 37 \\
\hline 5 & Toilet & $\mathrm{c}$ & 12 & 2 \\
\hline 6 & Kitchen & $c$ & 11 & 5 \\
\hline 7 & Loft \& Cellar * & h. & 9 & 5 \\
\hline 8 & Entrance & a. & 7 & 19 \\
\hline
\end{tabular}


Table 3 Analysis of variance (One-may ANOVA) of mean checklist scotes of groups of subjects with and without falls or indoor falls during follow-up. adjusted for thairs $(\mathrm{N}=287)$

\begin{tabular}{lcccc}
\hline Groups of subjects & Mean & $95 \%$ C & F & -value \\
\hline Fallers & 14.9 & $13.8-16.1$ & 2.0 & $0.16 * *$ \\
Non-fallers & 14.0 & $13.4-14.7$ & & \\
Indoor fallers & 1.4 .1 & $12.7-15.8$ & 0.1 & $0.75 * *$ \\
Non-indoor fallers & 14.4 & $13.7-15.0$ & & \\
\hline Fallers* & 12.6 & $11.8-13.5$ & 1.4 & $0.24 * *$ \\
Non-fallers* & 12.0 & $11.5-12.6$ & & \\
Indoor fallers* & 12.0 & $10.9-13.1$ & 0.2 & $0.62 * *$ \\
Non-indoor fallers* & 12.3 & $11.8-12.8$ & &
\end{tabular}

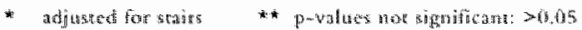

Table 4 Prevalence of and odds ratios for risk caregorier and locations for indoor falls $(\mathrm{N}=287)$

\begin{tabular}{|c|c|c|c|c|c|}
\hline \multicolumn{2}{|c|}{ Risk-categories } & \multirow{2}{*}{$\begin{array}{l}\text { Cut-of } \\
\text { wallue } \\
>0\end{array}$} & \multirow{2}{*}{$\begin{array}{c}\text { Prevallence } \\
\frac{(\%)}{52}\end{array}$} & \multirow{2}{*}{$\begin{array}{l}\text { OR } \\
1.0\end{array}$} & \multirow{2}{*}{$\begin{array}{l}95 \% \mathrm{CH} \\
0.6-1.8\end{array}$} \\
\hline 1 & Floor: & & & & \\
\hline II & Lighting & $>1$ & 78 & 0.7 & $0.4-1.4$ \\
\hline III & Walking space & $>0$ & 16 & 1.5 & $0.7-3.0$ \\
\hline $\mathbb{N V}$ & Stairs & $>0$ & 57 & 1.1 & $0.6-1.9$ \\
\hline$v$ & Obstacles & $>2$ & $5 \pi$ & 1.5 & $0.9-2.7$ \\
\hline $\mathrm{vl}$ & Miscellaneous & $>3$ & 82 & 0.6 & $0.3-1.1$ \\
\hline \multicolumn{2}{|c|}{ Locations } & $\begin{array}{l}\text { Cutwoff } \\
\text { value }\end{array}$ & $\begin{array}{c}\text { Prewalence } \\
\qquad(\%)\end{array}$ & or* & $95 \% \mathrm{Cr}$ \\
\hline a & Entrance & $>1$ & 23 & 2.5 & $1.4 .4 .6 * *$ \\
\hline b & Stairway & $>1$ & 36 & 0.8 & $0.4-1.5$ \\
\hline$c$ & Kutchen & $>1$ & 41 & 0.9 & $0.5-1.5$ \\
\hline$d$ & Bathroom & $>3$ & 33 & 0.6 & $0.3 \times 1.2$ \\
\hline e & Toillet & $>2$ & 22 & 0.9 & $0.5-11.8$ \\
\hline$f$ & Bedrwom & $>3$ & 32 & 1.3 & $0.6-1.9$ \\
\hline$g$ & Living room & $>2$ & 31 & 1.2 & $0.6-2.1$ \\
\hline h & Loft ed Cellar & $>0$ & 33 & 0.7 & $0.4 \cdot 1.3$ \\
\hline
\end{tabular}


Home-safety

checklist
12\%), dangerows shower (39\%), wep stais and sharp turns in start $(18 \%$ and $11 \%)$

Table 2 presents the prevalence of potential risk factors for indoor falls by location, adjusted for stairs. In addition, table 2 presents the reported percentage of fallers with indoor falls by location. It show that the stairway (24\%), followed by the bedroom (19\%) and the bathroom (18\%) represent the locations in which most potential risk factors are recorded. Most indoor fallers, however, reported falls in the living room (37\%), followed by entrance and bedroom (19\% both). Only seven percent of indoor fallers reported falls on stairs and in bathrooms. Falls in kitchen, loft and cellar were reported in five and falls in coilet in only two percent of the indoor fallers.

Table 3 presents the results of the analysis of variance (One-way ANOVA). It does not reweal significant differences between the means of checklist scores of groups of subjects with or without falls and with or without indoor falls during the follow-up period. The same results were obtained if there is adjusted for stairs.

A bivariate analysis of the risk groups medium plus high (cut-off point: 10 ; prevalence: 80 percent) and high (cut-off point: 19 ; prevalence: 20 percent) against the group with indoor falls and stairs, potentially the group with the highest risk, yielded no significant associations between checklist scores and indoor falls: OR: 1.6 (CI 95\%:0.5-4.9) and OR: 0.7 (CI 95\%:0.3-1.9). respectively.

Table 4 presents cut-off values, corresponding prevalences of and odds ratios for risk categories and locations for indoor falls during follow-up. Except for falls in the entrance, no significance was found. The analysis of locations was completed by Bonferroni adjustment, resulting in Cl 95\%: 1.1-5.9 for the entrance, which still remains significant $(30)$.

\section{Discussion}

This home-safety checklist for assessment of indoor fall risk for Iderly persons, living in the community was developed as a part of a baseline examination of potential risk factors for falls. The avaluation of this checklist revealed that the application as an instrument for screening has no predictive value for indoor fall risk in the elderly. In several ways we tried to find a correlation between indoor risk factors and indoor falls. Except for falls in the entrance we found no evidence of a significant contribution of indoor risk factors to falling. An explanation for the lack of an association between potential indoor risk factors and indoor falls 
might be the assumption, that elderly people are used to envirommental hazards in their own homes $(23,31)$.

Applicarion of this checklist resulted in an overwew of the prevalence of potential risk factors for indoor falls by their locations. Frequency counts of potential risk factors revealed that mobile and immobile risk factors are about equally distributed with a wide range in frequency. In addition, there is an important difference between the prevalence of potential risk factors by location and the locations in which falls were reported to have accurred during the follow-up period.

Regarding the total checklist scores, analysis of variance did not reveal any difference in checklist scores for subjects with or without falls and indoor falls, not ewen if controlled for stairs. Application of the checklist in a potentially high risk group. i.t. fallers with stairs in their homes, compared to the rest of the population revealed no significant associations between the scoces of potential risk factors and indoor falls. Finally, bivariate analysis did not give any significant association of potential risk categories and their locations with indoor falls, except of the entrance. An explanation for this finding may be that the entrance is a transit between indoor and outdoor space, where adaptation problems may arise such as adaptation to lighoness or darkness (32).

The development of a checklist for home hazards meets two main limitations. Firstly, the lack of useful definitions and standardized assessment methods of extrinsic risk factors for falls and secondly, the inter- and intra-observer variability. The first point concerns the question how to define indoor risk factors for falling and how to assess them. No definitions in literature were availlable. To cope with this problem a Delphi procedure was conducted. Regarding the assessment of indoor fall risk factors only non-palidated checklists are circulating without published evaluation. The second item, the inter- and intra-observer variability is a reliabiluty problem. The inter-observer variability is related to a lack of cleat definitions of risk factors for falls and to differences in interpretation of the items between observers. The intra-observer variability is caused by insufficient routine and experience of the examiners. We have tried to overcome this shortcoming by training the examiners in both performance and interpretation of tests and scores. An inter-observer test gave a reasonable Cohen"s kappa of 0.66 .

The duration of the follow-up period seems rather short compared to other prospective studies with a one year follow-up $(3,4,12,13,21)$. However, because of expected high incidence of 
Home-safety

checklist

falls of about $40 \%$ in the population of 70 years and over, the sample size guess appeared to be sufficient for an adequate analysis: no essentially different outcomes in significance of indoor fall risk factors were to expect if the follow-up period had been longer.

From a methodological point of view two other remarks have to be made. Firsty, the telephone calls did not reveal that participants rook any measures of home adjustments after the home-safety assesment, which might have influenced the results of the evaluation of the checklist. And secondly, a potential risk factor becomes an actual risk factor if analysis reveals a significant increase of falls during follow-up due to that particular risk factor. However, we did not check the condition for this, i.e. the actual use of all locations of the dwelling by the participants.

There are indications that the statement cited in the introduction is confirmed by our results: extrinsic risk factors play an additional role to intrinsic risk factors $(3,9)$. The actual contribution of indoor risk factors to falls in the elderly remains unclear (33). Our hypothesis is that indoor risk factors are not to be considered primarily as causal factors but more as factors giving occasion to falls. Elderly people with important intrinsic risk factors do fall anyhow, but when, where and how they fall is a matter of randonness or occasion. It means that regarding fall risk prevention a general improvement of the enwironmental conditions in which elderly people stay will have limited results. More prospcctive studies are needed to obtain evidence for this hypothesis.

Based on our results the application of this checklist cannot be recommended with regard to preventive measures, neither in a screening programme, nor in activities of everyday care. The benefit of home wisits to assess fall risk by use of checklists can be doubted and may have contrary effects: every change in home conditions as a result of not evidence-based assessments might prowoke new hazards. The consequence for fall preventive programmes and activities in everyday care is that the attention, paid to conditions caused by intrinsic risk factors, has to prevail over the methodological assessment of extrinsic hazards.

\section{Acknowledgements}

We are gratefil to the the three physicians who carried out the baseline examination: Hanneke Hamers, Djouke Bussemakers and Bert Schilte, and the members of the Delphi consensus group: $A$. Backhuijs-Ammerlaan, Y. Curfs, J. Schurgers, M. Tielen and A. 
Home-safety

checklist

Huigarts Wet $1992 ; 35(2): 57-60$.

12. Campbell AJ, Borrie MJ, Spears GF. Risk factors for falls in community-based prospective study of people 70 years and older. 1 Geront:Med Sci 1989:44:112-7.

13. O'Loughtin $J L$, Robitalle $Y$, Boivin $J-F$, Suissa S. Incidence of and risk factors for falls and injurious falls among the communitydwelling elderly. Am J Epidem 1993;137:342-54.

14. Sialenhoef PA, Crebolder HFJM, Knottnerus JA, Horst van der FGEM. Incidence, risk factors and consequences of falls among elderly subjects living in the community. A criteria-based analysis. Eur J Pub Health 1996;7:328-334.

15. Rubinstein LZ, Robbins $A S$, Schwman BL, Rasado J. Osterweil $D$. Josephon KR. Falls and instability in the elderly. J Am Geriatr Soc. $1988 ; 36: 266-78$.

16. Archea JC. Environmental factors associated with stair accidents in the elderly. Clin Geriatr Med 1.985;1:555-68.

17. Lilley JM, Arie $T$, Chilvers CED. Accident involving older people: a review of the literature. Age ageing 1995;24:346-65.

18. Rodriguez JG, Sattin RW, DeVito CA, Wingo PA. Developing an environmental hazards assessment instrument for falls among the ellerly. In: Weindruch $R$, Ory $M$ (eds.). Frailty reconsidered: reducing frailty and fall-related injuries in the elderly. Springfield, Illinois: Charles $\mathrm{C}$ Thomas.

19. Cutson TM. Falls in the elderly. Am Fam Phys 1994;49:149-56. 20. Rubinstein LZ, Robbins AS, Josephson KR, Schulman BL, Osterweil $D$. The value of assessing falls in an elderly population. $A$ randomized clinical trial. Ann Int Med 1990:113:308-16.

21. Campbell AI, Borrie MJ, Spears GF, Jackson SL, Brown JS, Fitzgerald JL. Circumstances and consequences of falls experienced by a community population 70 year and over during a prospective study. Age ageing 1990;19:136-41.

22. Northidge ME, Nevit MC, Kelsey JL, Link B. Home hazards and falls in the elderly: the role of health and functional status. Am J Public Health 1995:85:509-15.

23. Tineti ME, Speedhley M. Prevention of falls among the elderly. N Eng J Med 1989;320:1055-9.

24. Cwikel J, Fried $A V$. The social epidemiology of falls among community-dwelling elderly: guidelines for prevention. Disability and Rehabilitation, 1992;14:113-21.

25. Kellogg International Workgroup on the prevention of falls by the elderly. The prevention of falls in later life. Dan Med Bull 1987:34:Suppl4:1-24.

26. Tideiksaar R. Falls in older persons. M Sinai J Med 1993;60: 
515-21.

27. Linstone HA, Torof M. The Delphi Method. Techniques and applications. Addison-Wesley Publishing Company. London, 1975. 28. Fink $A$, Kosecoff $I$, Chasin $M$, Brook RH. Consensus methods: characteristics and guidelines for use. Am J Publ Health $1984,74: 979-83$.

29. Grol RTPM, Everdingen wan JE, Caspari AF. Invoering wan richtlijnen en veranderingen. De Tijdstroom, Utrecht, 1994.

30. Bland JM, Altman DG. Multiple significance tasts: the Bonferroni method. BMJ 1995:310:170.

31. Campbell AJ, Reinken J, Allan BC, Marinez GS. Falls in ald age: a study of frequency and related clinical factors. Age Ageng $1981 ; 10: 264-70$.

32. McMurdo ME, Gaskell A. Dark adaptation and falls in the elderly. Gerontology 1991; 37(4): 221-4.

33. Carter SE, Campbell EM, Samson-Fistier $R W$, et al. Environmental hazards in the homes of older people. Age Agening 1997;26:195-202. 
CHAPTER 10 $\mid$ Gait disorders

Chatacteristics of eldetly whith git disonders and self-reported causes.

Swbrtited as:

Buys MFA, Stalenhow PA, Diederiks JPM, Knotenerus JA. Crebolder HFJM. Kenmerken wan oudaren met loopstoomissen en door hen gerapportearde oorzaken. 


\section{Gait disorders}

\section{Abstract}

Objective To determine the characteristics of elderly people living in the community with gait disorders and self-reported causes.

Design Crossusectional, descriptive.

Setring General practice.

Methods A mail questionnaire on incidence of, risk factors for and health consequences of falls in the elderly was sent to 274 independently living elderly persons of 70 years or over. The answers to the question: "Do you generally have problems with walking?" obtained from 1648 respondents (response: 60\%), were used to determine the characteristics of elderly people with a gait disorder. In addition, an inventory was made of the self-reported causes of those who indicated they had a gait disorder.

Results Response to the questionnaire was $60 \%$. A gait disorder was reported by 800 of the 1648 respondents (48.5\%). Their main characteristics were age 80 years or over, more near-falls and falls in the previous year and a moderate to bad perceived health starus. In addition, in comparison with those without a gatt disorder they appeared to have lower scores for health variables, functioning and quality of life. The most relevant reported causes of gait disorders related, apart from the locomotion system, to the cardiovascular. respiratory and central nervous systems, and general deterioration.

Conclusion Nearly one half of the elderly of 70 years or over reported having a gait disorder. They were older and had significantly more unfavourable scores for fall history, health status, functioning and quality of life compared to those without a gait disorder. Self-reported causes lay, apart in the locomotion system, in the cardiovascular, respiratory and central nervous systems, and general deterioration.

Keywords: Community-living elderly, gait disorders, causes, falls. 


\section{Introduction}

Mobility impaiment in the sense of the possibilty to move, is a serious problem in the elderly. Together with other disturbanes of functioning it hampers quality of life, well-being and the possibility to continue living independently. The main catuses of mobility impaiment are gait disorders, which are risk factors for falls and determinants of coping ability. Consequently, it is important to identify, diagnose, treat and prevent these disorders in an early stage $(1-10)$.

In the literature, gait disorders comprise a multitude of disorders. affecting different organ systems (11-13). In addition, useful data on possible causes among the population of independent living elderly persons are scarce. It is presumed that an accumulation of disorders provides the most of the explanation for the decline of functioning.

In their contacts with the general practitioner (GP), many elderly persons report complaints about walking. Nevertheless, one of three elderly persons with serious mability complaints never requests help $(10,14)$.

To obtain more insight into the characteristics of independently living elderly people with gait disorders and the causes of them, we conducted a study on the basis of the following study questions:

- What are the characteristics of elderly persons who report a gait problem?

- What are the causes of gait problems as perceived by elderly persons?

\section{Methods}

The investigation is part of a cross-sectional study on incidence of, risk actors for and health consequences of falls in elderly people aged 70 years or over. A questionnaire was sent to all persons aged 70 year or over $(N=2744)$, on the list of thre primary health care centres and one group practica. The questions concerned falls and mobility-related wariables as follows:

Socio-demographic situation: Age, gender and marital status.

Health stam: Nature and number of complants (20 in total) and disorders (17 in total), use of medication (yes/no), and categorics of prescribed medication regularly used, which may have influence on mobility (sedatives, anti-depressants, hypnotics, anti-bypertensives, diuretics, heart agents and other medication), the perceived health status on a 3 moint scale (good, moderate or bad), and the use of 


\section{Gait disorders}

alcohol in a 7-point scale ("never" to "more than 40 glasses a week" $k^{3 *}(15)$.

Fontioning: "The level of functioning was determined using three measurements:

- The short version of Sickness Impace Profile (SIP68), a measurement consisting of six components concerning functioning (somatic and psychological autonomy, physical and social mobility, and social and emotional behaviour) (16);

- The Activities of Daily Life and Particular activities of Daily Live ( $\mathrm{DDL} / \mathrm{PDL}$ ): six modalities concerning transport, cooking. household, washing, taking medication, and toiletting, expressed in the sumscore of separate 3-point scales ("no help needed", "some help needed" and "help necessary") (17);

- The Quality of Life (QL), determined by sumscores of two separate 7-point scales concerning feeling of happiness ("very happy" to "wery unhappy") and satisfaction ("very satisfied" to "very dissatisfied") (18).

Mobiliry: The criterion for having a gait disorder was derived from the answers to the question: "Do you generally have problems with walking?" with possibilities to answer in a 5-point scale: "yes, a great deal", "yes, many", "yes and no", no, not really" and "no, certainly not". Those who answered with one of the first three categories were subsequently asked in an open question about what they perceived to be the cause of the problem with walking: "What is, according to you, the cause of your problems with walking?" The answers were coded independently by three experienced general practitioners (GPs) according to the International Classification of Primary Care (ICPC) (19). In case of differences, a fouth GP being a particular expert on ICPC. was consulted, who determined the definitive code (20).

Falls: The number of falls (6-point scale: "never" to "5 times or more") and near-falls (4-point scale: "never" to "4 times or more") in the previous year and fear of falling (4-point scale: "never" to "always") (21).

Self-reported gait problems were used as dependent variables; the other wariables as independent.

Bivariate associations were calculated and expressed in relative risks with their $95 \%$ confidence intervals. T-tests and the Mannw Whiney test were used to test the differences with $\alpha=0.05$ as threshold value for significance.

The study design was approved by the Medical Ethical Board of the University Hospital Maastricht. 


\section{Resulls}

Charatieristics of elderly people wh a gaif disorater

The response to the questionaine wis $60 \%(\mathbb{N}=1659)$. Becanse it appeared that 11 or the respondents could not walk at all, they were subsequently excluded from this part of the study. As a consequence. 1648 elderly persons were included, 1 percent women, with a mean age of 76 years (SD 5.1).

Of the 1648 elderly persons 800 reported having a gait disorder, 64 percent of them women. Table 1 presents the categorical variables that show a strong association with gait disorders. Elderly persons wich a gait disorder differentiate themselves particularly by a poorer perceived health status, a higher age, a near-fall and, to a lesser extent, a fall in the previous year. The numerical wables, associated with self-reported gait disorders, are given in table 2. People with a gait disorder have significanty unfavourable scores for both the health variables investigated and functioning according to the SIP68, PDL and QL.

\section{Canses of gait disorders}

Figure 1 presents an overwiew of the causes, reported by 800 respondents, expressed in the code letters of the chapters of the ICPC. It appears that as expected, the most frequently reported

Table 1 prewallences and relative risks of characteristics of elderly persotas with self-reported gait disorders in categorical variables.

\begin{tabular}{|c|c|c|c|c|}
\hline \multirow{3}{*}{ Characteristics } & \multicolumn{2}{|c|}{ Prevallence $(\%)$} & \multirow[t]{3}{*}{$\mathbf{R R}$} & \multirow[t]{3}{*}{$95 \% \mathrm{CI}$} \\
\hline & $\mathbf{L}+$ & $\mathbb{L}$ & & \\
\hline & $N=800$ & $N=48$ & & \\
\hline \multicolumn{5}{|l|}{ Socio-demographic variables } \\
\hline Age 280 years & 3 & 15 & 2.1 & $1.7+2,5$ \\
\hline Genditer: fenterale & 64 & 59 & 1.1 & $1.0 \times 1.2$ \\
\hline Widow/alone & 50 & 44 & 1.1 & $1.0 \ldots 1.3$ \\
\hline \multicolumn{5}{|l|}{ Falls } \\
\hline Fall in previous year $\geq 1$ & 53 & 35 & 1.5 & $1.3-1.6$ \\
\hline Near-fall in previous year $\geq 1$ & 71 & 31 & 2.1 & $1.9-2.3$ \\
\hline \multicolumn{5}{|l|}{ Healin } \\
\hline \multicolumn{5}{|l|}{ Perceiwed health stacus: } \\
\hline moderate or bad & 63 & 20 & 3.1 & $2.7-3.5$ \\
\hline 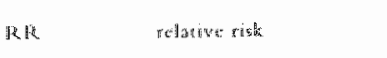 & $1+$ & Hain dist & presertat & \\
\hline Hsto confidene interual & $1 \ldots$ & कू⿻上丨 & ibsene & \\
\hline
\end{tabular}




\section{Gait disorders}

causes concern the locomotion system ( $L$ codes). The $L$ codes are differentiated according to organ sites (knee, hip, leg, back, fowt and other) and compared to the other ICPC categories. It is noticeable that a relatively high number of respondents repon cardiovacular ( $\mathrm{K}$ codes), neurological (N codes), general (A codes) and respiratory $(\mathrm{R}$ codes) causes for their galt disorder.

Table 3 presents in ICPC codes the "top ten" of the causes of gait disorders most frequently reported by the 800 respondents. It appears then, that causes of gait disorders are identified far more in terms of complaints than in terms of diagnoses.

Table 2 Mean scores and significance levels of characteristics of elderly personst wich and without self-reported gant disorders in numerical variables.

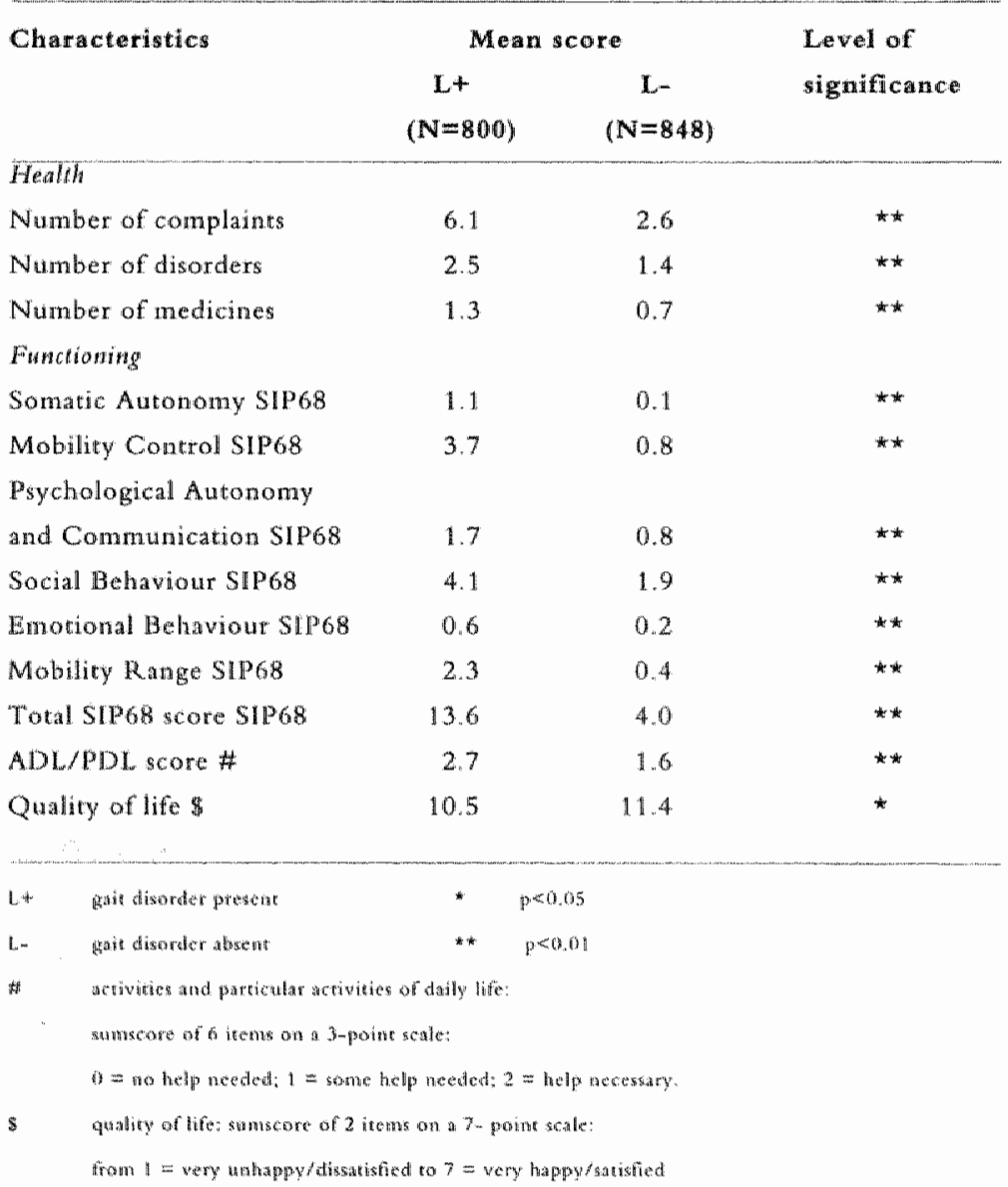




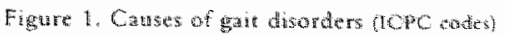
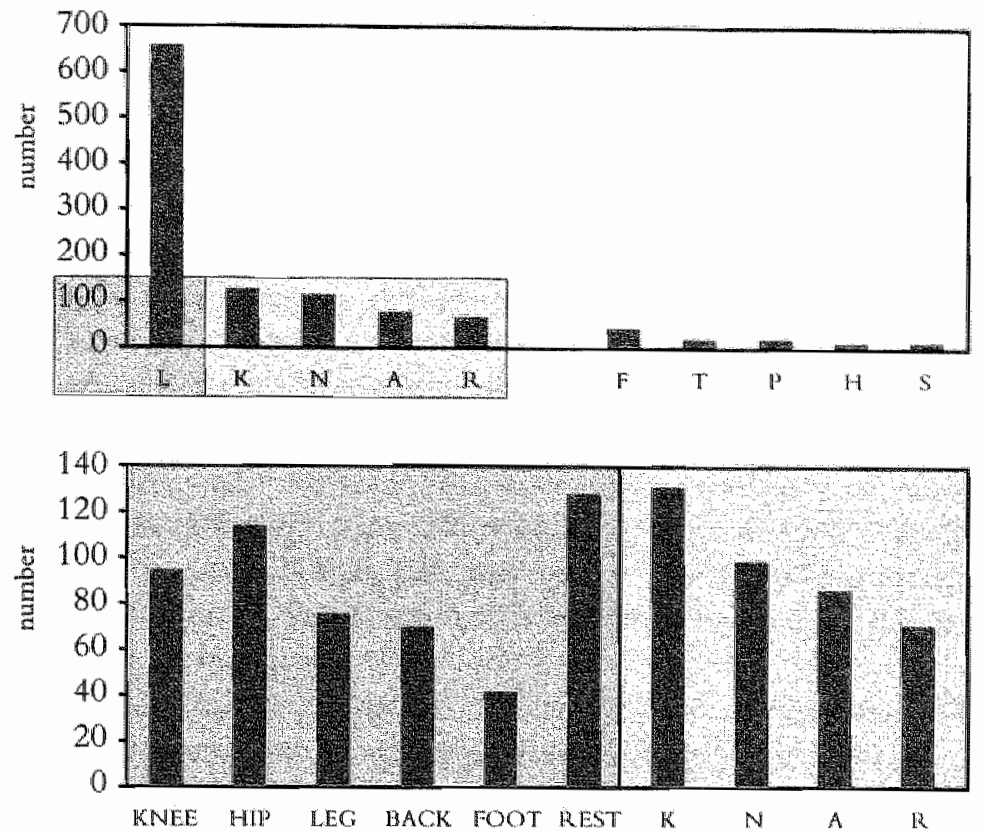

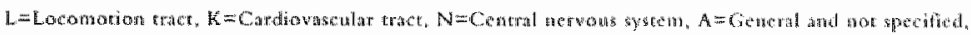

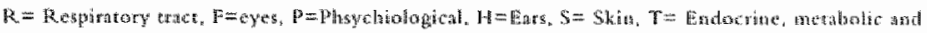
alturicakacion

Table 3. "Top-ten" of the most frequenrly reported causes of gait disoxders $(N=800)$

\begin{tabular}{|c|c|c|c|}
\hline $\begin{array}{l}\text { Reported } \\
\text { causes }\end{array}$ & $\begin{array}{l}\mathbb{I C P C} \\
\text { cods }\end{array}$ & Number & Parcontageras \\
\hline 1. Complaints/synuptoms of leg & $\mathbb{L} 14$ & 69 & 8.6 \\
\hline 2. Vertigo/dizziness & $\mathbb{N} 17$ & 65 & 8.1 \\
\hline 3. Complaints/symptoms of hip & L13 & 62 & 7.8 \\
\hline 4. Disorders of periphural arteries & $\mathrm{K} 22$ & 57 & 7.1 \\
\hline 5. Shortmess of breath & $\mathrm{R} 02$ & 53 & 16.6 \\
\hline 6. Complaints/symptoms of knee & $\mathscr{L} 15$ & 52 & 6.5 \\
\hline 7. General deterioration & $\mathrm{A} 04$ & 49 & 6.1 \\
\hline 8. Complaints/symptoms of back & L02 & 43 & 5.4 \\
\hline 9. Arthrosis deformans of knee & 290 & 38 & 4.8 \\
\hline 10. Complaints/symptoms of foo: & L17 & 37 & 4.6 \\
\hline
\end{tabular}




\section{Discussion}

\section{Cail disorders}

This study shows that nearly half of the independently living elderly persons of 70 years or over reported having a gait disorder. Particularly elderly persons who perceived their health status as moderate or bad, who were 80 years of age or over, and who experienced a near-fall (and to a lesser extent a fall) in the previous year, have a greater relative risk of having a gait disorder. In addition. elderly persons with a gait disorder have significanty poorer scores for health indicators, functioning, activitics and particular activities of daily life and quality of life.

Gait disorders are not only the result of problems of the locomotion system, but a substantial part of the causes are consequences of complants and disorders of the cardiovascular, respiratory and central nervous systems, and general deterioration. These are important and underestimated categones of causes of gait disorders: a fact that deserves further consideration in the prevention of gait disorders.

Post-registration of the causes of gait disorders using the ICPC, may raise some objections. Little is known about the use of the ICPC where clarification during a doctor-patient encounter is not possible: interpretation and codification of the responses maly reduce the level of information and may be open to bias.

Gait disorders concern many more aspects of daily life than only somatics and coping ability. The use of the other SIP68 scores can identify the strong association that not only somatic aspects but also emotional and social aspects have with gait disorders. Possibly influence flows in both directions. It is of great importance that both in daily care and in the design of preventive programmes atention is paid to eldenly persons who already have a gait disorder or who are at risk of developing one (21-24). Moreover, besides the am to improve the gait pattern and the general condition, it is necessary to take the cardiovascular, respiratory and neurological status into account.

\section{Ackowlledgement}

We are grateful to the general practitioners Th.M.E. Govaert, MD. PhD, R.M.F.M. Leclercq, MD, and J.F.M. Metsemakers MD,PhD, for their help with coding according to the criteria of the $1 \mathrm{CPC}$. and the statistical analysis. 
This study was supported by a grant from the Zorgondertoek Nederland (ZON, formerly The Praeventiefonds). Project number: $28-2365$.

\section{References}

1. Duncan PW, Chander J, Studenski So et al. How do physiological components of ballance affect mobility in old age? Arch Med Rehab $1993 ; 74: 1343-9$.

2. Hough JC, MCHenry MP, Kammer LM. Gait disorders in the elderly. An Fam Physician 1987;35:191-6.

3. Tineti ME. Performance-oriented assessment of mobility problems in elderly patients. J Am Geriatr Soc 1986;34:119-26.

4. Tineti ME, Willians TF, Mayewsket R. Fall risk index for elderly patients based on a number of chronic disabilities. An J Med $1986 ; 80: 429-3,4$.

5. Lundgren-Lindaruist $B$, Jetre $A M$. Mobility disability among elderly men and women in Sweden. Int Disabil Studies 1990;12:1-5.

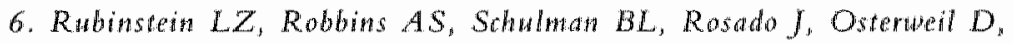
Josephson KR. Falls and instabilicy in the elderly. J Am Geriatr Soc $1988 ; 266-78$.

7. Grimby $A$, Wiklund 1 . Health relaced quality of life in old age. A study among 76 -year old Swedish urban citizens. Scand J Soc Med $1.994 ; 22(1): 7-14$.

8. Tinetti $M E$, Spechley $M$, Ginter $S F$. Risk factors for falls among elderly persons living in the community. N Eng J Med $1988 ; 26: 1701-7$.

9. Stalenhoef PA, Crebolder HFJM, Knotherus JA, Horst wan de FGEM. Incidence, risk factors and consequences of falls anong elderly subjects living in the community: a criteriabased analysis. Eur J Publ Health, 1997:7:328-34.

10. Stalewhoef PA, Hwinen LGJ, Sdhonck RSM, Knotmenus JA, Hort wan der FGEM, Crebolder HFJM. Huisbezoek door do wijkverplegkundige kan bijdragen aan de kennis van de huisarts over oudere patienten (Home visits by community nurses may contribute to general practitioner's information about ellderly patients). Ned Tijdschr Geneeskd 1996:49:2464-7.

11. Tineth $M E$, Ginter SF. Identifying mobility dysfunctions in dderly patients. JAMA 1988:259:1190-3.

12. Nutt JG, Marsden $C D$, Thompson $P D$. Human walking and higher-level gait disorders, particularly in the elderly. Neurology $1993 ; 43: 268-9$ 


\section{Call disorders}

13. Sudarky $L$, Ronthal M. Gait disorders among elderly patients. A survey study of 50 parients. Arch Neur 1983;40:740-3.

14. Oosten wa $N$, Duyn $J$. Ouderen met chronische bewegingsproblemen. Hoe huisartsen de (preventieve) zorg kumnen verbeteren (Elderly patients wh chronic gant disorders. How general practitioners can improve (preventive) care). Med Contact $1991 ; 46: 562-4$.

15. Bos van den GAM. Zorgem van en voor chronisch zieken. Thesis. 1989, Bohn, Scheltema en Holkema, Amsterdam.

16. Bruin de AF, Buys $M$, Witte de LP, Diederiks JPM. The Sickness Impact Profile: SIP68, a short generic version. First evaluation of the reliability and reproducibility. Clin Epidemiol 1994;47(8):86371 .

17. Menan RF. The AIMS approach to health status measurement: conceptual background and measurement properties. J Rheum $1982 ; 27: 1344-52$.

18. Dowell $I$, Newell $C$. Measuring health: a guide to rating scales and questionnaires. University of Ottowa. Oxford: Oxford University Press, 1987.

19. Lamberts $H$, Wood $M$ (eds). ICPC. International Classification of Primary Care. Oxford: Oxford University Press, 1987.

20. Metsemakers JFM. Unlocking patients' records in general practice for research, medical education and quality assurance: the Registration Network Family Practices. Diss. 1994. Thesis Publishers, Amsterdam.

21. Cuikel $J$, Fried $A V$. The social epidemiology of falls among community-dwelling elderly: guidelines for prevention. Disabil and Rehabil 1992;14(3):113-21.

22. Province MA, Hadley EC, Hornbrook MC, er al. The effects of exercise on falls in elderly parients: a preplanned meta-analysis of the FICSIT trials. JAMA 1995;273:1341-7.

23. Tineti ME, Baker DI, MCAvay $G$, et al. A multifactorial intervention to reduce the risk of falling among elderly people living in the community. N Engl J Med 1994;331:821-7.

24. Fiatarone MA, ONeill EF, Ryar ND, et al. Exercise training and nutritional supplementation for physical frailty in very elderly people. New Eng J Med 1994;330:1769-75. 


\section{CHAPTER 11}

The general practitioner

Falls in the elderly: the inwolvenent of the general practitioner.

Published as:

Stalenhoef PA, Busse $S$ van der, Knotnerus JA, Crebolder HFIM. Vallen van ouderen: het horen, zien, doen an laten van de huisarts. Huisarts Wet 1998;41(5):241-5. 
The general practilioner

\section{Abstract}

Ain To detcrmine the involvement of the general practioner (GP) with falls in the elderly living in the communty regatding diagnosis, treatment and prevention.

Design Cross-sectional study

Setting General practice

Methods Data from a telephome follow-up study on falls in the elderly, aged 70 years and over, randomly selected from the response-population to a mail questionnaire on falls $(N=1660)$ and stratified on fall history, age and gender ( $N=303$ ), were compared to data from a questionnaire sent to the GP's of the participating elderly. In this way the extent of reporting of falls to the GP was determined. The management of the GP in elderly who had fallen, regarding diagnosis, treatment and prevention and their estimation of fall risk and risk factors for falls, were determined as well.

Results Eighty percent of falls reported in the follow-up by the participants were not known to the GP. The GPS were informed about only half of the falls with serious consequences. The examination by the GPS was mainly directed at the detection of injury and yielded little information about the cause of the fall. Their management after a fall concemed particularly referring to a physiotherapist, giving extra advice, contacting the family and paying extra attention. Little attention was paid to the use of medication. In 170 out of the 303 elderly persons ( 56 percent), the GPs assessed an increased fall risk, of which mobility disorders played a main role.

Conclusion GPs are aware of only 20 percent of all talls in the clderly population. Their examination is not cause-directed. In about half of the elderly they found an increased fall risk, particulary due to mobility disorders.

Keywords: falls, elderly, generall practice, reporting, patient management, fall risk. 


\section{Introduction}

Among elderly people aged 65 years or over, $25-40$ percent have at least one fall a year. Wonen have more falls than men and falls increase with age (1-4). The incidence of fractures is about six percent of all falls, with hip fractures one percent (4).

Fot the general practitioner (GP) it is important that recurrent falls by an elderly person have to be considered as a sign of alarm, because a great number of cases originate in one or mote underlying disorders (5). Prevention of falls in the elderly has to be based on the understanding of the incidence of and risk factors for falls (5). In studies on falls in the elderly conducted between 1981 and 1994, and selected in a Medine search, the GP was hardly mentioned, while he is often confronted with this problem (6). Hale er al. reported that the estimation of the mobility of the elderly by the $G \mathrm{P}$ is a good predictor of falls; in contrast, the estimation of risk of falls and injury by the GP would not have any predictive value $(7,8)$.

The majority of falls are not repouted to the health care: percentages of 80 to 95 percent are mentioned $(1,2,9,10)$. Halle et al. found that less than a fith of all falls are registered by the GP (10). Part of the explanation for the underreporting to the GP may be that eiderly people quickly forget that they have fallen, which results in the so-called "recall bias". Even injuries are poorly recalled $(10,11)$.

The involvement of the $G \mathbb{P}$ with falls in the elderly was investigated on the basis of the following study questions:

- To what extent are GPs informed about falls in elderly people aged 70 years or over?

- Which management do GPs undertake in case of a fall by an elderly person, regarding diagnostic, cherapeutic and preventive activities?

- What is the risk cstimation on falls in the clderly by the GPs?

\section{Methods}

A mail questionnare on the incidence of, tisk factors for and consequences of falls in the elderly, was sent to all persons aged 70 years or over, registered in three primary health care centres and one duo group practice $(N=2744)$, connected to the Registation Network Family Practices (RNH) (12). After one written reminder a valid questionnaire was received from 1660 perrons (response: 60 percent). Of these 1238 persons gave written consent for 
The general practitlonert

participarion in the follow-up study (response: 75 percent). distributed in $56 \%$ non-fallers, $26 \%$ one-time fallers and $18 \%$ recurrent fallers $(\geq 2$ falls).

Based on fall incidences in the prewious year, three groups were randomly formed from this population - each of about 100, in total 311 persons - and stratified on age and gender. The distribution in fall groups and stratification on age and gender was done to obtain a more balanced distribution of numbers of persons in the fall groups, men and women, and persons aged $70-80$ years and 80 years and over. Of these 303 persons indicated their willingness to particpate in a 36-week telephone follow-up with telephone calls every six weeks concerning incidences, causes and consequences of falls.

During follow-ap, the loss due to death, admission into hospital, incapacity and refusal totalled 21 , leaving data from 282 alderly persons available for a comparative analysis of the results from follow-tup and GP questionnaires.

To the $16 \mathrm{GPS}$ a questionnaire was sent with the request to report for each participant, using the patient record, their awareness of a fall in the follow-up period and if so, which causes they percenved, which injury had possibly occurred, which consequences there were and which management they had made.

In addition, they ere asked afterwards to give a risk estimation of the fall risk on a 5-point rating scale, and in case of an increased risk, to mention the risk factors that were of interest according to thetn.

In this way ewo sets of data were generated: one from the 282 elderly persons that completed the telephone follow-up and one from the inquiry among the GPs concerning the 303 elderly that started the follow-up study.

For each patient data on the incidences of falls reported by the GP were compared to the falls reported by the participating elderly during the follow-up. In this way the extent of under-and overreporting to the GPs could be determined.

From the results conceming the managenent by the GPS in case of a fall regular counts werc produced. The outcomes were statistically tested by the Chi-square test where necessary. The mean ages of the persons in the groups non-fallers, one-time fallers and recurrent $(\mathrm{2x}$ ) fallers were compared to each other using one-way ANOVA. The threshold value for significance was determined as p-value < 0.05 .

A "fall" is defined as unintentionally coming down on the floor or to a lower level by whatever cause. "Underreporting" is defined as 
Zalmstra, occupational therapists; F. Steegh, district murse and $K$, Ruiter, social insurance expert. We also rhank W. Bak, rehabilitation specialist for his support, Jos Hamers, research assistant for his help in the analysis, A. Kester, statistician for his advice and Lilian Hesemans, secretary for her assistance in collecting data.

Financial Support

This study was supported by a grant from the Zorgonderzoek Nederland ( $Z O N$; fomerly the Praeventie Fonds).

\section{References}

1. Prudhom D, Grimley Evans J. Factors associated with falls in the clderly: a community study. Age Ageing 1981:10:141-6.

2. Blake AJ, Morgan K, Bendall MJ, et al. Falls by elderly people at home: prevalence and associated factors. Age Ageing 1988;17:365-72.

3. Tineri $M E$, Speehley $M$, Ginter $S F$. Risk factors for falls among elderly persons living in the community. N Eng I Med $1988 ; 319: 1701-7$.

4. Nevitt $M C$, Cummings SR, Kidd S, Black D. Risk factors for recurrent nonsyncopal falls. A prospective study. JAMA $1989 ; 261: 2663-8$.

5. Speechley $M$, Tineti $M E$. Falls and injuries in frail and vigorous community elderly persons. I Am Geriatr Soc 1991;39:46-52.

6. Cumbing RG, Klineberg RJ. Fall frequency and chancueristics and the risk of hip fractures. JAGS 1994;42:774-8.

7. Tineti ME. Prevention of falls and fall injuries in elderly persons: a reseatch agenda. Prev Med 1994:23:756-62.

8. Lach HW, Reed AT, Arfen CL, Miller JP, Paige GD, Birge S], Peck WA. Falls in the elderly: reliability of a classification systen.) Am Geriatr Soc 1991;39:197-202.

9. Morfith JM. Falls in old people at home: intriasic versus enviromental factors in causation. Public Health Journal of London, 1983:97:264-70.

10. Grafmans WC, Ooms ME, Hofstee HMA, Bezemer PD, Bonter LM. Falls in the elderly: a prospective study on risk factors and risk profiles. Am J Epidem 1996:143:1129-36.

11. Soomers-Tumings JMSJG, Crebolder HFJM, Bewsmans GHMI, Bal RM. Falls by the elderly. An exploratory study in generall practice. 
the percentage of elderly persons that reported having expenienced a fall in the follow-ap, which was not known to the GP. "Overreporting" is defined as the percentage of elderly persons that reported not having fallen during the follow-up, but who had fallen according to the GP.

\section{Results}

Ninety-two elderly subjects $(33$ percent) reported having fallen at least once during follow-up and half of them more than once. There were no significant differances between the mean ages of the fallers and the non-fallers $(p=0.7$ in one-way ANOVA $)$, but the people aged 80 years or over had significantly more falls than those under 80 years $(P<0.001$ in Chi-squate test). There were no significant differences in talls between men and women $(p>0.05$. Chi-square test).

Of the 92 elderly subjects that had fallen during follow-up, the GPs were informed about one or more falls conceming 18 persons and not informed about 74 persons (reporting: 20 percent and underreporting: 80 percent). The GPs reported a dall in 8 persons who according to their own statement not had fallen (overreporting: 4 percent).

During the inquiry the GPs reported a fall by 31 persons during follow-up, of whom 13 more than once. Injury occurred in 18 of them (58 percent); in nine of them seriously: six fractures, of which one hip fracture, one luxation of the hip, one tratimatic plexus injury of the $\mathrm{leg}$ and one distorsion of the cuff of both shoulder joints. Light injuries, such as contusions, abrasions and a wound needing suturing, were recorded in 14 patients. Especinlly women and persons of 80 years or over suftered injury: 13 out of 18 injured elderly subjects were 80 years or over and 17 of them were female.

Further examination as to the cause of a fall was done more often in the absence of injury than in its presence. Accorling to the GPs, there were noticeable consequences of a fall in five patients, all female: fear of falls in five, a mobility disorder in four. general deterioration and other symptoms in two persons.

Of the 92 elderly persons who had fallen, 43 reported in the telephone follow-up being injured due to a fall, of which 21 reported having been treated for it. In only the half of the 21 who were treated for an injury, did the GPs know about a fall In four persons with a fracture the GPs did not know that these fractures were caused by falls. And of those, who suffered injury that did not 
The general practitioner

need to be treated, the GPs were not aware of any single fall. The GPs reported injury in nine patients who did not mention it in the telephone inquiry; five of them were lost to follow-up.

In the 31 persons whose GPs were aware of falls, the GPs reported totally 47 causes, on average 1.5 cause a person. Gair problems and dizzness were reported ten times. Other causes that were mentioned were five times a stroke, four times stumbling. three times getting sick, twice a fall from stairs, and once poor wision. slippery floor, infection with fever, paroxysmal atrium fibrillation and bike accident. In seven of the 31 cases the cause was not known to the GPs.

Table 1 presents an overview of the physical and additional examination by the GP into the cause of a fall in 31 patients. In 12 patients they did not do any examination. Judgement of the haemodynamic situation, the state of consciousness, the cognitiwe status and the pattern of gait were most frequently carried out. Much less frequently other tests of mobility, such as the standing and trunk balance, the Romberg test, the senso-motoric

Table 1 Physical and additional examination into causes of the fall in 31 elderly persons. Nurmbers.

Blood pressure in sitting/lying position

Pulse qualities

Consciousness

Cognucive stanus

Gait pattern

Mood

Check of medication

Standing balance

ADL functions

Romberis

Laboratory tests

Home-safery check

Sensomotoric qualities of the feet 3

$x-$ ray

Trunk balance

Inspection of the feet 2

Blood pressure after one minute standing 1

Trendelenburg (one leg stance)

Tandem gait 1

Vision 0

Mo examination into causes 
Table 2 Patient managenent in 3 elderly who had fallen. Known to dhe Cr. Numbers.

Physiotherapy H

Concrete advice 11

Contast with fanily 8

Cull in communty aturse

7

Extra atention

Call in non professional aid 5

Consult specialist 4

Call in ramily care 3

Stop medication 2

Information about medication

Further examination

Home-safery advich

Change of management

Charge of medication

Table 3 Estimation of risk factors by the GPs in 170 elderly persons with an increased fall risk.

\begin{tabular}{|c|c|c|}
\hline Risk factor & Namber & Percentage \\
\hline Mobility disonder & $\| 15^{*}$ & 68 \\
\hline Dizuness & 65 & 38 \\
\hline Bad condition & 45 & 26 \\
\hline Multi-medication & 42 & 25 \\
\hline Getering wholl & 38 & 22 \\
\hline Depression & 30 & 18 \\
\hline Lomeliness & $29 *$ & 17 \\
\hline Psychopharmaceuticals & 27 & 16 \\
\hline Cognitive disorder & 23 & 14 \\
\hline Poor vision & 22 & 13 \\
\hline Hazardous dwelling & 16 & 9 \\
\hline Risky behaviour & 15 & 9 \\
\hline Orthostatio hypotension & 8 & 5 \\
\hline Ocher risk fuctors & 3 & 2 \\
\hline
\end{tabular}

* Significandy mote often than in persons with a low fall risk: peot05 
The general practitioner

examination of the feet, the Trendelenburg sign (one leg stance) and the tandem gait were performed.

In only six of 19 paticnts did the examination yield important information about the cause of the fall According to the GPs, in no single case did a check of the medication give additional information about the cause. Generally, the examination was not telated to the supposed cause of the fall.

Measures taken by the $G P_{s}$ with reference to a fall are presented in table 2. Here again there was no relationship between the management and the supposed cause of the fall. In 10 percent of the 31 patients who had fallen, the GPs did not give an explicit management.

From the answers on a 5 moint rating scale appeared that in 170 of the 303 participants ( 56 percent), about whom the GPs had filled in the questionnaine, the GPs subsequently determined the presence of an increased risk of falling. Table 3 presents an overview of the risk factors indicated by the GPs in these 170 elderly subjects. Risk factors which are present significantly more frequently in persons with an apparent increased fall risk according to their GPs, compared to persons with low risk, were loneliness, bad condition, mobility disorder and poor vision ( $p<0.05$ in the Chi-square test). Extrinsic risk factors, such as a hazardous dwelling and risky behaviour, played a minor role according to the GPs.

In the judgement of the GPs, 66 of the 92 subjects who had fallen during follow-up had an increased fall risk. Of the 190 persons, who had not fallen during follow-up, the GPs did not find an increased fall risk in 99 , but did indeed find so in 91 individuals.

\section{Discussion}

The GPs were informed about approximately 20 percent of the elderly who had reported a fall during the 36 -week follow-up. This percentage is in accordance to earlier studies $(1,9,10)$. Conversely, four percent of the elderly did report a fall to the GP, but not in the telephone follow-tup. Prestumably, this is a consequence of recall bias and loss to follow-up $(10,11)$. Only falls in which complaints that may or may not be consequences of injury occurred were reported to the GPs. Apparently, that is the only reason for the elderly to consult their GP in the event of a fall.

According to the GPS, fall-related injuries occur mainly in women over 80 years, which may also be determined by stratification. In case of injuries due to a fall, the GPs performed less examination into the possible cause of the fall than when no injury had 
occurred. This suggests, that GPs primarily difect their attention to the injury. It was remarkable, that the $\mathrm{GP}^{\mathrm{s}}$ were not aware of a fall in four elderly subjects with fractures due to falls.

According to the GPs, the causes of falls are mostly gait problems, dizziness, stumbling, or becoming unwell. Their examination into the cause of a fall was generally not goal-directed and also ylelded little additional information. It was salient, that exitmination into the mobility disorders was mainly focused on the gait pattern and much less on balance, while balance too, is considered as an important risk factor for falls (13).

In elderly subjects with an increased fall risk, mobinty disorders were reported by the $G P_{s}$, indeed as the most important risk factor for falls, which is in accordance with the opinion of many authors $(3,4,6,7,13-16)$. Measures subsequent to a fall were not always taken and the nature of the measures taken was not determined by the cause of the fall. Medication was little checked, allhougl use of medication is among the main risk factors for falls $(3,4,6)$. In persons with an evidently increased fall risk, the GP considered especially the risk factors loncliness, bad condition, mobility disorder and poor vision as responsible.

The results of this study were obtained from two data collections: data from the GP inquiries concerning 303 slderly persons, who started the follow-up study, and data from 282 elderly that completed follow-up. Among the 21 persons that were lost during follow-up, there were five elderly subjects, which had according to the GPs one or more falls. These have been included into the regular counts of the outcomes, but have been excluded in the comparison of the outcomes of the two data collections to determine the extent of reporting.

The study population is formed by random samples from the population responding to a mal questionnaire stratified on age and gender. As a consequence only significant differences in incidence of falls were found in the elderly of 80 years and ower were found, but no significant differences in sex and age, as mentioned in several other studies, were observed $(1-4)$.

The four participating practices are characterized by their organization in primary health care teams and connection to the Registration Network Family Practices: this makes them distinctive from the "average" general practico. Howewer, they do not differ from other Dutch practices regarding the percentage of registered elderly individuals of 70 years or over. In addition, there are no reasons to suppose that the GPs differentiate themselves in their management from that which is customary in general practice in 
The general

practitioner

regard to falls in the elderly. It may be assumed that the quality of the registration by the participating GPs is at a sufficient level. because of their parcipation in the Registration Network Family Practices are subject to procedures of quality assurance (12).

The GPs filled in the questionnaires after the follow-up study, which of course may have influenced their estimation of the fall risk. However, its direction is not clear. Therefore, the answer to the third study question is explorative in nature.

Regarding falls in the elderly, the GP is dealing with an "iceberg" phenomenon: he is confronted with only approximately 20 percent of all falls in the elderly and almost exclusively when there are complaints or injury as consequences of, or in reference to, a fall. He focuses primarily on the diagnosis and treatment of complaines and injury and scarcely on the background of the causes of the fall. The GP's task is mainly in the area of secondary prevention: the conscientious and timely tracing of the underlying causes of and risk factors for falls in the elderly and subsequently trying to eliminate these causes.

From recent intervention studies it is known that improvement of the mobility and muscle strength may lead to a decrease of the number of falls $(17-19)$. Other measures belonging to the area of the secondary prevention are reduction of injury due to a fall, such as teaching patients how to get up and the application of absorbing floor strfaces and hip protectors. However, little is known about the effects of these measures in community-dwelling elderly.

\section{Acknowledgement}

We thank the participating general practioners: $G$. Castermans, Th. Govaert, R. Helmers, L. Huynen, R. Leclercq, M. Maskant, A. Muysken-du Saar. M. van Nunen, J. Paas, M. Peeters, G.J. van Schendel $(\dagger)$, B. Schilte, M. van Venrooy, F. Vissers and P. Voorhoeve.

The study "Falls in the elderly: incidence of risk factors for and consequences of falls in the elderly", from which this article originated, was financially supported by ZorgOnderzoek Nederland ( $Z O N$ ), formerly the Praeventiefonds (Number of the project: 28 $2365)$. 


\section{References}

1. Sooner-Tuthes JMSIG, Crebolder HFM, Benmans CHM, Bal RM. Het vallen van ouderen. Een exploratieve studie in de huisartspraktijk. Huisarts Wet 1992;35(2):57-60.

2. Wild D, Nyak US, lsades B. How dangerous are falls in old people at home? BMJ 1981:282:266-8.

3. O'Loughlim JL, Robiatle $Y$, Buivin J-F, Sitissa S. Incidence of and riskfactors for falls and injurious falls among the communitydwelling elderly. Am J Epid 1993;137(3):342-54.

4. Tineti ME, speechley M. Cinter SF. Risk factors for falls among elderly persons liwing in the community. N Engl J Med $1988 ; 319(26): 1701-7$.

5. Stalewhoef PA, Fiolet JFBM, Crebolder HFJM. Vallen van ouderen: een valkuil? Huisarts Wet 1997;40(4):

6. Stalenhoef PA, Crebolder HFJM, Katomentus JA, wanderhorst FGEM. Incidence, risk factors and consequences of falls among elderly subjects living in the community: a criteria-based analysis. Submitted september 1996.

7. Hale WA. Predicting elderly patients' mobility usung fall history and physician assesment. Fam Med 1990:22:383-7.

8. Hale WA, Delaney M, McGaghie HC. Characteristics and predicrors of falls in elderly patients. J Fam Pract 1992;34:577-81.

9. Graham H), Firth J. Home accidents in older people: role of primary health care team. BMJ 1992;305:30-2.

10. Hale WA, Delaney $M J$, Cable $T$. Accuracy of patient recall and chart documentation of falls. J Am Board Fam Pract 1993;6:239-42. 11. Cummings SR, Nevitr MC, Kidd S. Forgetting falls. The limited accuracy of recall of falls in the elderly. I Am Geriatr Soc $1988 ; 36: 613-6$.

12. Metsewakers JFM. Unlocking pationes records in general practice for research, mediacla education and quality assurance: the Registartion Network Family Practices. Ansterdam: Thesis, 1994.

13. Tineti ME. Performance-oriented assessment of mobility problems in elderly patient. I Am Geriatr Soc 1986:34:119-26.

14. Campbell AJ, Borrie MJ, Spears GF, al. Circumstances and consequences of falls experienced by a community population 70 years and over during a prospective study. Age Ageing $1990 ; 19: 136-41$.

15. Camplell AJ, Reinken J, Allan BC, Martinez CS. Falls in old age: a study of frequency and related clinical factors. Age Agcing $1981 ; 10: 264-70$.

16. Newitt $M C$, Cummings SR, Kidd $S$, Black D. Risk factors for recurrent nonsyncopal falls. A prospective study. JAMA 
$1989 ; 261: 2663-8$

The general practitioner
17. Tineti ME, Baker DI, MAvay $G$, et al. A multiactorial interwention to reduce the risk of falling among elderly people living in the communty. N Engl J Med 1994:331:821-7.

18. Fiatarome MA, O'Neill EF, Doyle Ryan N, et al. Exercise training and nutritional supplementation for physical frally in very elderly people. New Engl J Med 1994:330:1769-75.

19. Prowince ME, Hadley EC, Hombrook MC, et al. The effects of exercise on falls in elderly patients: a preplanned meta-analysis of the FICSIT trials. JAMA 1995;273:1341-7. 
CHAPTER 12

General discussion

163 


\section{Introduction}

General discussion
This chapter presents and comments on the main results of this study on falls in community-dwelling elderly with respect to the four aims: 1. the occurrence and incidence; 2 . the determinants and risk factors; 3 . the health consequences and 4 , the relation to genetal practice. The tmethodological strengths and limitations are discussed. Subsequently, the implications for general practice and proposals for preventive activities, are presented. And finally, suggestions for further research and training conclude this chapter.

\section{Main results}

\section{Occurrence and incidence of folls and fall-related injuries}

In the literature review (Chapter 4) preference based on criteria for methodological quality, was given to four prospective studies, which enabled us to make an overall picture of incidence of falls and injuries (1-4). Yearly incidences of "ever falls" from these four range from 32 to 57 percent, depending on population characteristics and selection procedures $(5,6)$. Yearly incidences of recurrent falls, however, are provided only in half of the 14 studies included and range from 13 to 42 percent $(1-4,9,11,12)$. Similarily, not all studies provided incidences of injuries. In the 14 studies selected major injury ranged from 0.5 to 8.9 percent and minor injuries from 37 to 56 percent of all falls $(1-4,12-14)$

Chapters 6,7 and 8 contain outcomes on incidence of falls and injuries from the community surveys and the prospective cohort study. Table 1 presents a comparison of incidences of falls from the review with those from our own sudies. Comparison of data from the wo community surveys with the same design and methodology results in lower incidences in survey 1 , due to inclusion of participants from 55 years of age or older.

Data from the prospective study (Chapter 8) were obtained from a 36-week follow-up period. Conversion to a yearly incidence by a factor of 1.4 results in higher rates for falls and recurrent falls but lower for injuries, compared to incidences from the two community surveys. However, in the review of 14 selected studies surprisingly there were no evident differences in yearly incidences between retrospective and prospective studies, which illustrates the relativity of the weight of recall bias in retrospective studies $(7,8)$. Comparison of injury rates from the four preferred studies yields relevant differences of minor and major injuries. The incidence of major injuries from Tinetti's study are higher due to a higher age 
Table 1 Incidence of ewer falls $(21$ fall), recurrent talls ( 22 falls) and iajuries due to fals fron 4 preterted studies salected from a criteria-based analysis (1997) and from own studies (percentases)

\begin{tabular}{|c|c|c|c|c|c|c|}
\hline Selected studies & $\mathbb{I} \geq \mathbb{1}$ & $1 \geq 2 \star$ & $\begin{array}{l}\text { Minor } \\
\text { injury }\end{array}$ & $\begin{array}{l}\text { Major * } \\
\text { injury }\end{array}$ & Fractures & Hip fractures \\
\hline $\begin{array}{l}\text { Tinetti et al. (1) } \\
275 \text { years; } N=336)\end{array}$ & 32 & 17 & sxp & 12.5 & 6.3 & 1.5 \\
\hline $\begin{array}{l}\text { Nevite et al. }(2) \\
(260 \text { years; } N=325)\end{array}$ & 57 & 31 & 56 & 4.5 & 3.1 & 0.2 \\
\hline $\begin{array}{l}\text { Campbell et al. }(3) \\
\text { e70 years; } N=761 \text { ) }\end{array}$ & 35 & 16 & $\begin{array}{l}37 m^{*} \\
41 w^{*}\end{array}$ & $\begin{array}{l}4.1 \mathrm{~m}^{*} \\
12.5 \mathrm{w}^{*}\end{array}$ & $\begin{array}{r}2 \\
\times \quad 4\end{array}$ & $\begin{array}{l}1.1 \\
1.5\end{array}$ \\
\hline $\begin{array}{l}\text { O'Loughlin et al. (4) } \\
\text { (265 years; } N=409\end{array}$ & $\begin{array}{l}29 \mathrm{~m} \\
34 \mathrm{w}\end{array}$ & $\begin{array}{l}12 \mathrm{~m} \\
14 \mathrm{w}\end{array}$ & 43 & 4.5 & 2.5 & 1.5 \\
\hline
\end{tabular}

\section{Stalenhoef et al.}

Survey 1

(255 years; $\mathbb{N}=405$ )

Sinvey 2

(270 years; $N=1660)$

Prospective study**

(270 years; $N=287$ )

$\begin{array}{llllll}25 & 13 & 38 & 5.8 & 2.6 & \text { np } \\ 44 & 19 & 20 & 4.7 & 2.7 & 0.6 \\ 46 & 22 & 35 & 5.7 & 2.8 & 1.4\end{array}$

\section{* $\mathbb{2} \geq 1$ \\ $1 \geq 2$ \\ Antmos injiury \\ Major imjury \\ Fractures \\ Ming tractures \\ เกา \\ w

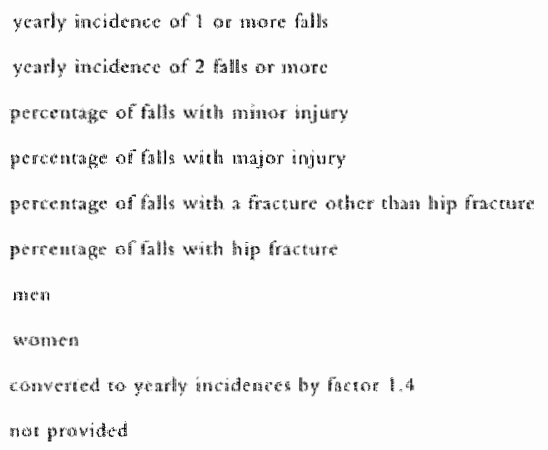

category of the population (75 years or over) (1).

\section{Determinants and risk factors}

In table 2 the significance of the twelve main determinants and risk factors identified in the four preferred studies from the literature review is compared with the studies presented here. Not all dat from our own studies are comparable, because study methods are 


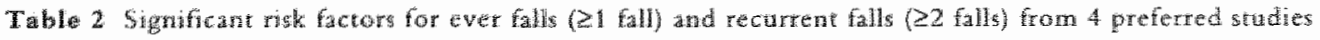
nelected in a crieriaboged analysis (1997) and from own muties

\begin{tabular}{|c|c|c|c|c|c|c|c|c|c|c|c|c|}
\hline Gelected studies & 1 & 2 & 3 & 4 & 5 & 6 & 7 & 8 & 9 & 10 & 11 & 42 \\
\hline Tinetriog a (1) & - & - & - & + & - & $\cdots$ & - & - & - & + & + & + \\
\hline Vevet co al. (2) & - & + & - & - & - & - & + & - & - & $\stackrel{4}{t}$ & + & - \\
\hline Gamploull/w (3) & $=$ & $\infty$ & - & + & - & + & - & + & + & - & + & - \\
\hline O'loughlin et al. $(4)$ & - & $\propto$ & 4 & - & - & + & - & - & - & - & + & - \\
\hline
\end{tabular}

\section{Stalenhofet al.}

5 thway

Surtay 2

Proptpecrive study

\begin{tabular}{|c|c|c|}
\hline th & sognifficant & 1 sociambengegraplic variabes \\
\hline- & nest thentiourane & 2 hestedar of previous falls \\
\hline$i w i$ & 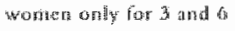 & 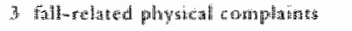 \\
\hline * & nor applicible. & 4. the ol zelatives/hyporacs \\
\hline \multirow[t]{8}{*}{$\operatorname{lig}$} & nat pronted & 5. the of antiodepressuns \\
\hline & & 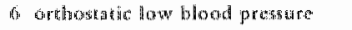 \\
\hline & & 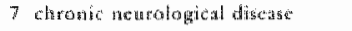 \\
\hline & & 8 increased body sway \\
\hline & & 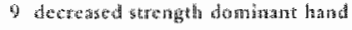 \\
\hline & & 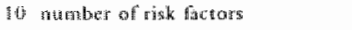 \\
\hline & & It lazabilicy disudors \\
\hline & & 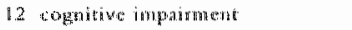 \\
\hline
\end{tabular}

\section{General discussion}

used and previous falls belong to the outcome, and not to the independent variables, unlike the prospective study. Mobility disorders bellong to the most constant risk factors for falls, both in the review and in our own studies $(1-4,9-17)$. The use of sedatives and hypnoxics are considered important risk factors by two authors only; moreover they do not play a relewant role in our study $(1,3)$. It is noticeable in our prospective study, that age and gender do not play a significant role as independent determinants of falls, in contrast to what is found in other studies $(7,15-17)$. This may be due to suppression by other stronger variables with an age and gender dependence.

Survey 2 and the prospective cohort study both yielded risk models, consisting of variables showing significance in logistic analyses. However, the risk models are not comparable, but can be considered as complementary. To determine which risk model is 
preferable and whether they are interchangeable, equivalent or complemantary, further research is demanded. The risk model derived from the community survey, a logistic model with two variants, consists of data from the regular medical history and the patient's record, wich can be supplemented by data from the MG SIP68. The logistic risk models from the prospective study comprise, in addition to age, gender and fall history, variables derived from the performance tests. The complementarity of both types of models lies in the variables, relared to mobility impaiment, which show strong associacions with ever falls and recurrent falls. The sex differences of many risk factors may be accounted for by the important differences in muscle strength between men and women. This hypothesis, howewer, needs further investigation: the determination if and to what extent sex-related decrease of muscle strength, measured by hand dynamomerty, is a causing factor among risk factors related to mobility, particularly balance and gait (18).

In a supplementary study of survey 2 the prevalence and significance of gat disorders in relation to falls were investigated (Chapter 10). About 49 percent of the respondents $(\mathbb{N}=1648)$ reported to have a gait problem. The main determinants of gait disorders appeared to be age of 80 years or over, multiple falls or near-falls in the previous year, a moderate to bad perceived health status and low scores on physical health parameters, daily functioning and quality of life. Apart from the locomotion system a noticeable proportion of the reported causes of gait disorders relate to the respiratory and the cardiovascular systems, the central nervous system and general impairment.

\section{Heall comsquences other than dired injuries}

Health consequences of falls other than direct injuries concen fallrelated mortality, included indirect mortality, the impact of talls on functioning and mobility, and psychosocial consequences. Not all selected studies in the literature review provided data on these health consequences. The studies which did, had a prospective design and labelled functioning as a risk factor and not as a consequence of falls $(1,3,4,19)$. Only Nevitt et al, mentioned "activity limitation due to fall" as a consequence (2). Generally, due to the absence of a time sequence it is difficult to trace from retrospective studies whether falls directy cause a decline of functioning or only serve as a marker fot them (21). Associations found are rather explained by plausibility than by evidence. 
prospective out of 14 studies selected and vary from 2 to 25 percent during one-year follow-up, depending on methodology and population $(1,2,4,19)$. However, fall-related mortality was not investigated in our studies.

In community survey 1 (Chapter 6) the impact of gait problems and falls on functioning was one of the study objectives. The outcome was that falls, contrary to gait problems and mental indicators, only have a minor impact on functioning, measured by mobility range and social activities. Falls are apparently to be regarded as "a final stage", having no specific influence on functioning. Due to the retrospective design this conclusion is indicative and based on climical plausibility.

In the mail questionnaire in community survey 2 (Chapter 7 ) fear of falling is reported by 48 percent of the respondents. Again due to the retrospective design, no conclusion can be drawn whether it concerns cause or effect of falls. Probably it is a matter of circularity of causes and consequences.

\section{Relation to genteral pracice}

In the reviewed studies (Chapter 4) the task and role of the GP. with regard to falls in the elderly, is not even mentioned (22). As part of the prospective cohort study we nnvestigated the involvement of the 16 GPs of the participants of the follow-up study (Chapter 11). Overall, 20 percent of all, mainly injurious, falls are reported to the GP, which is congruent with data from literature (23-25).

In their management, GPs primarily direct their attention to the detection and treatment of injury, and much less to fall-related risk factors and background variables. It seems that many $G P_{s}$ are used to a diagnostic approach, in which an evidence base is missing. Mostly, risk factors are not systematically assessed and even if they are, the assessment is quite incomplete. The physical examination in relation to falls often did not appear to be targeted on the cause of the fall and generally yielded little information. If further physical examination was done, it was directed mainly to gait problems and far less to balance disturbances. Blood pressure is usually measured, but seldom in upright position in order to detect orthostatic low blood pressure. Measures, taken as a consequence of a fall, mainly concern referral to other professional or nonprofessional care providers, and only in a minority of them concern the assessment and change of risk factors. In summary, the management of the patient with a fall by the GP is fragmentary and not very rational, and does not seem to be based 
on kmowledge of incidence and risk factors, a primary condition for a preventive approach.

\section{Methodologicall aspects}

Methodologically, the study for this thesis consists of three categories:

1. A criteria-based analysis of the literature (Chapter 4):

2. Retrospective studies: two community surveys (Chapters 6 and 7), a cross-sectional study on gait problems (Chapter 10) and a cross-sectional study among GPs (Chapter 11):

3. Prospective studies: a cohort srudy (Chapter 8) and an exaluation of a checklist on indoor fall risk (Chapters 9).

In this section methodological strengths and limitarions of design and methods will be discussed.

\section{Strengths}

- The research questions were investigated by varions scudy methods: a criteria-based literature review, retrospective and a prospective studies, which provide possibilities to compare data (Chapter 5).

- The literature review (Chapter 4) was based on wo sets of criteria: three criteria for inclusion and ten criteria for quality (26). This offered the advantage of comparing data from the studies included among themselves and with our own studies in an accurate and systematic way (27). In addition, it yielded a rather complete picture of the many aspects of falls in community-living elderly, which was then used as a guide for the design of the baseline assessment of our follow-up study.

- The study has been conducted in two different populations at risk: a sample from a population of 655 persons of 55 years or over from one general practice (population A; survey 1: Chapter 6) and a population of all 2744 persons of 70 years or over registered in four general practices (population $B$; survey 2 : Chapter 7 and the prospecrive study: Chapter 8). The similar design and methods in community survey 1 and 2 , provided opportumities to compare data and draw conclusions. (See figure $\mathbb{1}$, Chapter 5)

- The participating general practices are connected to the Registration Network Family Practices. The adwantages ate adequate age and gender registers, uniform way of registration and submission to a quality assurance system (28).

- Mail surveys offer the advantages to reach many persons and to get answers on many questions in a short time against relatively low 
General discussion coste (Chapters $6,7,10$ and 11 ).

- The participants were recruiced from population-based registers, which means well-defined population denominators in analyses. In addition, data from the investigation of the GPs involvement with falls in the elderly, regarding diagnosis, treatment and prevention, could be linked to data from the retrospective and prospective studies (Chapter 11).

- The follow-up study among a stratified sample out of the respondents of the mail survey offers some advantages. Outcomes of the mail survey, such as data on falls in the previous year, could be used as independent variables in the follow-up study and data from both studies could be compared or linked, which provides insight into the consistency of data. Analysis of data from the mail survey and the follow-up study yielded two complementary logistic risk models for the prediction of falls, one model consisting of variables from medical history and one mainly from performance tests. (Chapters 7 and 8).

- Loss to follow-up in the prospective study was limited: data from 287 out of the 311 persons participating inirially (92 percent) were available for analysis (Chapter 8 ).

\section{Limitations}

- The non-response in the surveys 1 and 2 is 38 and 40 percent, respectively, with higher responses in the younger age categories. Because of an age dependence of falls and a number of risk factors. observed outcomes are lower than expected. Reasons for nonresponse were not investigated, in considetation of privacy (Chapters 6 and 7 ).

- Because of the absence of validated and evidence-based protocols. feasible for generall practice, we had to use a non-validated baseline assessment protocol on fall risk, developed in a consensus procedure (Chapter 8).

- The consensus procedure was carried out strictly according to the principles and rules for nominal group process consensus procedures (29). Based on the majority of votes, the decision was taken to measure blood pressures only in sitting and lying positions, and not, as usual and as recommended in literature to detect orthostatic hypotension, in upright position. As a consequence of this decision, no data of orthostatic blood pressure as risk factors for falls were available (Chapter 8 ).

- The duration of the follow-up period was 36 weeks, shorter than one year, which is usual in comparable studies. A longer exposure period was not possible for reasons of budget. In addition. calculated guess of the 36 weeks follow-up time did not reveal any 
disadvantages, except for a limited number of reported falls in the follow-up period. Therefore in the andysis a differentiation of frequency of falls in the recurrent fall group was not possible (Chapter 8).

- The interobserver test of the checklist on indoor fall risk was conducted on a small scale, i.e. in only ten random cases among two observers, resulting in a Cohen's kappa with a moderate outcome: 0.66 (Chapter 9).

- Athough the evaluation of the home-safety checklist as an instrument for screening has appeared to be negative, it might be useful if intrinsic risk factors are also taken into account simultaneously. However, we were not able to evalluate the walue of this checklist in relation to intrinsic risk factors on an individual level. This would need a more extensive and datailed study (Chaprer 9).

- The checklist on indoor falls was only applied in the own dwelling. No conclusions can be drawn about its value in other indoor enviromments (Chapter 9).

- The GPs filled in the questionaires after the follow-up study. This might have been influenced their estimation of the tall risk of the participating persons, although the direction of this influence is not clear (Chapter 11).

\section{Implications for general practice}

Falls in the elderly are multifactorial events and this makes it difficult to assess risk factors separately and to choose elements for prevention. From an increasing number of randomized trials that have shown evidence for the effectiviness of interventions to prevent falls and subsequent injury in oldet people, there is a strong conviction that preqention is beneficial (30). But, still, full agreement is lacking about the identification of optimal prevention strategies (31). In general practice, prevention has to be done by the $G P$ in a primary care team, mainly on a secondary and tertiary level (32). This means a constant awareness of and alertness for potentiall fall risk and risk factors for falls by the GP, an altitude to assess determinants and risk factors ath a view to prevention and preparedness to cooperate with other primary health care providers to develop and evaluate preventive activities. The Dutch health care system offers the GP the conditions for health promotion and anticipatory care through regular consultation and contintous tare. The GPS ${ }^{0}$ knowledge of patients" medical history, lifestyle, risk profile, health perceptions and personal circumstances gives them 
opportumities to integrate aspects of health promotion and prevention into their daly care (33).

Our studies offer detalled insight into the incidence of falls and injuries and prowide tools for the assessment of risk factors.

Ceneral discussion
Without great efforts, each GP is able and has the capacity to assess these risk factors. The medical registers provide data, which are sufficient for a first identification of most clderly persons at risk. In a subsequent step, it seems feasible to add other variables, such as results of performance tests on balance and gait, to obtain more detailed information. Clinical evaluation of this approach is recommendable.

Preventive home wisits seem to be useful in improving the health status of communtty-dwelling elderly people only if restricted to the elderly with a poor health status (34). Home visits to assess risk factors for indoor falls using a checklist should be done only in relation to the assessment of intrinsic risk factors for falls and not be used as a separate general method for screening (chapter 9). However, in combination with an assessment of intrinsic risk factors it might be beneficial for the individual, because information about the presence and the location of potential risk factors in the dwelling can be integrated into a personal prevention programme.

An approach for assessment and classification of fall risk, based on outcomes of our studies, could be done on five successive levells:

Level 1: Identification:

The first identification of community-dwelling elderly at risk for falling by use of a risk model based on medical history and/or patient's record.

Level 2: Confirmation

After a first identification of the elderly at risk, the identification can be confirmed using a risk model based on performance tests.

Level 3: Classification

The elderly person at risk and assessed by the two risk models, and thus having one of more risk factors for falls, can be classified into a four-axis classification model:

Axis I Physical condition

Axis II Mental condition

Axis III Functioning and mobility

Axis IV Environmental hazards in the dwelling

Ideally, each axis can be scored on a quantitative rating scale, resulting in a fall risk profile.

Level 4: Codifiation 
In a fourth step the elderly person at risk for falling and classified in the four-axis system should be codified scording to the $1 C P C$ system (35). This means that the problem criteria correspond to the criteria used in the problem-oriented approach of the $1 \mathrm{CPC}(36)$. However, at present a specific code for falling is missing. For the time being, the $\mathbb{L} 28$ code, indicating "disability and mobility impaiment" can be used, until international. consemus is reached on more detailed proposals.

Level 5: Determination of preventive activities

The last step is to determine which preventive activities are needed in a particular person or parricular group of persons based on the classified risk factors.

One of the essentials of our study is the finding that falls are markers for frailty and impaiment and therefore deserve special attention from the GP. One-time fallers have a different risk profile from recurrent fallers. Every first fall should be considered as potentially the first fall in a series, until accurate assessment by medical history and physical examination reveals that no important risk factors for falls are present. The recurrent fallers, however, represent a separate category and require for a different approach. They have to be considered as belonging to potentally high risk group, and need to be speciall subjects for anticipatory and preventive care.

Evidence-based preventive strategies should be developed and evaluated, based on a number of criteria. The first criterion is the identification and scoring of a person into a classification model, which provides a characteristic of a person at risk. The second criterion is the estimation of the presence of preventable risk factors. If no preventable risk factors are present, no preventive activities should be conducted. The third criterion are the results and validity of preventive activities in general practice. And finally. the fourth criterion is the feasibility of preventive activitias in general practice.

\section{Further research and training}

Four general recommendations for further research can be made. Firstly, evaluation studies on the application of prediction models in general practice are recommended. In this regard, sex-differences of several variables, particularly mobility tests, need further exploration. 
General discussion and from assesment procedures needs a closer prospective evaluation: are the models to be used separately or only complementarily? And if separately: which model is preperable?

Thirdly, the identification of the elderly at risk for talling by use of risk models may be beneficial for the individual patient with regard to secondary and tertiary prevention, if integrated in every day care. However, regarding the development of preventive programmes in primary care, it seems rational to reach consensus first on the benefits of fall preventive activities. In addition, an analysis of costs against returns of fall prevention programmes in primary care is needed. If, subsequently, agreement about the benefits of fall prevention in primary care is reached, a furthez question has to be answered concerning "the prevention paradox" (37): are preventive activities to be addressed only to elderly people at risk for falling (secondary and tertiary prevention), or, taking the high incidence of falls into account, to all elderly people (primary prevention)?

Finally, intervention studies in general practice have to provide answers on questions of feasibility and validity of preventive activities in general practice. Criteria for fall risk have to be developed. Cut-off points and validity of a fall risk assessment protocol have to be determined in follow-up studies. Outcome criteria for fall prevention in general practice have to be developed. Because of the importance of the problem and the impact of falls on daily living. falls in the elderly deserve attention in the undergraduate and postgraduate curriculum, as well in the continuous medical education of the GP. A first step is awareness and alertness concerning this phetiomenon: falls may be a signal of disease, imparment or deterioration. A second step is the actual traning of assesmemt procedures to be integrated into the physical and mental examination of all elderly persons at risk. And finally, the implementation of a preventive approach in primary care entails the teaching of knowledge and understanding of the incidence, determinants and health consequences of falls in communitydwelling elderly.

Our findings, based on data from community-dwelling elderly people, contribute to the development of criteria for an evidencebased identification of the community-dwelling elderly at risk for falling, both for daily care and for prevention. 


\section{References}

1. Tineti ME, Speedley $M$, Ginter $S F$. Risk factors for falls among elderly persons living in the community. N Engl J Med $1988 ; 319: 1701-7$.

2. Nevitt MC, Gummings $S R$, Kidd $S$, Black D. Risk factors for recurrent nonsyncopal falls: a prospective study. JMMA $1989 ; 261: 2663-8$.

3. Camplell AJ, Borrie MJ, Spears OF, et al. Circumstances and consequences of fills experienced by a community population 70 years and over during a prospective study. Age Ageing $1990 ; 19: 136-41$.

4. O'Lomghlin $/ L$, Robitalle $Y$, Boinin $J-F$, Susst S. Incidence of and risk factors for falls and injurious falls among the communitydwelling elderly. Am J Epidemiol 1993;137:342-54.

5. Sithi-amom $C$, Poshyarhinda $V$. Bias. The Lancet 1993;342:2868.

6. Asch DA, Jedrziewski MK, Christakis NA. Response rates to mail surveys published in medical journals. J Clin Epidemiol $1997 ; 50: 1129-36$.

7. Cammings SR, Nevit MC, Kidd S. Forgetting falls. The Jimited accuracy of recall of falls in the elderly. JAGS 1988;36:613-16.

8. Hale WA, Delamey MJ. Cable Th. Accuracy of patient recall and chart documentation of falls. J Am Board Fam Iract 1993;6 $: 239-42$.

9. Pradham D, Grimley Evans J. Factors associated with falls in the elderly: a community study. Age Ageing $1981 ; 10: 141-6$.

10. Blake AJ, Morgan K, Bendall MJ, et al. Falls by elderly people at home: prevalence and associated factors. Age Ageing 1988;17:36572 .

11. Clark RD, Lord SR, Webster IW. Clinical parameters associated with falls in an elderly population. Gerontology $1993,39: 117-53$.

12. Hale WA, Delaney MJ, Mc Gaghic WC. Characteristics and predictors of falls in elderly patients. I Fam Pract 1992:34:577-81.

13. Dothmon $J H$, Andrews $K$. Prevallence, chardeteristics and factors associated with falls anong elderly living at home. Aging $1991 ; 3: 219-28$.

14. Lord SR, Ward JA, Willians Ph, Anstey KJ. An epidemiological study of falls in older community-dwelling women: the Randwick falls and fractures study. Aus J Publ Health 1993;17:240-5.

15. Cwikel J. Falls among elderly people living at home: nedical and social factors in a national sample. Israel I Med Sci $1992 ; 28: 446-53$.

16. Yasumura $S$, Haga $H$, Nagai $H$, Suzuki $T$, Amano $H$, Shibala $H$. 


\section{General discussion}

Rate of falls and the correlates among elderly people living in an urban community in Japan. Age Ageing 1994:23:323-7.

17. Campbell AJ, Spears GF, Borrie MJ. Examination by logistic regression modelling of the variables which increase the relative risk of elderly women compared to elderly men. J Clin Epidemiol 1990:43:1415-20.

18. Judge JO, Whipple RH, Wolfom LI. Effects of resistive and balance exercises on isokinetic strength in older persons. JAGS $1994: 42(9): 937-46$

19. Wild D, Nayak USL. How dangerous are falls in old people at home? Br Med J 1981:282:266-8.

20. Gradmans WC, Oons ME, Hofstee HMA, Bezemer PD, Bouter $L M$, Lips $P$. Falls in the elderly: a prospective study of risk factors and risk profiles. Am J Epidemiol 1996;143:1129-36.

21. Flescher RH, Flether SW, Wagner EH. Clinical epidemiology. Baltimore, USA: Willimas \& Wilkins, 1988.

22. Stalenhaef PA, Crebolder HFMM, Knomerus JA, wan der Horst FGEM. Incidence, risk factors and consequences of falls among elderly subjects living in the community. A criteria-based analysis. Eur J Publ Health 1997;7:328-34.

23. Soomers-Turlings JMSJG, Crebolder HFJM, Bewswans GHMT, Bal RM. Het vallen van ouderen. Een exploratieve studic in de huisaartspraktijk (Falls by the elderly. An exploratory study in general practice). Huisarts Wet 1992;35:57-60.

24. Graham HJ, Finth $J$. Home accidents in older people: role of primary health care team. BMI 1992;305:30-2.

25. Hale WA, Delaney MI, Cable $T$. Accuracy of patient recall and chart documentation of falls. J Am Board Fam Pract 1993:6:239-42. 26. Sacket $D L$, Haynes $R B$, Tugwell P. Clinical epidemiology. A basic science for clinical medicine. Boston/Toronto; Little, Brown and Company.

27. Bourer LM, Van Dongen MCJM. Epidemiologisch onderzoek; opzet en interpretatie (3e druk) (Epidemiological research: design and interpretation-3rd ed.). Houten/Diegem; Bohn Stafleu Van Loghum, 1995.

28. Metsanakews JFM, Höppener $P$, Knotwerus JA, Kodeen RJ. Limonard ChBG. The Registration Netwark Family Practices: a computerized health information system in the Netherlands. Bri Med J Pract 1992:42:102-6.

29. Fink A, Kosecaff J, Chassin M, Brook RH. Consensus methods: characteristics and guideline for use. Am J Publ Health 1984;74:979-83. 
subsequent injury in older people. Quality in Health Care $1996: 5: 243-9$.

31. Timetti ME. Prevention of falls and fall injuries in elderly persons: a research agenda. Prewent Med 1994:23:756-62.

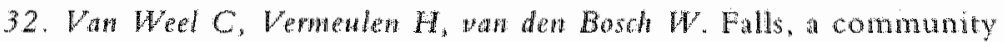
care perspective. The Lancet 1995;345:1549-51.

33. Crebolder HFM, wan der Hors FG. Anticipatory care and the role of Dutch general practice in health promotion. A critical reflection. Patient Educ Couns 1996:28:51-5.

34. Van Rossun HJL. Effects of preventive home visits to the elderly. Thesis, Masticht University: Datawyse/University Press. 1993

35. Lamberts $H$, Food $M$ feds.j. ICPC International Classification of Primary Care Oxford: Oxford University Press, 1987.

36. Classification Commitee of WONCA. ICHPPC-2 defined. Inclusion criteria for the use of the rubrics of the Intermational Classification of Health Problems in Primary Care. Oxford: Oxford University Press, 1983.

37. Cunning-Schepers LJ. Dwalingen in de metbodologic. V. De preventieparadox: weinigen met hoog risico versus wellen met matig risico (Deviations in methodology. $V$. The prevention paradox: few with high risk versus many wh moderate risk). Ned Tijdsch Geneeskd $1998 ; 142(33): 1870-3$. 

SUMMARY 


\section{Sum mary}

This thesis deals with falls in the community-dwelling elderly from the point of view of the general practitioner (GP). Falls in the elderly are one of the major health problems in health care. They ate characterized by a high incidence, multiple contributing risk factors and important post-fall morbidity and, manly indireculy, mortality.

The GP faces this problem very often, in different circumstances and conditions. A fall, particularly a first fall, has to be considered as a potential signal of a disease, inability or the beginning of deterioriation. Therefore, every fall requires an accurate evaluation of its cause and contributing risk factors. Considering the high incidence of fall-related injuries, particularly hip fractures, both secondary and tertiary prevention in primary health care need to be developed. Another important aspect for the $\mathrm{GP}$ concerns the management of the patient with a fall, regarding diagnostic, therapeutic and preventive measures.

Chapter 1 is a general introduction to this primary care-based study. It gives our definition of a fall, a description of fall mechanisms, the aims and related study questions, and the structure of the thesis.

The main objectives of this study consist of four areas. Each area is covered by one or more study questions.

\section{Aim $I$. Occurrence and incinence}

- Question 1: What is the incidence of falls?

Ain II. Determinants and risk factors

- Question 2: What are the determinants of and risk factors for falls?

- Question 3: What is the relationship between intrinsic (personrelated), extrinsic (cnvironment-related) and activity-related risk factors for falls?

- Question 4: What are the characteristics of elderly people with one-time, recurrent and no falls?

Aint III. Heallh consequences

- Question 5: What are the health consequences and the impact on daily functioning?

Aint IV. Relation to general practice

Question 6: What is the involvement of the general practioner with falls and fallers?

- Question 7: What are the elements of a fall risk assessment in general practice?

- Question 8: Which recommendations can be made to the general practitioner regarding fall risk assessment and prevention? 
Chapter 2 introduces the subject with three cases from general practice. The cases are examples of various and real situations in general practice: a first fall due no mainly somatic causes, the recurrent faller with multiple patient-related risk factors and the elderly patient at risk for falls and near-falls living in a twelling with many environmental risk factors. The theme runming through this chapter is the awareness that falls, particularly recurrent falls, have to be considered as potential markers of discase, disability or beginning deterioration, or, in case of a first fall, as the potential start of a series of falls to come. An accurate assessment of causes and risk factors may be needed. Understanding the incidence and risk factors may contribute to a systematic approach. In the considerations of possibilities of prevention, the pros and cons of preventive measures have to be evaluated.

Chapter 3 gives the results of a prelimimary study on health status and functioning of the elderly, living in the communty and particulary the contribution of home visits by the community nurse to the GP's information about his elderly patients.

In a cross-sectional design a random sample of 50 elderly persons of 70 years and over was taken from the $70+$ popullation of a primary health care centre. The GP's information with and without the contribution of the home visit by a communty nurse was studied. About 34 percent of complaints and disabilities were not known to the GP. Particularly, it concerned depressive feclings, urinary incontinence, mobility impaiments and slcep disturbances. Gait disonders were reported by approximately 40 percent and falls by 20 percent of the participants. The main determinants of functional decline were gait disorders and depressive feclings.

Chapter 4 presents a systematic rewiew of the fall-related literature on incidence of, risk factors for and health conseguences of falls in communiry-dwelling elderly people. A Medline search was camied out using relevant key words. This yiulded 274 references, which were submitted to thee inclusion criteria regarding originality of the studies, aims and target populations. Fourten studies were selected and submitted to a methodological evaluation on the basis of ten criteria for quality. Four studies met all, or nearly all methodological criteria and were given preference in the interpretation and description af the results. Approximately 30 percent of all community-dwelling elderly persons of 65 years and

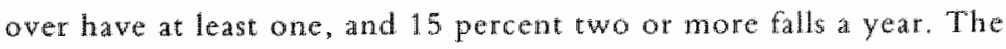
main risk factors, which were labelled as significant by the authors 
themselves, belong exclusively to the intrinsic (person-related) risk factors: cognitive impaiment, balance and gait disorders, use of sedatives and hypnotics, a history of stroke, advanced age, arthritis of the knee and a high level of dependence. Extrinsic (enviromment-related) risk factors did not play a significant role as independent risk factors in any of the 14 selected studies. Not all of the selected studies provided data on health consequences. Major injury was reported in half of one percent to nine percent and fractures in three to 14 percent of all falls.

Chapter 5 discusses the design and methods of the surveys. The community surweys are carried out in two different primary care populations $A$ and $B$. Community survey 1 on gait problems and falls was performed among a random sample of 730 persons aged 55 years or over, registered in a primary health care centre. Community survey 2 on incidence of, risk factors for and consequences of falls, covers a cross-sectional study among all 2744 elderly persons, aged 70 years or over, on the list of three primary health care centres and one duo practice, and submitted to an exclusion procedure by their own GPs. Of the 1660 respondents to this survey, 1238 gave written consent for participation in a followup study. Out of them andom sample of 311 elderly persons stratified on age, gender and fall history was taken for a baseline assessment on fall risk and a subsequent follow-up study, with telephone calls every six weeks. (See figure 1, Chapter 5)

The mail questionnaires in both surveys were similar. They consist of questions on fall-related items of incidence, determinants and health consequences of falls. The baseline assessment protocol of the follow-up study was constructed on the basis of the results of a nominal group consensus procedure on fall risk and risk factors for falls and carried out in standard conditions by thee traned physicians. The subsequent 36-week telephone follow-up with sixweekly telephone calls was also standardized and performed by trained interviewers.

A home-safety checklist on indoor fall risk was constructed by a Delphi consensus group, consusting of five occupatonal therapists, at social insurance expert and a district community nurse, resulting in a five-minute home-safety check on indoor fall risk factors, as a part of the baseline assessment.

The 16 GPs received about each participant a mail questionnaire about their involvement with falls and dealing with falls reported to them, their diagnostic and therapeutic management and their estimation of fall risk and risk factors. 
Chapter 6 presents the description of the results of communicy survey 1, conducted among a random sample of 730 persons of 55 years and over. It deals with the impact of gait problems and talls on functioning. As outcome variables for functioning the mobility range and social activities were used. It turned out that there was a significant association between falling and age, and even more between gait problems and age. The main risk factors tor talls were female gender, a poor physical health status and gat problems. Fals have some negative intluence on functioning, but mental heath indicators and gait problems appeared to have much more impact on functioning.

In chapter 7 the results of a cross-sectional study are presented. Using a mail questionnaire sent to all 2744 elderly persons aged 70 years or over, registered in three primary health care centres and one duo general practice, the incidence of, risk factors for, and health consequnces of falls among community-dwelling clderly were investigated. Incidence and injury rates are in accordance to data from literature: 25 percent of the respondents had at least one fall and 19 percent two falls or more in the previous year. Fractures were reported by eight percent of the fallers: hip fractures by about one percent and other fractures by nearly seven percent. Bivariate analys yielded many risk factors that showed a siguificant association with ever falling and recurrent falls. However, logistic regression revealed a limited number of independent and significant risk factors for falls and recurrent falls due to the dependence of risk factors on each other. The strongest risk factors for recurrent falls were: female gender, age 80 years or over, the presence of a chronic neurological disorder, the use of anci-depressants, problems of balance (dizziness), and sense organs (impaired wision or hearing) and complaints of muscles and joints. These risk factors are components of a logistic risk model. The addition of an indicator of mobility impairment to the risk model, a score of $\geq 3$ on the Mobility Control (MC) from the Sickness 1 mpact profille, short version (SIP68), did not yield an essential improvement of the performance of the risk model: the values for the Area Under the Receiver Operator Characteristic ( $R O C$ ) Curve, the AUC, indicating the predictive power of the model, were 0.73 and 0.75 , respectively. The statistically optimal cut-off value was found at 0.26. At this cutoff value the sensitivity was 64 percent and the specificity 71 percent and the positive and negative predictive vallue $(P V+$ and $P V-) 42$ and 86 percent, respectively. Also these values yiclded only slightly better performances with the addition of the 
MC SIP68.

For the GP the main conclusion from this study is that the contriburing significant risk factors to a risk model for the prediction of recurrent falls are easily and directly derivable from the parient records. In this way it is possible to identify the elderly at risk for falling at an initial stage, with satisfactorily diagnostic and predictive vallues.

Chapter 8 deals with the results of a prospective study an predictors of falls, with emphasis on performance tests. From the respondents to the mail questionnaire in community survey 2 , who gave written consent for further participation, a random sample of 311 persons was taken after stratification on fall history, age and gender. They were wisted at home for a one hour standardized baseline assessment on fall risk, performed by three trained physicians. The baseline consisted of an interview, tests on physical health and mobility, and a check on indoor fall risk using a checklist. Because of the absence of a validated and for general practice feasible fall risk assessment, the baseline assessment was developed in two consensus panels: a nominal group procedure for the assessment on health and mobility and a Delphi procedure for the home-safety checklist. Subsequently to the home visit, a 36-week follow-up study with telephone calls every six weeks was conducted to obtain outcome data for falls and fall-related conditions.

Altogether 197 falls were reported by 95 of the 287 participants ( 33 percent), who completed follow-up. One fall was reported by 49 (17 percent) and two or more falls by 46 (16 percent) persons. Out of the fallers 43 ( 45 percent) suffered injury: hip fractures by two and other fractures by four persons. Bivariate analysis yielded a number of fall-related risk factors that showed a significat association with ever falling, one-time falls and recurrent falls. Logistic regression resulted in two logistic models for the prediction of ever falls (Model 1) and for the prediction of recurrent falls (Model 2). The main determinants of ever falls were a history of two or more falls in the previous year, decreased somatic autonomy, nueasured by the $\$ 1 P 68$ and reduced strength of feet. For recurrent falls the strongest independent determinants were a history of two or more falls in the previous year, a depressive state of mind, measured by the depression subscale of the Symptom Checklist (SCL90), poor scores for hand grip strength, measured by hand dynamometry and an abnormal postural sway. The models had a good fit on the goodness-of-fir test according to Hosmer Lemeshow. The ROC analysis of the modells gave a 
statistically optimal cut-of value of both models at 0.30 with sensitivity of 67 and 59 percent and specricity of 63 and 87 percent, respectively. The positive predictive values $(\mathrm{PV}+)$ were 47 and 52 percent; the negatiwe predictive walues (PV-) 79 and 90 percent, respectively. The predictive power is expressed in the value for the AUC, resulting in a moderate value of 0.69 for Model 1 and a reasonable value of 0.79 for Model 2. These fall predictive models are feasible in general practice and can be applied separately or complementarily, as a confimation of the risk model obtained from the patients' medical record, as described in Chapter 7.

Chapter 9 presents the results of the assessment of indoor fall risk by use of a home-safety checklist on indoor fall risk. The checklist was developed in a Delphi consensus procedure with a panel, consisting of five occupational therapists, a social insurance expert and a district community nurse. The checklist consists of 116 cells if stairs are present and of 96 cells if not. The checklist has six categories of potential risk on the $Y$ axis: foors, lighting. walking space, stairs, obstacles and a category warious risk factors. On the $X$-axis the locations of the dwelling are placed: entrance, stairwa, kitchen, bathroom, toilet, bedroom, living room and cellat and loft. During the home visit for baseline assessment on potential risk factors for falls the dwellings of all 311 participants were inspected. assessed and recorded on the checklist. Potential risk factors for indoor falls belong equally to structural (immobile) and to nonstructural (mobile) risk factors. The locations of the dwelling, in which most potential risk factors are situated are whe stairway, the bedroom and the bathroom, but these scores do not correspond to locations in which falls actually occur. Bivariate anlysis did not reweal a significant association of high checklist scores and fall risk. except for falls in the entrance.

The conclusion of this study is that a checklist nay be uscful to identify potential risk factors for indoor falls by type and by location, but does not have any predictive valuc for actual indoor falls, falls in the entrance excluded. Lightwdark adaptation and other adaptive mechanisms might be the explatiation for the exception of the entrance.

Chapter 10 deals with the results of an analysis of two questions of the mail questionnaire in survey 2 , concerning self-perceived gait disorders and causes. Approximately half of the elderly aged 70 years or over report having a gait disorder. The main characteristics of them are age 80 years or over, more than one near-falls and falls 
Summary

in the prexious year and a moderate to bad perceived heall status. In addition, compared to those without a gait disorder they had lower scores for health variables, functioning and quality of life. Perceived causes lie, in addition to the locomotive tract, in the cardiovascular and respiratory trace, the central nervous system and general deterioration. possibly underestimated causes of gait disorders.

In hapter 11 the results of the investigation of the involvement of the GP in falls by the elderly are described. Data from the telephone follow-up were compared to data from a questionnaire about each participant of the follow-up study, sent to the 16 GPs. Eighty percent of all falls reported by the participating elderly during the follow-up were not known to the GP. Only about half of all falls with major injury were known to the GPs. The examiation of the elderly after a fall was mainly directed to identify injury and yielded little information about the canse of a fall. The management by the $G \mathrm{P}$ after a fall concerned mainly referral to a physiotherapist, giving advice, contact with members of the family and offering extra surveillance. Little attention was paid to the use of medication. In 170 of the 303 participating elderly ( 56 percent), the GPS estimated an increased fall risk, in which mobility disorders played the main role.

In chapter 12 the main results of the study are presented according to the the aims and study questions. The methodological strengths and limitations are discussed and implications for general practice are formulated. In addition, recommendations for research and training are given.

This study yielded an overview from literature and from empirical investigations of incidence of, risk factors for and health consequences of fills in the community-living elderly. The importance of falls as markers for disease, disability and frailty is emphasized. Another outcome is that the GP is able to predict falls using risk models consisting of variables directly derivable from patients' medical records or asy to assess from tests. These prediction models are of interest in the development of preventive strategies in primary care. A stepwise approach to assess and classity fall risk is introduced, but its validation and feasibility in general practice has to be evaluated by future research. 
SAMENVATTING 


\section{Samenvatting}

In dit proefschrift wordt het vallen van zelfstandig wonemde ouderen bestudeerd wanuit het gezichtspunt van de huisarts. Het wallen van ouderen behoort tot én wan de belangrijkste gezondheidsproblemen in de gezondheidszorg. Het wordt gekenmerkt door een frequent vóórkomen, een veelheid van oorzaken en risicofactoren, die exaan ten grondslag liggen en belangrijke gevolgen wat betreft morbiditeit en, meestal indirecte, mortaliteit.

De huisarts heeft vaak met dit probleem te maken, in allerlei ornstandigheden. Vallen wan ouderen, en in her bijzonder herhald vallen, dient te worden beschouwd als een teken van ziekte. beperking of het begin van algemene achteruitgang. Daarom is bij iedere val een nawgezer onderzoek naar de oorzaak en de risicofactoren op zijn plaats. Gelet op de hoge frequentie van letsels door vallen, vooral de heupfractuur, is het nodig dat secundaire en tertiaire preventie in de eerstelijns gezondheidszorg worden ontwikkeld. Een ander belangrijk aspect voor de huisarts is zijn beleid wat betreft diagnostiek, therapeutische en preventieve matregelen, bij een patient, die is gevallen.

Hoofdsuk 1 is een algemene inleiding tot deze eerstelijns studie. Wij geven onze definitie van vallen, een beschrijving van valmechanismen, de doelstellingen en de onderzoeksvragen. Bovendien wordt een beknopt overzicht gegeven van de opzet van dit proefschrift.

De doelstellingen van deze studie bestrijken wier gebieden. Op elk gebied zijn één of meer vraagstellingen van toepassing.

\section{Dootstelling I Vobrkomen en incidentie}

- Onderzoekvraag 1: Wat zijn de incidenties van vallen?

Doelstelling II Determinanten en risicafactoren

- Onderzockvraag 2: Wat zijn de determinanten en risicofactoren van vallen?

- Onderzoekvragg 3: Wat is het verband tussen intrinsieke (persoonsgebonden), extrinsieke (omgevingsgebonden) en activiteiten gebonden risicofactoren van vallen?

- Onderzoekvraag 4: Wat zijn de kenmerken van ouderen met érnmalig, herhaald en niet vallen?

Doelstelling III Gevolgen voor de gezondheid

- Onderzoekvragg 5: Wat zijn de gevolgen voor de gezondheid en het dagelijks functioneren?

Doelstelling VI Relatie met de huisartspraktijke

- Onderzoekvraag 6: Wat is de betrokkenheid van de huisarts met 
wallen en vallers?

- Onderzoekragg 7: Uit welke elementen bestaat een onderzoek naar valisico in de huisartsprakrijk?

- Onderzoekvrags: Welke anbevelingen aan de huisarts knuner worden gedaan aan de huisarts wat betreft onderzoek nar valristeo en preventie?

In hoofdstuk 2 geven we een inleiding op het onderwerp an de hand van drie casus uit de huisarteraktijk. Do casus zijn voorbeelden van verschillende en resle situaties een oudere met een eerste val ren gevolge wan woormamelijk hohamelije oorzaken, een oudere mer herhald vallen, die vele parientgebonden risicofactoren heeft en een oudere met een hoog risico op vallen en bijna-vallen, die woont in een huis met veel omgevingsgebonden risicofactoren

In dit hoofdzak wordt de nadruk gelegd op het besef, dat vallen, en in het bijzondere herhald vallen, dient te worden beschouwd als mogelijke voorbode van ziekte, beperking of beginnende algemene achteruitgang, of, in geval wan een eerste val, als het mogelijke begin van een reeks van komende valincidencen. Een nawgezet onderzoek nar de oorzaken en risicofactoren kan nodig zijn. Kennis over het vórkomen en de tisicofactoren kunnen bijdragen. aan een systematische anpak. In de beschouwing over mogelijkheden van preventie dient en afweging te worden gemakt van de voor-en nadelen wan preventieve matregelen.

In hoofdstuk 3 beschrijven we de resultaten van een voorbercidende studie over de gezondheidstoestand en her functioneren van zelfstandig wonende ouderen. Vooral de bijarage dic het huisbezock van de wijkverpleegkundige kan bicden an de kennis wan de huisats over zijn oudere patienten word behcht.

Het betreft een dwarsdoorsnede onderzok, warin ecn aselcete steekproef werd genomen van 50 ouderen van 70 jar of ouder wit de populatie wate cen gezondheidscentrum. De kennis, die huisartsen hebben over hun oudere patienten werd onderzocht. Verwolgens werd nagegan op walk gebied en in wolke mate dezc kennis met de bijdrage van het huisbezock door de wijkverpleegkundige kon worden aangevuld, Ongeveer 34 procent wan de klachten en beperkingen van ouderen waren bij de huisarts miet bekend. Het betroffen vooral depressieve gevoelens, incontinentie woor urine, beperkingen van het bewegingsaparat en slaapstoomissen. Loopstoomissen werden gemeld doot ongever 40 en vallen door 20 procent van de dechemers. De belangrijkste 
determinater van functionele achteruitgang waren loopstoornisgen en depressieve gevoalens.

Hoofdstk 4 biedt een systematisch overzicht van de literatuur over vallen met betrekking tot vórkomen, risicofactoren en gevolgen voor de gezondheid van vallen wan zelfstandig wonende ouderen. A Medline zoekactie werd uitgevoerd an de hand van relevante sleutelwoorden. Dit leverde 274 artikelen op, die werden onderworpen an drie inclusiecriteria betreffende de oorspronkelijkheid van de studies, de doelstellingen en de doelpopulaties. Veertien studies werden geselecteerd en vervolgens methodologisch geevalueerd met behulp van tien methodologische kwaliteitscriteria. Vier studies beantwoordden aan alle - of bijma alle - criteria en werden bij de interpretatie en de beschrijving van de uitkomsten extra belicht. Bijna 30 procent van alle zelfstandig wonende ouderen van 65 jaar en ouder valc tenminste énmal en 15 procent twee maal of vaker per jaar. De belangrijkste, door de auteurs zelf significant genoende risicofactoren behoren uitsluitend tot de intrinsieke (persoonsgebonden) risicofactoren: geestelijke achteruitgang, balans- en loopstoomissen, gebruk wan kalmeringsen slapmiddelen, een beroerte in de voorgeschiedenis, een hoge leeftijd, arthrose van het kniegewricht en een hoge mate wan afhankelikheid. Extrinsieke (omgevingsgebonden) risicofactoren speelden geen rol van betekenis als onathankelijke risicofactoren in de 14 geselecteerde studies. Niet alle studies verstrekten gegevens over de gevolgen van vallen voor de gezondheid. Ernstig lersel werd genoemd in een half tot negen procent en botbreukan in cirie tot 14 procent van alle valincidenten.

In hooflstuk 5 worden het onderzoekontwerp en de onderzoekmethoden van de studies besproken. De twee postenquetes ziju uitgevoerd in twee verschillende eerstelijns populaties. Onderzoek 1 is een dwarsdoorsnede studie over de invloed van loopstoornissen en vallen op het functioneren. nitgevoerd in een aselect getrokken steekproef van 730 personen van 55 jaar of ouder en ingeschreven in een gezondheidscentrum. Onderzoek 2 over vórkomen, risicofactoren en gevolgen van vallen, betreft eveneens een dwarsdoorsnede onderzoek. De onderzoekspopulatie bestond wit 2744 ouderen van 70 jaar of ouder, ingeschreven in drie gezondheidscentra en een groepspraktijk, die door hun eigen huisartsen in stat werden geacht an bet onderzoek deel te nemen. Van de 1660 personen, die een bruikbare vragenlijst hadden ingevuld gaven 1238 
schriftelyk toestemming voor deelname an cen wervolgondetzok. Uit hen werd en op leetud. geshach en valgeschiedenis gestrarificerde steekproef getrokken van 311 ouderen. Zij namen deel an een prospectief onderzoek, bestande uit een huisberoek woor een nullijnonderzock nar valrisico en een 36 weken durende verwolgstudie met idere 6 weken een telefonisch contactizie Hoofdstuk 5. figunr 1)

De post-enquetes in beide onderzocken waren ongever gelij. Zij bevatten vragen over onderwerpen met betrekking bot vallen zoals vórkomen, determimanten en gevolgen voor de gezondheid var vallen. Het protocol van het nullijnonderzoek werd gemaktran de hand van de uirkomsten van een discussic over warisico en risicofactoren van vallen in een panel van deskundigen op dit terrein. Het nullijnonderzoek werd uigevoerd onder standard condities door dric geinstrueerda artsen. Het daropvolgende telefonisch wervolgonderzoek werd eveneens gestandardiserd uitgevoerd door geoefende interviewers.

Een checklist op valrisico bimnenshuis werd onwikkold door con Delphi consensus groep, bestande wit vijt ergotherapenten ecn deskundige op het gebied van sociale verzekeringen on een districtswijkverplecgkundige. De inspectie van do woning op valrisico an de hand van deze checklist duurde ongeveer vijf minuten en makte deel wit van het nullijuonderzoek.

De zestien deelnemende huisartsen ontvingen een post-enquete over hun betrokkenheid met vallen. Hen werd gevraggd per patient een vragenlijst in te vullen over aan hen gemelde valincitenten, bun diagnostisch en cherapeutisch beleid on hun inschatting wan valrisico en risicofactoren.

Hoofdsuk 6 geef de beschrijuing wan de uitkomsten wan onderzock 1. witgevoerd in een aselecte steekproef van 730 personen van 55 jaar of ouder, ingeschreven in een gezondheidscentrum. Hex betreft de invloed van loopstoornissen en vallen op het functioneren. Als uitkomstyariabelen voor functioneren werden het mobiliteitsberck en de mate van sociale activiteit gebrukt. Het bleck, dat or een verband wan betekenis bestond tussen vallen en leefrij, maar neer nog tussen loopstoornissen en leeftijd, De belangrijkste determinaten wall vallen waren het vrouwelijk geslache, cen slechte gezondheidstoestand en loopproblemen. Vallen heaft weliswar enige negative invloed op het functioneren, mat dit wordt sterk overtroffen door geestelijke gezondheid indicatoren en loopstoornissen. 


\section{Samenvatting}

In hoofdsuk 7 worden de resultaten van een dwarsdoorsnede onderzoek beschroven. Met behulp wan een vragenlijst, toegestuurd aan alle 2744 ouderen van 70 jaar of ouder, ingeschreven in drie gezondheidscentra en een groepspraktik, werden het voórkomen, de risicofactoren en de gevolgen voor de gezondheid van vallen van zelfstandig wonende ouderen onderzocht. Uitkomsten over het vóórkomen van vallen en letsel ten gevolge van vallen zijn ongeveer in overeenstemming met gegevens uit de literatuur: 25 procent wan de respondenten viel tenminste éen keer en 19 procent twe keer of vaker in het voorafgaande jaar. Botbrenken werden gemeld door acht procent van de vallers: heupfracturen door ongeveer één procent en overige fracturen door bijna zeven procent. Bivariate amalyse leverde veel risicofactoren op met een significant verband met wallen en herhald vallen. Maar de logistische regressie resulteerde in een beperkt antal onathankelijke en significante risicofactoren van vallen en herhald vallen ten gevolge van onderlinge afhankelijkheid. De sterkste risicofactoren van herhaald vallen waren: het vrouwelijk geslacht, een leeftijd van 80 jat of ouder, de aanwezigheid van een chronische neurologische ziekte, het gebruik van anti-depressiva, batansstoornissen (duizeligheid), zintuigproblemen, zoals verminderd gezichtsvermogen of gehoor en spier- en gewrichtsklachten. Deze risicofactoren zajn de componenten van een logistisch risicomodel. De toevoeging van een indicator voor een bewegingsstoornis, een score van 3 of meer op de Mobiliteits Controle van de verkorte versie van de Sickness Impact Profile (SIP68), leverde geen wezenlijke verbetering van de resultaten van het risicomodel op: de warden van de Area Under the Receiver Operator Characteristic ( $R O C$ ) Curve, the AUC, en mat voor de voorsellende kracht van het model, waren bijna gelijk, respectivelijk $0,73 \mathrm{en} 0,75$. Het statistisch optimale afkappunt werd gevonden bij 0,26 . Bij dit afkappunt was de sensitiviteic 64 procent en de specificiteit 71 procent en de positieve en negaticve voorspellende warden (PV+ en PV-) respectivelijk 42 en 86 procent. Ook deze waarden vertoonden slechts een geringe verbetering bij toevoeging van de MC SIP68.

De bellangrijkste conclusie voor de huisarts uit deze studie is, dat de significante risicofactoren die bijdragen an een risicomodel voor de woorspelling van herhaald vallen, gemakkelijk en direct zijn af te leiden wit het dossier van de patient. Op deze wijze is het mogelijk de oudere met werhoogd valrisico in een vroegtijdig stadium op te sporen met bevredigende diagnostische en voorspellende warden. 
Hoofdsrsk 8 gat over de uithomsten van een longitudinale studie over predictoren wan vallen met de nadruk op uitwoeringstesten. Uit de 1238 van 1660 respondenten van de post-enguete van onderzoek 2, die schriftelijk toestemming gaven voor verdere deelname, werd na stratificatie op valgeschiedenis, leefijd en geslacht, een aselecte steekproef getrokken wan 311 persomen. Zij werden thuis bezocht voor een én uur durend gestandardiseerd nullijnonderzock op valrisico, witgevoerd door drie geinstueende artsen. Het nullijnonderzoek bestond wit cen interview, testen op lichamelijke gezondheidstoestand en mobiliteit en een inspectie van de woning op valrisico an de hand van een checklist. Omdat er geen gevalideerd en voor de huisartsprakijk geschik onderzoekprotocol op valrisico voor handen was, werd het nullijnonderzoek ontwikkeld in twee consensus paneis: een panel van vijf deskundigen op het terrein wan vallen voor het lichamelijk onderzokprotocol en een Delphi consensus procedure met zeven deskundigen voor de ontwikkeling vat een checklist op valrisico binnenshuis. Na het huisbezoek werd cen 36 weken durende vervolgstudie, bestaande uir zes wekelijkse telefonische contacten, uitgewoerd om gegevens over vallen en omstandigheden, die met vallen verband houden, te verkrijgen.

In totaal werden 197 valincidenten gemeld door 95 van de 287 deelnemers (33 procent), die het vervolgonderzoek voltooiden. Eun val werd gemeld door 49 (17 procent) en twee of meer valincidenten door 46 (16 procent) personen. Van de vallers lieper 43 personen ( 45 procent) letsel op: een heupfractuur bij wee en een andere fractuur bij wier personen. Bivariate analyse leverde een antal risicofactoren wan vallen op, die en significant verband vercoonden met vallen in het algeneen, esmmalig en herhald vallen. Logistische regressie leverde wee logistische modellen op voot de voorspelling van wallen in het algemeen (Model 1) an herhald vallen (Model 2). De belangrijkste onafhankelijke determinaten var vallen in het algemecn waren twee of meer walincidenten in thet voorafgande jar e en verminderde somatische autonomie, bepald met de SIP68 en verminderde vockracht. De sterkste onafhankelijke determinanten watherhald vallen waren twee of meer valincidenten in het voorafgande jaar, cen depressieve gemoedstoestand, gemeten met de depressie subschal van de Symptom Checklist (SCL90), slechte scores voor de hand knijpkracht, gemeten mer de handdynamometer en een abromale postural sway.

De modellen hadden goede uitkomsten bij de test volgens Hosmer Lemeshow. The ROC analyse van de modellen leverde en 
samenvating statistisch optimal akappunt van beide modellen bij 0.30 op met een senstiviteit van respectivelijk 67 en 59 procent en en specificteit van respectivelijk 63 en 87 procent. De positieve voorspellende warden $(P V+)$ waren 47 en 52 procent; de negatieve voorspellende warden (PV-) 79 ex 90 procent. De woorspellende kracht is uirgedrukt in de warde voor de AUC, met een matige warde van 0,69 voor Model 1 en een redeljke warde van 0,79 voor Model 2. Deze modellen voor de voospelling van vallen zijn toepasbat in de huisartspraktijk en kunnen apart of complementail worden gebruikt, als een bevestiging van het risico model verkregen uit het patiètendossier, beschreven in hoofdstuk 7.

In hoofdstak 9 worden de uitkomsten wan het onderzoek van de woning op risicofactoren voor binnenshuis vallen aan de hand van een checklist beschreven. De lijst is ontwikkeld in een Delphi consensus procedure door een panel, bestaande uit vijf ergotherapeuten, een deskundige op het gebied van de sociale verzekeringen en een districts wijkverpleegkundige. De checklist bestaat uit 116 cellen bij anwexigheid van trappen en 96 cellen findien er geen trappen zijn in de woning. Op de $Y$-as stan zes categories van potentielle risicofactoren: vloeren, verlichting, loopruimte, trappen, obstakels en en categorie diverse risicofactoren. Op de $X$-as stan de vertrekken van de woning: de entree, het trappenhuis, de keuken, de badkamer, het toilet, de slapkamer, de woonkamer en de kelder/zolder. Tijdens het huisbezoek voor thet mullijnonderzoek van potentiele risicofactoren voor binnenshuis vallen werden de woningen van alle 311 deelnemers geinspecteerd en werden potentiele risicofactoren geregistreerd op de checklist. Potentiele risicofactoren voor vallen binnenshus behoren gelijkelijk tot de structurele (immobiele) en tot de niet-structurele (mobiele) risicofactoren. De vertrekken van de woning, warin de meeste risiscofactoren voorkomen, zijn het crappenhuis, de slapkamer en de badkamer, max deze scores komen niet overen met de vertrekken, warin valincidenten zich ook werkelijk voordoen: de woonkamer, de slaapkamer en de entree. Bivariate analyse leverde geen significant verband op tussen hoge scores op de checklist en valrisico, uitgezonderd voor vallen in de entree.

De conclusie, die uit deze studie kan worden getrokken is, dat een checklist weliswaar nuttig kan zijn om potentiele risicofactoren van binneushuis vallen naar soort en nar vertrek op te sporen. mar geen voorspellende waarde heeft voor valincidenten binnenshuis 
uitgezonderd yoor vallen in de entree. De verklaring hierwor kan zijn dat ouderen problemen hebben met licht-donker adapratio en andere adaptaties in de entree.

Hoofstak 10 beschrije de resultaten wan een andys wan twe vragen wit de vagenlijst van post-enquete 2 , betrefende doot ouderen zelf ervaten loopstoomissen en oorzaken ervan. Ongeveer de helf van de ouderen van 70 jat of ouder, meldden eon loopstoomis te hebben. De belangrijkste kenmerken wa hen zijn: een leeftijd van 80 jaar of hoger, esn of meer val-en bijnavalincidenten in het voorafgaade jaar en een matig of slecht erwaren gezondheidstoestand. Bovendien hadden zij. vergeleken met degenen zonder loopstoornis lagere scores voor gezondheidsvariabelen, functioneren en kwaliteit wan leven. Genoemde oorzaken behoren, behalve tot het bewegingsaparat, tot het hart-vatstelsel, de luchtwegen, het centrale zenuwstelsel en algemerue achteruitgang, welke warschijnlijk onderschate oorzaken van loopstoomissen vormen.

In hoofastw 11 worden de uitkomsten vali het onderzoek nata de betrokkenheid van de huisarts met vallen van ouderen beschreven. Gegevens wit het telefonisch verwolgonderzock werden vergeleken met gegevens afkomstig van een vragenlijst, toegestuturd an the 16 huisartsen van de deelnemers aan het vervolgonderzoek. Tachtig procent van alle, door de deelnemende ouderen in het vervolgonderzoek gerapporteerde, valincidenten waren niet bekend bij de huisarts. Slechts ongever de helf wan alle valincidenten met ernstig letsel was bekend bij de huisartsen. Het onderzoek van onderen na een val was vooral gericht op het diagnosticeren van letsel, maar lewerde in het algemeen weinig informatie op over de oorzak van de val. Het beleid van de huisartsen na een wallet vooral verwijzing nax een fysiotherapeut, het geven van gerichte adviezen, overleg met familie, het inschaketer van de wijkverpleegkundige en het geven van extra andacht. Woinig aandacht werd besteed aan het gebraik van medicatic. Bij 170 wan de 303 deelnemende ouderen (56 procent) gaven de huisartsen een opgave van een verhoogd walrisico, warbij stoornissen wan het bewegingsapparatit de belangrijkste waren.

In hoofdsule 12 worden de belangrijkste resultaten van het onderzok gepresenteed in samenhang met de doelstellingen an de onderzoekwagen. De methodologisch sterke en zwakk punten worden besproken en de consequenties voor de huisartspraktijk 


\section{Samenvatting}

worden genoemd. Ook worden en verder onderzoek en opleiding.

Deze studie geeft een overzicht van uitkomsten wan de literatuur en eigen onderzoek wan thet yórkomen, de risicofactoren en de gevolgen woor de gezondheid van vallen van zelfstandig wonende ouderen. Het belang van vallen als teken van ziekte, beperking en zwakte is benadrukt. Een andere uitkomst is, dat de huisarts in stat is vallen te voorspellen met risicomodellen, bestaande wi variabelen, die ditect zijn af te leiden wit het patientendossier of gemakkelijk zijn te onderzoeken met testen. Deze voorspellende modellen zijn van belang voor de ontwikkeling van preventieve strategiein in de eerstelijns gezondheidszorg. Een stapsgewijze benadering om valrisico te beoordelen en in te delen is geintroduceerd, mar de betrouwbarheid en de geschiktheid ervan moeten nog nader worden bepaald in toekomstig onderzoek. 
DANKWOORD (ACKNOWLEDGEMENT) 


\section{Dankwoord}

Het verrichter wan een promotieonderzok is sen boeiende tocht door vaak onbekend, soms makkelijk, maar vak moeilijk beganbaar terrein. Meestal loop je in gezelschap en soms loop je alleen, mat zonder gidsen, dragers en helpers hal je de eindbestemming niet. Niet voldoende kan benadrukt worden, dat dit proefschrift tot stand is gekomen dankzj de inspanningen, de betrokkenheid, het enthousiasme en de vriendschap van velen. En daarwoor wil ik hier op de laatste bladzijden van dit boek mijn dank en wardering uitspreken in de hoop niemand te vergeten.

In de eerste plats wil ik naturijk bedanken alle ouderen, die bereidwillig hebben deel genomen an dit onderzock en hun kostbare tijd hebben willen besteden a h het invullen van vragenlijstem en het ondergaan van allerlei testen. Dit proefschrift is opgedragen an mijn ouders en schoonouders, warmee ik mijn dankbarheid en respect jegens hen tot uitdrukking wil brengen, mar darbij ook, symbolisch alle ouderen, die hebben deelgenomen aan dit onderzoek, wil betrekken.

Mijn collegae in het gezondheidscentrum Dr. van Kleef, Ber Huynen, Pie Castermans, Mieke Maaskank en Bert Schilte en de assistentes Riet Hautvast, Linda Gilissen-van Laar, Bianca PaatsMawhin, Iris Willems en Lilian Claessens-yan Wel wil ik bedanken voor dingen, die moeilijk te benoemen zijn. Vooral jullie begrip en belangstelling, mar ook morele en praktische steun en het opvullen van allerlei gatjes, die ontstonden omdat de aansluiting. tussen praktijk en faculteit nou eenmaal niet altijd "raadloos" is of als ik verkerend in "hogere onderzoeksferen" well eens de dagelujkse gang wan zaken in de praktik uit het oog verloor. Bèr en Pie, ik verheug mij erop jullie als collega's en vrienden nast mij te hebben tijdens "Het Uur U".

De steun en inzet van de 18 huisartsen on hun assistentes van de wijf RNH-praktijken was voor de dataverzaneling onontbeerlijk. Assistentes en huisartsen van de praktjken Voerendaal, Heer. Hoensbroek, Stein en Van Kleef: bedankt yoor jullie hulp. Prakrijk Voerendaal: R. Panhuysen, P. Hulshof, E. Guldemond-Hecker; Praktijk Stein: Th. Govaert en R. Leclercq; Gezondheidscentrum Hoensbroek: G.J. van Schendel ( $T$ ), P. Voorhoeve, R. Helmers, M. van Nunen, J. Paas, en M. Wan Venrooy; Gezondheldscentrum Heer: A-M. Muysken-du Saar, M. Peeters en F. Vissers; Gezondheidscentrum Van Kleef: L. Huynen, G. Castermans, M. Maakant en B. Schilte.

Een grote stuwende kracht in dit werk was mijn promotor Prof. H. 
Crebolder. Beste Harry, als huisarts pur sang was ju als geen ander je bewust van de mogelijkheden en de beperkingen van de husists in het algemeen en van mij in het bijzonder. Telkens weer heb ji de doelstellingen, de onderzoekstappen en de witkonstan wan dic onderzok getoetst an de praktjk en dat waren altijd boeiende gesprekken. Ik zou iedereen zo'n promoror toewensen.

Mijn wetenschappelijke gids was vooral mijn promotor Prof. J.A. Knotrnerus. Beste André. jij was altijd wer in statt nast a je drukke werkzamheden je te verdiepen in de essenties van dit werk. wat leidde tot creatieve ideern en oplossingen en soms nieuwe paden. Genuanceerd, wist je me te wijzen op lacures of tekorkomingen.

Zonder mijn co-promotor Dr, J. Diederiks, met wie ik zeer vruchtbare, leerzame en ook gezellige uren achter de computer doorbracht, zou ik nu bij lange na niet toe zijn an dit dankwoora. Beste Jos, je was een uitstekende gids. Het KISS (Keep it Stupidly Simple) model en het aroma yn sigaren zullen mij blijuen herinneren aan jouw originele kijk op onderzoek.

Een grote steun en toeverlaat was Lilian. Hesemans, veel meer dan ean secretaresse, die in de fase van de dataverzameling meewerkte an dit onderzoek. Je toonde je zeer betrokken bij het wel en wee van ouderen en bij dit onderzoek. En in één adem genoend, Jo Hamers, destijds systembeheerder van onze vakgroep. Je hebt me geweldig geholpen met het witwerken van de vragenlijsten, het invoeren van alle data, het maken van de bestanden en het uitwoeren wan de eerste analyses. Frans van der Horst, jij was vooral in de beginfase van het onderzoek mijn "praatpaal" en droeg vooral idẹën an. Luc de Witte was een angenaam-kritische meedenker en wist mij soms voor ontsporen te behoeden. Van Arnold Kester, statisticus, heb ik geleerd, dat medische statistiek geen dor en saa vak is, maar leidt tot verdieping door een beter begrip van de data. En Erik van Rossum bleek een goede gesprekspartner wat betreft geriatrisch ondetzoek.

In ieder onderzoek zijn trouble shooters nodig. Gregor Fransen, jij was er een. Vlor en vakkundig hielp je me soms an oplossingen voor lastige problemen. Veel werk is verzet door de andere mensen van het MEMIC: datatypistes voerden de data van de vragenlijsten in en enquátrices voerden 1800 telefoongesprekken met ouderen met een war engelen geduld. Gertie Wijnands en Mieke Witte, ik. bedank jullie in naam van allen.

De artsen, die de ruim 300 ouderen thuis bexochten vor het nullijn onderzoek. Hanneke Hamers, Djouke Bussemakers en Bert Schilte, bedank woor jullie accurate inzet, becrokkenheid mar bok 
de lewke verhalen, die jullie meebrachten.

Wibert Bakx, rewalidatic arts, jij hebt me goed geholpen met de eerste opzet en uitwerking voor een onderzoekprotocol als voorberelding op de consensusprocedure. De leden van de twee consensus groepen will ik danken voor hun medewerking en hun

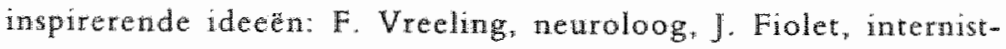
geriater, E. Lindeman, revalidatiearts en de huisarten $M$. SoomersTurlings en C. Ligthart Schenk voor hun bijdragen in het panel en de ergotherapeuten $A$. Backhuis-Ammerlan, $Y$. Cutfs, J. Schurgers, M. Tielen en A. Zalmstra, de districts wijkverpleegkundige $\mathbb{F}$. Stegh en de verzekeringsexpert $K$. Ruiter voor hum bijdragen an de Delphi procedure.

Job Metsemakers, Phil Govaert en Raymond Leclercq, bedankt voor jullie zorgvuldige controle van de $1 \mathrm{CPC}$ codes. Herbert Habets en Truus Breukers, zonder jullie wijkverpleegkundige inbreng was het onderzok in ons gezondheidscentrum niet mogelijk geweest. Fred Vreeling, neuroloog, bedankt voor jouw visie op enkele neurologische aspecten van het onderzoek. Ook Frans Verhey, psychiater, Niek Jaspers, psychomgeriater en Hans Fiolet, internist-geriater, bedankt voor adviezen op jullie vakgebied.

Het is voor mij een boeiende ervaring geweest, dat de samenwerking met studenten vruchtbaar en plezierig bleek en publicaties opleverde. Rene Lenoir hielp mij met hoofdstuk 4, Maya Buys met hoofdstuk 10 en Sandra van der Busse met hoofdstuk 11. Karrin Schiricke en Mignon Vloet zetten het onderzoek in Voerendaal op, verrichten de dataverzameling en makte een grondig onderzoekverslag, waaruit Hoofdstuk 6 is voortgekomen.

De "Mensen van de Gang" zijn voor ieder, die onderzoek doet en af en toe om en praatje verlegen zit, wan grote warde. Ik noem Piet Portegijs voor zijn enthousiasme en praktische tips, Paul Zwietering voor uitingen van lotsverbondenheid, Frank Buntinx voor de kopieen van artikelen in mijn postvak, Jelle Stoffers, woor praktische steun en advies en alle anderen poor hun belangstelling, sympathie en opbeurende opmerkingen.

Ine Siegelaar, Marlies Noevers, Jim Tatipata, Frits Ruyters, Linda Schilder, Babette Doorn en Hilde Sielhorst: jullie bedankt voor die kleine, mar onschatbare klusjes, die jullie voor mij, vaak "zomaar tussendoor" deden. René Kocken en Ellen Breevoort, jullie letten op de portemonnaie en dat is geen overbodige luxe gebleken. En dankzij Bob Wilkinson, vertaler, zijn hopelijk alle foucjes verwijderd en is de tekst veel leesbarder geworden. 
CURRICULUM VITAE 


\section{Carriculum vitae}

Pul Stalenhoef werd geboren op 11 november 1947 te Nederhort den Berg ( $\mathrm{NH}$ ). Na het behalen van het gymnasium $\mathrm{B}$ diploma an het voormalig R.K. Lyceum voor het Gooi (tegenwoordig Alberdingk Thijm College) te Hilversum in 1966, startte hij de studie geneeskunde an de Rijksmiversiteit Utrectit. Na het artsexamen in 1973, volgde hij de éenjarige huisartsopleiding te Utrecht.

In mei 1974 associeerde hij zich mer de huisartsen They Lemmens (†) en Léon Lodewick in een groepspraktijk, die in 1976 overging. in het gezondheidscentrum Dr. wan Kle fe te Mastricht.

Sinds 1976 heeft hij een deeltijdaanstelling buj de vakgroap huisartsgeneeskunde van de Universiteit Maastricht.

De huisartspraktijk in het gezondheidscentrum Dr. van Kleef wordt uitgeoefend in samenwerking met de huisartsen L. Huynen (vanaf 1980), G. Castermans (wanaf 1985) en M. Maaskant (vanaf 1990).

Paul was getrouwd met Betsy Halling ( $\$ 28$ november 1992). destijds huisarts en wetenschappelijk medewerker van de vakgroep Onderwijsontwikkeling en onderwijsrescarch wan de Universiteit Mastricht. Hun kinderen zijn: Anneneeltje (23), Pieter (21) en Klanrife (19).

Zijn levensgezellin is Josje Reuten-Scholte, weduwe van Bart W. J.M. Reuten. Hun kinderen zijn: Marieke (27), Job (24) en Joris Jan (21). 